University of Texas at El Paso

\title{
DigitalCommons@UTEP
}

Open Access Theses \& Dissertations

2009-01-01

\section{Failure Analysis and Materials Characterization of Hip Implants}

Amanda Marie Bastidos

University of Texas at El Paso, amanda.bastidos@gmail.com

Follow this and additional works at: https://digitalcommons.utep.edu/open_etd

Part of the Materials Science and Engineering Commons, and the Mechanics of Materials Commons

\section{Recommended Citation}

Bastidos, Amanda Marie, "Failure Analysis and Materials Characterization of Hip Implants" (2009). Open Access Theses \& Dissertations. 2644.

https://digitalcommons.utep.edu/open_etd/2644 


\title{
FAILURE ANALYSIS AND MATERIALS CHARACTERIZATION OF HIP IMPLANTS
}

\author{
AMANDA MARIE BASTIDOS \\ Department of Metallurgical and Materials Engineering
}

APPROVED:

Stephen W. Stafford, Ph.D., Chair

Luis Trueba, Ph.D.

Connie Gomez, Ph.D.

Patricia D. Witherspoon, Ph.D.

Dean of the Graduate School 
Copyright (C)

by

Amanda Marie Bastidos

2009 


\section{Dedication}

For my family, who supported my education from pre-kindergarten to graduate school and have always encouraged me to dream big and achieve every goal. 


\title{
FAILURE ANALYSIS AND MATERIALS CHARACTERIZATION OF HIP IMPLANTS
}

\author{
by
}

AMANDA MARIE BASTIDOS, B.S. Metallurgical and Materials Engineering

\section{THESIS}
Presented to the Faculty of the Graduate School of The University of Texas at El Paso
in Partial Fulfillment of the Requirements for the Degree of

MASTER OF SCIENCE

Department of Metallurgical and Materials Engineering THE UNIVERSITY OF TEXAS AT EL PASO

December 2009 


\section{Acknowledgements}

It is with great thanks to my adviser and mentor, Dr. Stephen W. Stafford, for his constant kindness, patience, and assistance, throughout my undergraduate and graduate college life. It was the Failure Analysis course taught by Dr. Stafford that most definitely fascinated my interest in metallurgical and materials engineering. I admire all of your experience in industry, the private sector, and the professoriate. I truly hope to be a metallurgist of your quality some day. You know so much!

Thank you to my committee members, Dr. Luis Trueba and Dr. Connie Gomez, for all of your recommendations to this research and thesis. You never once complained about my "extended deadlines." Dr. Trueba has always been a kind and caring professor who is continuously on the look-out for the well being of his students. Thanks again!

Further thanks are in store for David Brown who helped me with every technical aspect of this research. David has the solution for everything! The Metallography Laboratory of the El Paso Natural Gas Co. was kind enough to lend a hand when the research required larger testing equipment and further expertise. For her help with scanning electron microscopy and x-ray fluorescence I thank Dr. Shalayna Lair. More thanks goes out to David Tomlinson who fought through the tedious task of finding a working etchant for the cobalt-based alloy and for his assistance with optical microscopy.

To my friends and colleagues: Over the last two years, we have endured countless days and nights of study sessions, cramming, researching, presenting, debating lecture material, reinforcing technical concepts, complaining, celebrating, and relaxing. Because of your kindness and willingness to help me when I didn't know how to use equipment, needed assistance with lab 
work, or if you were just there to lend a listening ear, I acknowledge: Sara Gaytan, Brenda Machado, Diana Ramirez, Gina Heredia, Kristian Ortiz, Nayeli Camacho, and Chris Bradley.

I would also like to thank Dr. Richard Westbrook of The El Paso Orthopaedic Surgery Group and Nayeli Camacho, for providing the hip implant components studied in this research. 


\begin{abstract}
This research focused on the microstructural characterization and failure analysis of hip implant components. The main hip components analyzed were the femoral heads and the ultrahigh molecular weight polyethylene (UHMWPE) liners. Previous research has shown that hip implants tend to fail by the PE liners due to adhesive and abrasive wear, delamination, and third body particles (metals, ceramics, and PE). The methods and procedures for analyzing the said failures consisted of non-destructive and destructive evaluations. Non-destructive evaluations included of techniques such as visual characterization and dye penetrant inspection (DPI)-which displayed macroscopic surface details and presented initial clues as to the extent and causes of the failures. The use of attenuated total reflection infrared spectroscopy (ATR-IR) produced transmittance spectra for the PE liners to indicate the bonds and their associated wavelength energies. The destructive evaluations included metallography and scanning electron microscopy (SEM). These techniques revealed the microstructural characteristics of the metallic components and focused on microscopic cracks and abrasions from areas of delamination and adhesion in the samples. After further studies and analyses on the failed implants, the information and data shall be given to the collaborating orthopedic surgery group in hopes of altering new components to ensure increased implant lifetimes and less needed revision surgeries for hip replacement patients.
\end{abstract}




\section{Table of Contents}

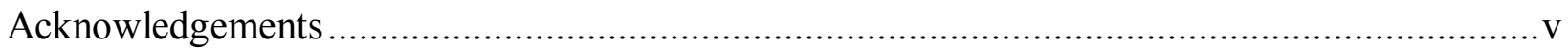

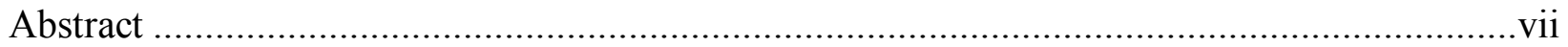

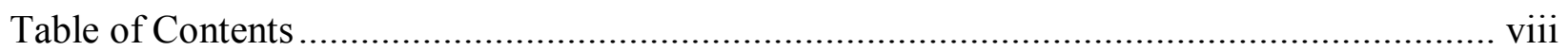

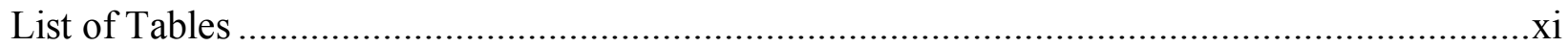

List of Figures ............................................................................................................

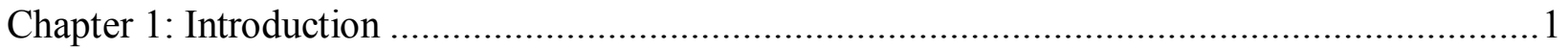

1.1 Total Hip Arthroplasty (THA) ...............................................................

1.1.1 Primary Indications for Total Hip Arthroplasties (THAs) ............................2

1.1.2 Hip Implant Components ................................................................... 3

1.1.3 Solid Freeform Fabrication ............................................................6

1.1.4 Cemented Stems vs. Cementless Stems ..................................................

1.1.5 Femoral Stem Sizes, Tapers, and Textures ....................................... 8

1.1.6 Post-Surgery Expectations …...................................................... 9

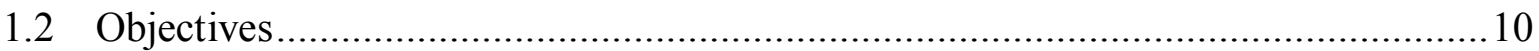

1.3 Overview of Following Thesis Chapters ..................................................... 13

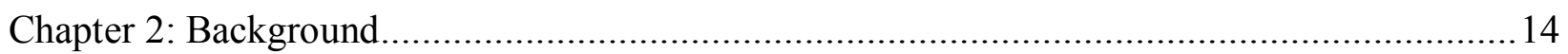

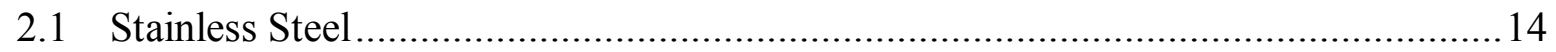

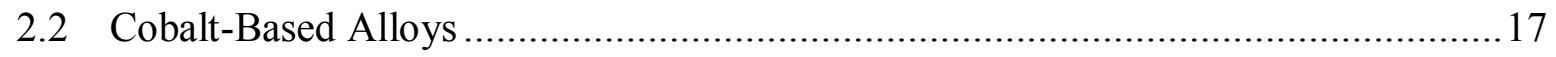

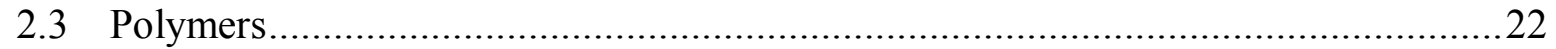

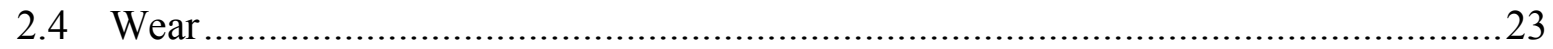

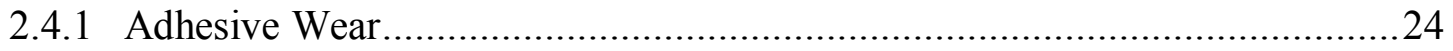

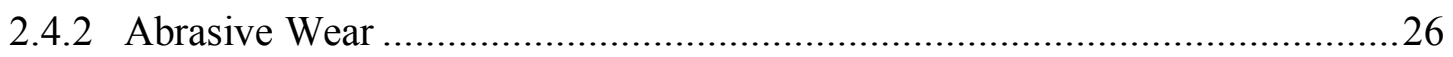

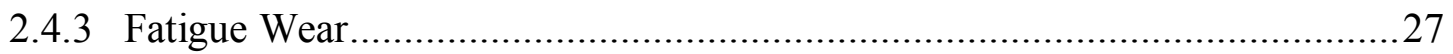

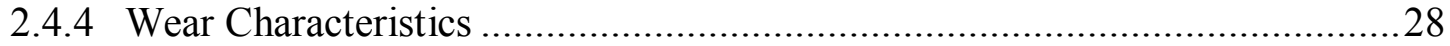

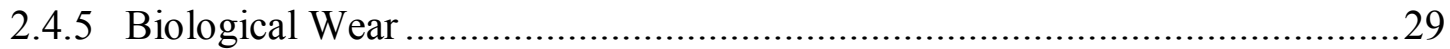

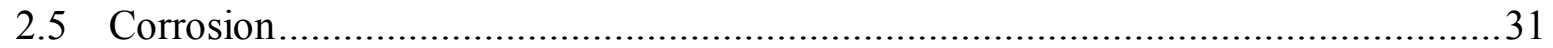

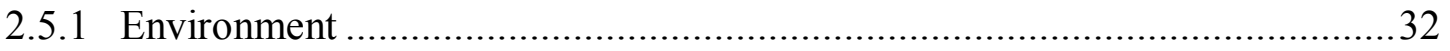

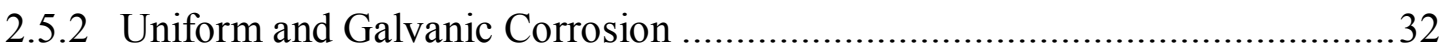




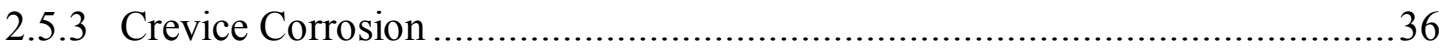

2.5.4 Pitting Corrosion.........................................................................................

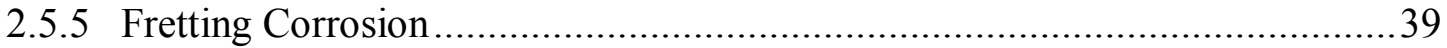

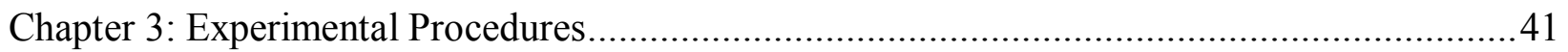

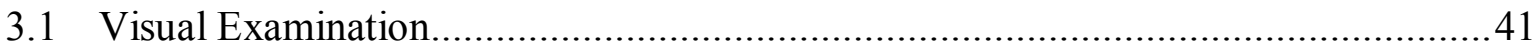

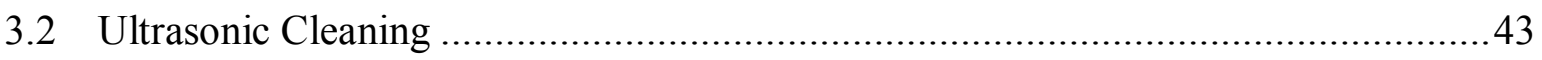

3.3 X-Ray Fluorescence (XRF) ................................................................................44

3.4 Fourier Transform Infrared Spectroscopy (FTIR) …………………………….....45

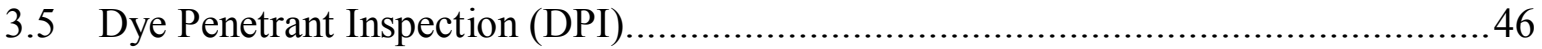

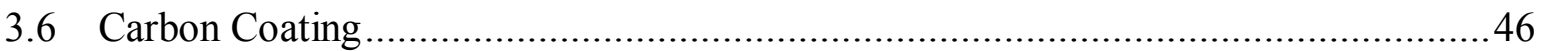

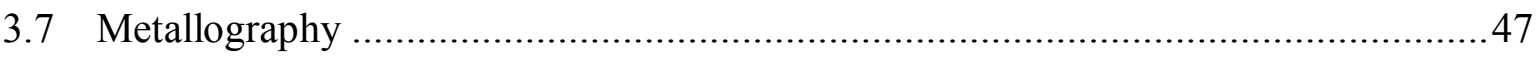

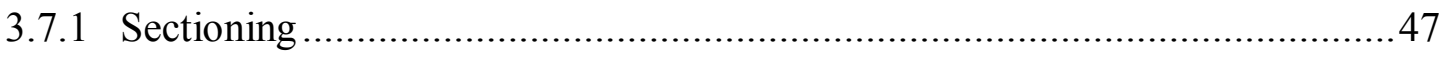

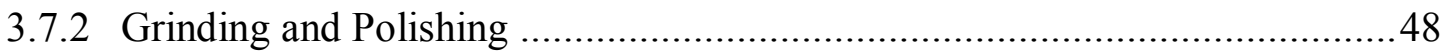

3.8 Scanning Electron Microscopy (SEM) ……………...........................................49

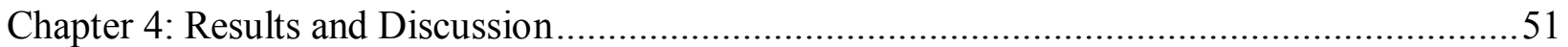

$4.1 \quad$ Patient and Component Backgrounds ................................................................51

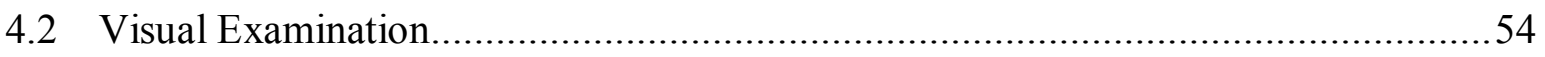

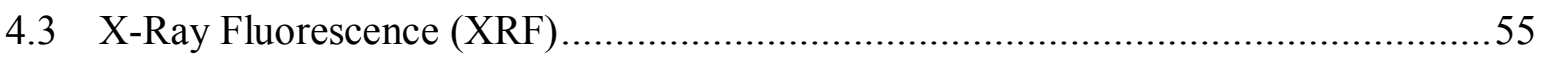

4.4 Fourier Transform Infrared Spectroscopy (FTIR) ………………………….........55

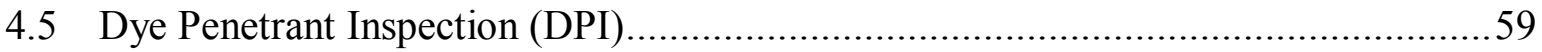

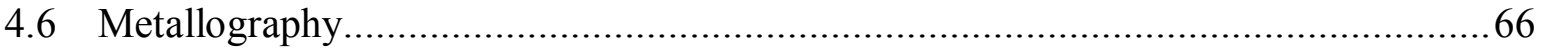

4.7 Scanning Electron Microscopy (SEM) ……………...........................................67

4.7.1 Ultra High Molecular Weight Polyethylene (UHMWPE) Liners ....................68

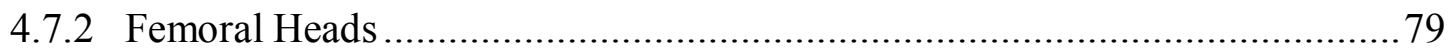

4.7.3 Foreign Particle

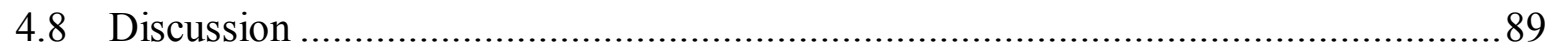

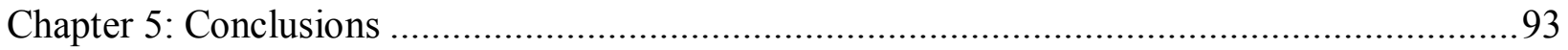

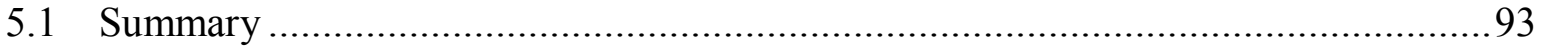

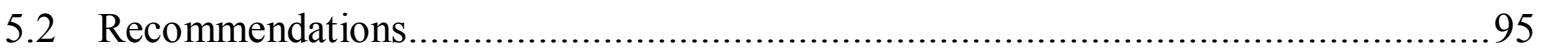




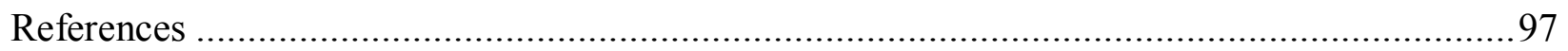

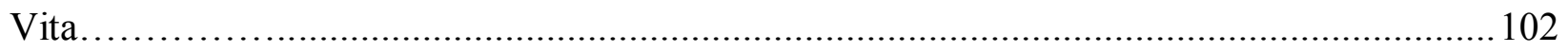




\section{List of Tables}

Table 1.1: Most frequent five principal diagnoses* in patients who underwent hip replacement

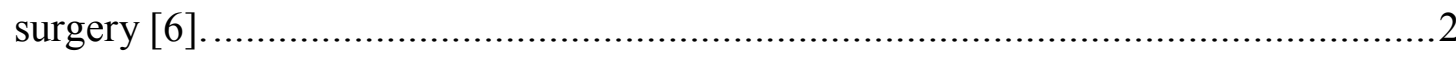

Table 1.2: Biomaterials used in total joint replacement [8] ...................................................

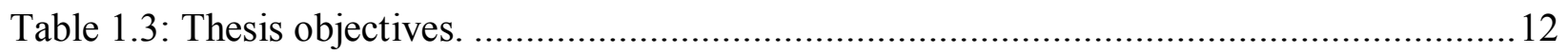

Table 2.1: Composition of austenitic stainless steels (balance \% iron) [8].................................15

Table 2.2: Mechanical properties of stainless steels in surgical implants [8] ............................16

Table 2.3: Chemical compositions of Co-based alloys for biomedical implants [30]..................19

Table 2.4: Mechanical properties of heat-treated Co-based alloys [35] ..................................21

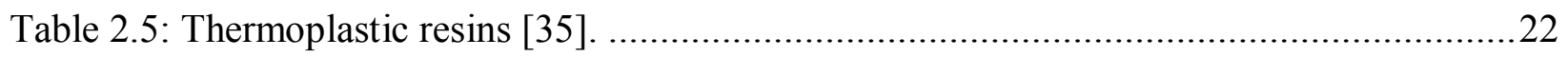

Table 2.6: Standard Electrochemical Series for selected material [50] .....................................34

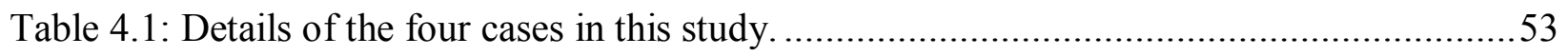

Table 4.2: Elemental compositions of femoral heads and acetabular shell.................................55

Table 4.3: Comparison of the reference wavenumber values with experimental wavenumber values. 


\section{List of Figures}

Figure 1.1: Normal hip vs. Arthritic hip [3] ..................................................................

Figure 1.2: Hip replacement assembly consisting of four key components: Stem, Head, Liner, and Shell [12].

Figure 1.3: Electron beam melted (EBM) titanium femoral stem with titanium mesh [14] ..........7

Figure 1.4: Hip prostheses: (a) Cemented, (b) Cementless [3] ............................................

Figure 1.5: Femoral stems: (a) and (b) Uncoated, (c) Coated, (d)-(f) Porous-coated [19]...........9

Figure 1.6: Radiograph of an implanted cementless THA [23] .......................................... 10

Figure 2.1: Severe deformation of a stainless steel femoral head cause by PE and alumina wear

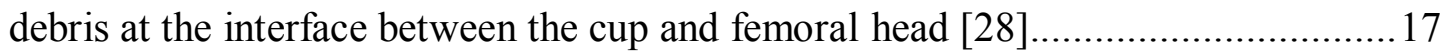

Figure 2.2: Cast Co-alloy femoral stem with a cast Co-alloy femoral head [33]...................... 18

Figure 2.3: Processing steps in the manufacture of UHMWPE implants: (a) Resin powder, (b) Semifinished rods that have been consolidated from the resin powder, (c) Machining of the UHMWPE rods on a lathe, (d) UHMWPE acetabular components after machining [36].

Figure 2.4: Wear tracks on Patient $\mathrm{W}$ femoral head at a magnification of $1000 \mathrm{x}$.

Figure 2.5: Bearings exhibiting different lubrication modes: (a) Boundary lubrication, (b) Mixed lubrication, (c) Fluid film lubrication [41]. .26

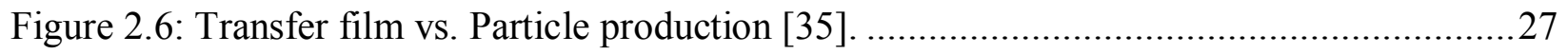

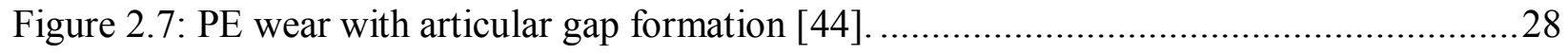

Figure 2.8: PE insert looking brittle in the rim, showing multiple continuous cracks, local polishing and subsurface delamination of the articular surface [44]. 
Figure 2.9: Metallic- or ceramic-type giant cells from the interface of a loose total hip joint

[46]. .30

Figure 2.10: PE wear particles in the surrounding tissue of an implant [44]. 31

Figure 2.11: Galvanic Series of some commercial metals and alloys in seawater [50]. .35

Figure 2.12: Crevice corrosion in a $\mathrm{NaCl}$ environment [53]. .36

Figure 2.13: Principal corrosion products in the taper connections identifies as: $A=$ mixed oxides and chlorides and $\mathrm{B}=$ chromium orthophosphate hydrate-rich material [52]. .37

Figure 2.14: Autocataylic processes in a corrosion pit [55]. .38

Figure 2.15: Patient $U$ femoral head with pits at a magnification of $800 x$.

Figure 2.16: Backscattered electron images of a $6 \mathrm{~mm}$ stainless steel neck taper after testing: (a) Corrosion product at low magnification of $95 x$, (b) Fretting corrosion attack at

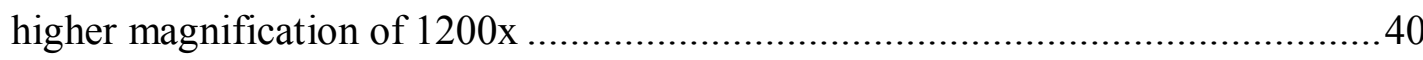

Figure 3.1: Patient E liner, head, and screws...................................................... 41

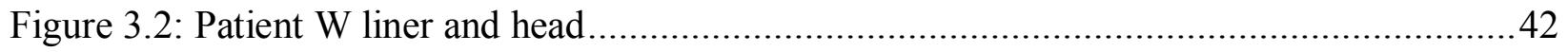

Figure 3.3: Patient H liner and head with an increased neck length....................................42

Figure 3.4: Patient $U$ acetabular socket and head .................................................... 42

Figure 3.5: Patient E components (a) as-received femoral head and liner, before ultrasonic cleaning, (b) after ultrasonic cleaning. 43

Figure 3.6: Patient E liner (a) Dye Penetrant Inspection (DPI), (b) After ultrasonic .................44

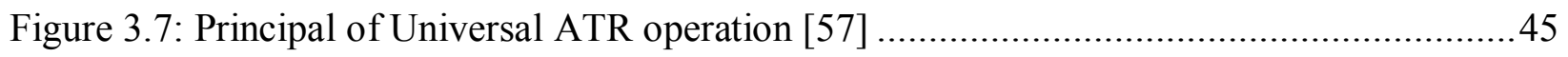

Figure 3.8: Patient H, UHMWPE liner after Dye Penetrant Inspection (DPI)........................46

Figure 3.9: Sectioning of Patient E femoral head ….................................................. 48

Figure 3.10: Femoral head cross-section displaying the hollow-centered, tapered bore .............48 
Figure 3.11: (a) Patient E femoral head with wear tracks at a magnification of 450x, (b) Patient W liner, area with plastic flow at a magnification of 400x. .50

Figure 4.1: Hip implant sections: A-stem size, B-stem length, C-offset, D-neck length [56].....54

Figure 4.2: Polyethylene infrared (IR) transmittance spectrum, wavenumber reference [58]......57

Figure 4.3: Patient E liner, IR transmittance spectrum. ..................................................58

Figure 4.4: Patient W liner, IR transmittance spectrum .............................................5

Figure 4.5: Patient H liner, IR transmittance spectrum....................................................58

Figure 4.6: Patient E liner with dimensional reference .....................................................59

Figure 4.7: Patient E liner: (a) indentations, (b) close up image of indentations and two foreign, metallic particles indicated with arrows.

Figure 4.8: Patient E liner: (a) frontal view of plastic deformation, (b) deformed material that flapped towards the center from the two sides, (c) deformed sprocket with plastic flow indicated by arrow, (d) right-hand view.

Figure 4.9: Patient W liner: (a) with dimensional reference, (b) closer image of surface deformation.

Figure 4.10: Patient W liner with radial crack.

Figure 4.11: Patient W liner: (a) frontal view of rim deformation and puncture, (b) side view ..63

Figure 4.12: Patient H liner: (a) vast amount of surface abrasions and large abrasive wear area, (b) abrasive wear.

Figure 4.13: Patient H liner: (a) plastic deformation, plastic flow, and radial crack, (b) closer image of plastic deformation, (c) side view of plastic deformation, (d) side view of radial crack. 
Figure 4.14: Patient E cobalt-alloy femoral head: (a) and (b) dispersed carbides, (c) and (d) casting defect.

Figure 4.15: Patient U stainless steel femoral head with variable grain sizes and annealing twins at a magnification of (a) 200x, (b) 400x.

Figure 4.16: Patient E liner: (a) wear tracks and surface debris, (b) impressions with wear tracks. .68

Figure 4.17: Patient E liner: (a) indentation, (b) closer image of indentation with plastic flow...69

Figure 4.18: Patient E liner: (a) surface debris, wear tracks, and foreign particle, (b) foreign particle with wear tracks.

Figure 4.19: Patient E liner: (a) indentations and foreign particle, (b) foreign particle with plastic

flow .71

Figure 4.20: Patient E liner: (a) indentations and wear tracks, (b) complex morphology of indentations .72

Figure 4.21: Patient W liner: (a) machine marks above PE fold, (b) two sets of evenly spaced machine marks, (c) and (d) abrasion on the interface of the rim surface and downward slope of the socket. .73

Figure 4.22: Patient W liner: (a) plastic flow, (b) surface indentations. .74

Figure 4.23: Patient W liner: (a) topical deformation, (b) multiple damage modes. .74

Figure 4.24: Patient W liner: (a) ripped layer of PE revealed a ductile fracture surface, (b) deformation containing PE surface debris and plastic flow, (c) close-up image of plastic flow lines, (d) more plastic flow lines with folded PE. .75

Figure 4.25: Patient W liner: (a) and (b) plastic flow in multiple directions with plastic flow lines, (c) and (d) PE that has been stretched and pulled apart. .76 
Figure 4.26: Patient H liner: (a) and (b) burnishing.

Figure 4.27: Patient H liner, abrasive wear of the socket.............................................78

Figure 4.28: Patient H liner: (a) and (b) ductile fracture surfaces. ...................................78

Figure 4.29: Patient E femoral head: (a) wear tracks and surface debris, (b) large streak of product deposit, (c) deposit and unimpaired surface, (d) wear tracks and product

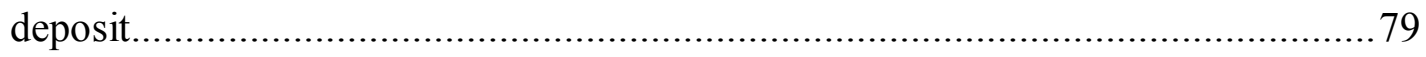

Figure 4.30: Patient E femoral head, EDS area analysis spectrum of surface deposit. ...............80

Figure 4.31: Patient E femoral head, EDS spot analysis spectrum of unknown product. ...........80

Figure 4.32: Patient W femoral head: (a) and (b) wear tracks and pits, (c) abnormal wear tracks,

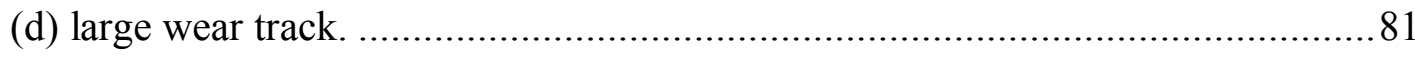

Figure 4.33: Patient U femoral head: (a) variable wear track sizes, (b) crevices. ......................82

Figure 4.34: Patient $U$ femoral head: (a)-(d) plastic flow and neighboring pits........................83

Figure 4.35: Patient U femoral head: (a) severe deformation and plastic flow, (b) crack and unknown black product.

Figure 4.36: Patient U femoral head: (a) significant amount of large crevices (visible to the naked eye), (b) crevice scars.

Figure 4.37: Patient U femoral head: (a) bulge with neighboring pits, (b) large bulge, smaller crevice, and wear tracks. .86

Figure 4.38: Patient U femoral head: (a) bulge with wear scars, (b) bulge at higher magnification. .86

Figure 4.39: Patient U femoral head: (a) crevice with unknown product, (b) wear scars. .87

Figure 4.40: Patient U femoral head, EDS area analysis spectrum of unknown product. .87 
Figure 4.41: Patient E foreign particle: (a) round particle with flattened surface, (b) wear tracks.

Figure 4.42: Patient E foreign particle, EDS spot analysis spectrum of foreign particle........ .88

Figure 5.1: Surface profilometry plot [60]. .95 


\section{Chapter 1: Introduction}

In biomedical applications, metallurgical and materials engineers are responsible for implant alloy and material selection based upon biocompatibility with the human body and resistance to corrosion, degradation, and wear [1]. The mechanical properties of materials used for implants must be able to duplicate the structures they are intended to replace. Metallic biomaterials are used for load bearing applications and must have sufficient fatigue strength to endure the rigors of daily activities [2]. Ceramic biomaterials are generally used for their hardness and wear resistance for applications such as articulating surfaces in joints and bone bonding surfaces in implants [2]. Polymeric materials are usually used for their flexibility and stability, but have also been used for low friction articulating surfaces [2].

The focus of this research was on failed metallic and polymeric hip components that were retrieved during revision hip replacement surgeries from four patients. After a thorough investigation, having utilized failure analysis techniques, the reasons for the ultimate failure of the implant components were explored. With the data acquired, the information shall be given to the collaborating orthopedic surgery group in hopes of altering new components to ensure longer implant lifetimes and less needed revision surgeries.

\subsection{Total Hip Arthroplasty (THA)}

First performed in 1960, total hip replacement surgeries have made some of the most important surgical advances in the last century [3]. According to the American Academy of Orthopedic Surgeons, more than 193,000 total hip replacements and 140,000 partial and revision 
hip replacements are performed each year in the United States [3,4]. A total hip arthroplasty (THA) involves the removal of diseased cartilage and bone and is then replaced with implant materials [5]. People in need of hip replacements typically stem from various cases of arthritis or injury [6]. In support of the previous statement, Table 1.1 displays the five most frequent diagnoses in patients who underwent hip replacement surgery in 2003 [6]. From the data collected by Zhan, it was observed that osteoarthritis compromised the largest percentage of THAs, fractures of the neck of femur for partial hip replacements, and complications of devices for revision surgeries [6].

Table 1.1: Most frequent five principal diagnoses* in patients who underwent hip replacement surgery. [6]

\begin{tabular}{|c|c|c|c|c|c|c|}
\hline Rank & Total Hip Replacement & $\%$ & Partial Hip Replacement & $\%$ & Revision Hip Replacement & $\%$ \\
\hline 1 & Osteoarthritis & 81 & $\begin{array}{l}\text { Fracture of neck of femur } \\
\text { (hip) }\end{array}$ & 88 & $\begin{array}{l}\text { Complication of device, implant, } \\
\text { or graft }\end{array}$ & 89 \\
\hline 2 & $\begin{array}{l}\text { Other bone, musculoskete- } \\
\text { tal diseases }\end{array}$ & 9 & Pathological fracture & 3 & Osteoarthritis & 2 \\
\hline 3 & $\begin{array}{l}\text { Fracture of neck of femur } \\
\text { (hip) }\end{array}$ & 4 & $\begin{array}{l}\text { Other bone, musculoskele- } \\
\text { tal diseases }\end{array}$ & 3 & $\begin{array}{l}\text { Fracture of neck of femur } \\
\text { (hip) }\end{array}$ & 2 \\
\hline 4 & $\begin{array}{l}\text { Complication of device, } \\
\text { implant, or graft }\end{array}$ & 1 & $\begin{array}{l}\text { Complication of device, } \\
\text { implant, or graft }\end{array}$ & 2 & Fracture of lower limb & 2 \\
\hline 5 & $\begin{array}{l}\text { Rheumatoid arthritis and } \\
\text { related diseases }\end{array}$ & 1 & Osteoarthritis & 1 & Other acquired deformities & 2 \\
\hline
\end{tabular}

\subsubsection{Primary Indications for Total Hip Arthroplasties (THAs)}

Where a healthy hip should have a rounded socket, good cartilage lining, and a strong femoral head, an arthritic hip tends to compose of narrow joint spacings and worn cartilage, as can be seen in Figure 1.1 [3]. Arthritis is due to an inflammation of the cartilage lining of joints and can cause bone deformation [7]. In severe cases, the cartilage continues to wear away and the bones rub against one another causing stiffness and pain. Other forms of arthritis include 
osteoarthritis, rheumatoid arthritis, and inflammatory arthritis. In terms of injuries, a hard fall, repeated loads and stresses (i.e., sports, walking, running, etc.), and improper care on the part of the patient can result in wear and ultimate failure of the joints [8]. Fractures of the acetabulum typically occur in young, healthy adults from high-energy traumas such as a traffic accident or a fall from a great height [9]. By contrast, geriatric patients may sustain an acetabular fracture from a simple fall due to the brittleness of osteoporotic bone [9]. These injuries have created cases of patients whose age range is from the very young to the very old. Though hip replacement surgeries are primarily carried out for people over 60 years of age, there are indeed cases of younger generations requiring hip replacements as well [4]. If medication and physical therapy are not producing rehabilitating results, THA is the final step that physicians take [10].
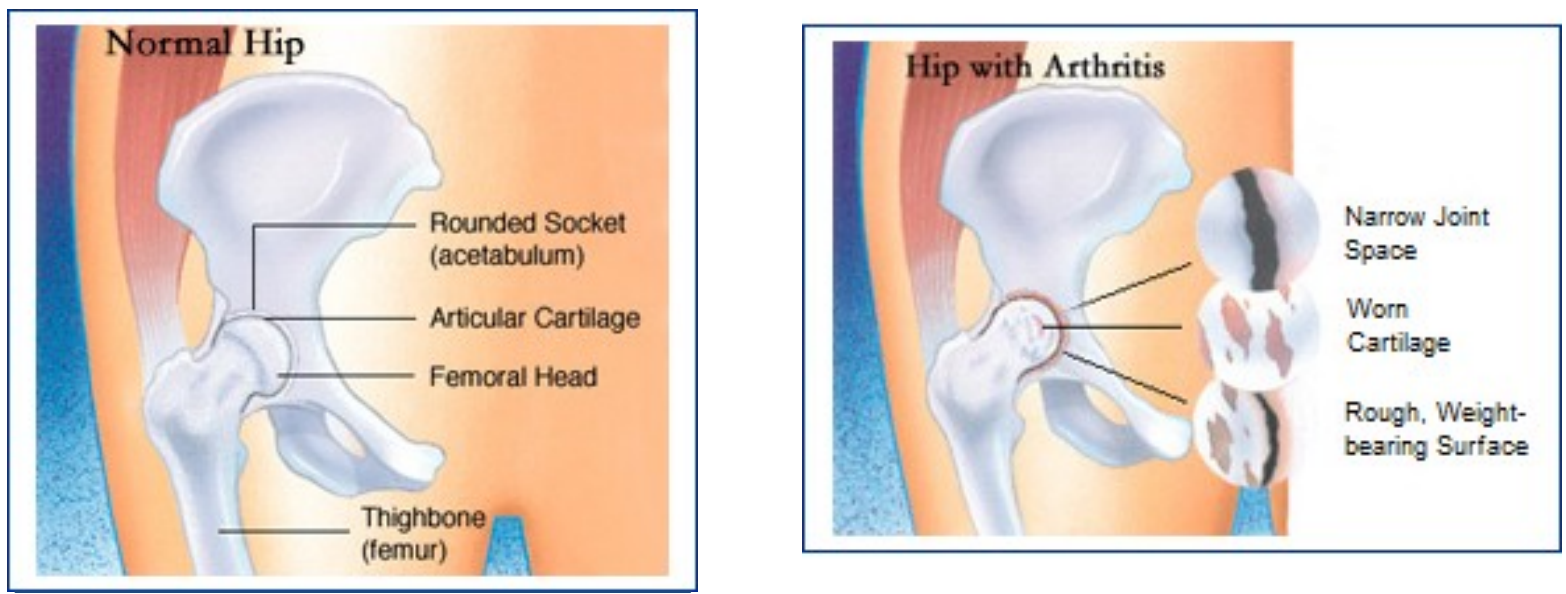

Figure 1.1: Normal hip vs. Arthritic hip [3]

\subsubsection{Hip Implant Components}

The main components of a THA, Figure 1.2, are generally referred to as the stem, head, liner, and shell, and Table 1.2 displays the different biomaterials in current use. The femoral 
stem can be a stainless steel, cobalt-based alloy, or titanium-based alloy. Orthopedic surgeons tend to select Ti-6Al-4V (i.e., Ti64) as the main femoral component for its desirable mechanical properties, corrosion resistance, and satisfactory local tissue response, in comparison with stainless steel, cobalt-based alloys, and composites [11]. Though Figure 1.2 displays a colored, ceramic femoral head, other biomaterials such as stainless steel and cobalt- and titanium-based alloys are also choice selections. It must be noted, however, that all components in this research involved the study of metallic femoral heads. The liner is an ultra high molecular weight polyethylene (UHMWPE) and the shell is generally manufactured from ceramic materials such as alumina or zirconia.

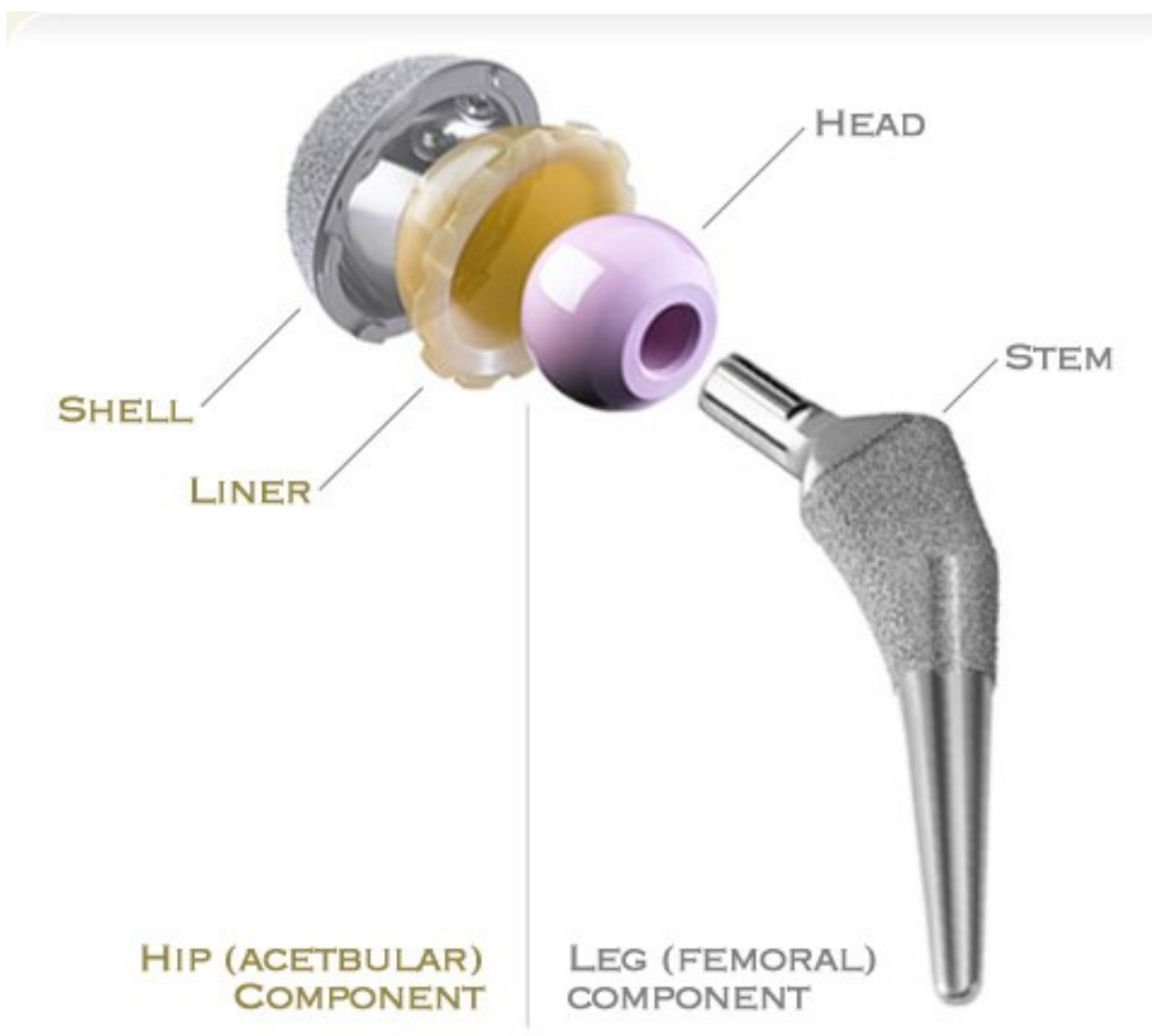

Figure 1.2: Hip replacement assembly consisting of four key components: Stem, Head, Liner, and Shell. [12] 
Table 1.2: Biomaterials used in total joint replacement. [8]

\begin{tabular}{|ll|}
\hline \multicolumn{1}{|c|}{ Material } & \\
Metals & \multicolumn{1}{c|}{ Application } \\
Stainless steels 316L & Femoral stems, heads \\
Cobalt-based alloys & Porous coatings, femoral stems, heads, tibial and femoral components \\
Cast Co-Cr-Mo & \\
Wrought Co-Ni-Cr-Mo & \\
Wrought Co-Cr-W-Ni & \\
Titanium-based materials & \\
CP Ti & Porous coatings second phase in ceramic and PMMA composites \\
Ti-6Al-4V & Femoral stems, heads, tibial and femoral components, porous coatings \\
Ti-5Al-2.5Fe & Femoral stems, heads \\
Ti-Al-Nb & Femoral stems, heads \\
Ceramics & \\
Bioinert & \\
Carbon & Coatings on metallic femoral stems, second phase in composites and \\
Alumina & bone cement \\
Zirconia & Femoral stems, heads, acetabular cups \\
Bioactive & Femoral stems, acetabular cups \\
Calcium Phosphates & Coatings on metallic and ceramic femoral stems, scaffold materials, \\
Bioglasses & second phase in PMMA and UHMWPE composites \\
Polymers & Coatings on metallic and ceramic femoral stems \\
PMMA & Bone cement \\
UHMWPE/HDPE & Acetabular cups, tibial and patellar components, porous coatings on \\
Polysuffolene & metallic and ceramic femoral stems \\
PTFE & Femoral stems, porous coatings on metallic femoral stems \\
Composites & Femoral stems, porous coatings on metallic femoral stems \\
Polymer-based & Femoral stems \\
Polysulflone-carbon & \\
Polycarbonate-carbon & \\
Polysulfone-Kevlar & \\
Polycarbonate-Kevlar & \\
\hline
\end{tabular}




\subsubsection{Solid Freeform Fabrication (SFF)}

THA components are manufactured in different sizes to accommodate varying patient sizes and heights. Though femoral stems tend to be manufactured as small, medium, and large, custom designed stems can also be produced. Solid freeform fabrication (SFF), or rapid prototyping, is a collection of techniques for manufacturing solid objects by the sequential delivery of energy and/or material to a specified point in space to produce that solid [13]. Commonly available techniques include electron beam melting, selective layer sintering, and shape deposition manufacturing, etc. [13].

Similarly, Murr and Wicker et al. at The University of Texas at El Paso (UTEP) have utilized the technique of rapid prototyping to produce hip implant components [14]. With a 3D CAD drawing of an actual acetabular socket, femur, and femoral head, electron beam melting (EBM) has produced small-scale, titanium components of near bone density with custom dimensions to match those of the THA patient [14]. The CAD to metal technology of the Arcam EBM allowed Murr to create solid and mesh femoral stems, where the mesh allows for bone resorption and provides similar mechanical properties to that of bone, Figure $1.3[14,15]$. The purpose for the fabrication of the titanium mesh was to provide a larger example of the porosity that would be seen on cementless stems. The EBM process encompasses the repeated layering and melting of atomic layers of titanium, steel, or niobium powder, until a component is produced. Since the component (i.e., femoral stem) is fabricated in such miniscule layers, immense detail can be achieved. 


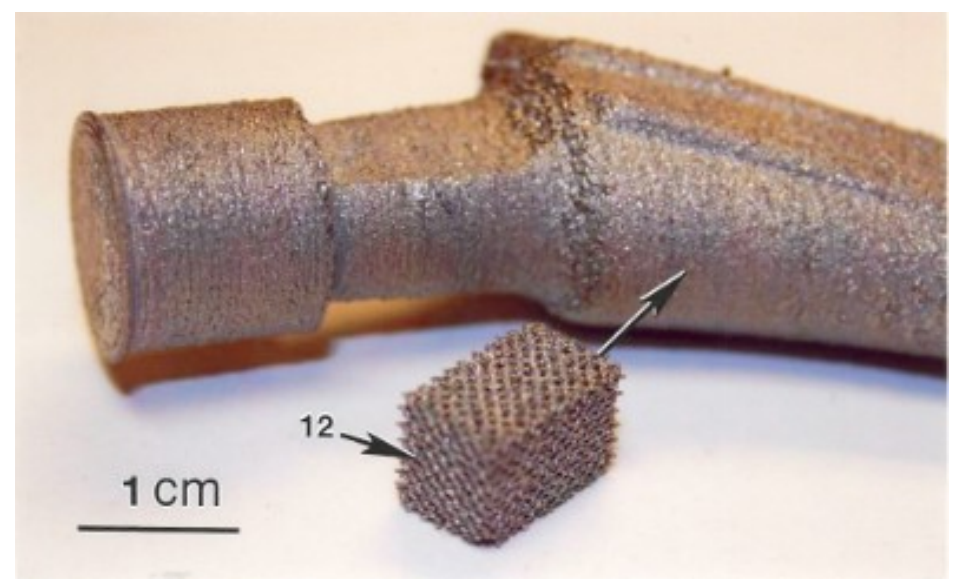

Figure 1.3: Electron beam melted (EBM) titanium femoral stem with titanium mesh. [14]

\subsubsection{Cemented Stems vs. Cementless Stems}

Given the benefits and consequences, the patient can select between a cemented or cementless total hip replacement (THR). In a cemented THR, the surgeon removes cancellous bone from the femur to ensure a snug fit for the bone cement (i.e., polymethyl methacylate or PMMA) and femoral stem, Figure 1.4a. Keep in mind that the bone cement is used with the acetabular socket components as well. The main purpose of the bone cement is to absorb forces acting on the hips and to act as a filler between the implant and bone, while coincidentally forming a mechanical bond with the bone [16]. Cemented implants generally perform well for over a decade in older, less active patients, whereas younger patients can have higher implant failures within the first five years [16]. The long-term success of cemented THRs is often limited by loosening of the femoral component [17]. During a cementless THR, the surgeon similarly removes cancellous bone from the femur but only enough to fit a porous-coated femoral stem, Figure 1.4b. In theory, the cementless THR is expected to reduce the chance of infection and loosening of the entire prosthesis [10]. To further the point, without the presence 
of PMMA particles in surrounding tissues, related infections and inflammations can be disregarded. Clinical and laboratory evidence suggests that the long term success rate of cementless hip stems is improved with an implant that provides maximal filling of the femoral canal and resistance to axial torques [18].
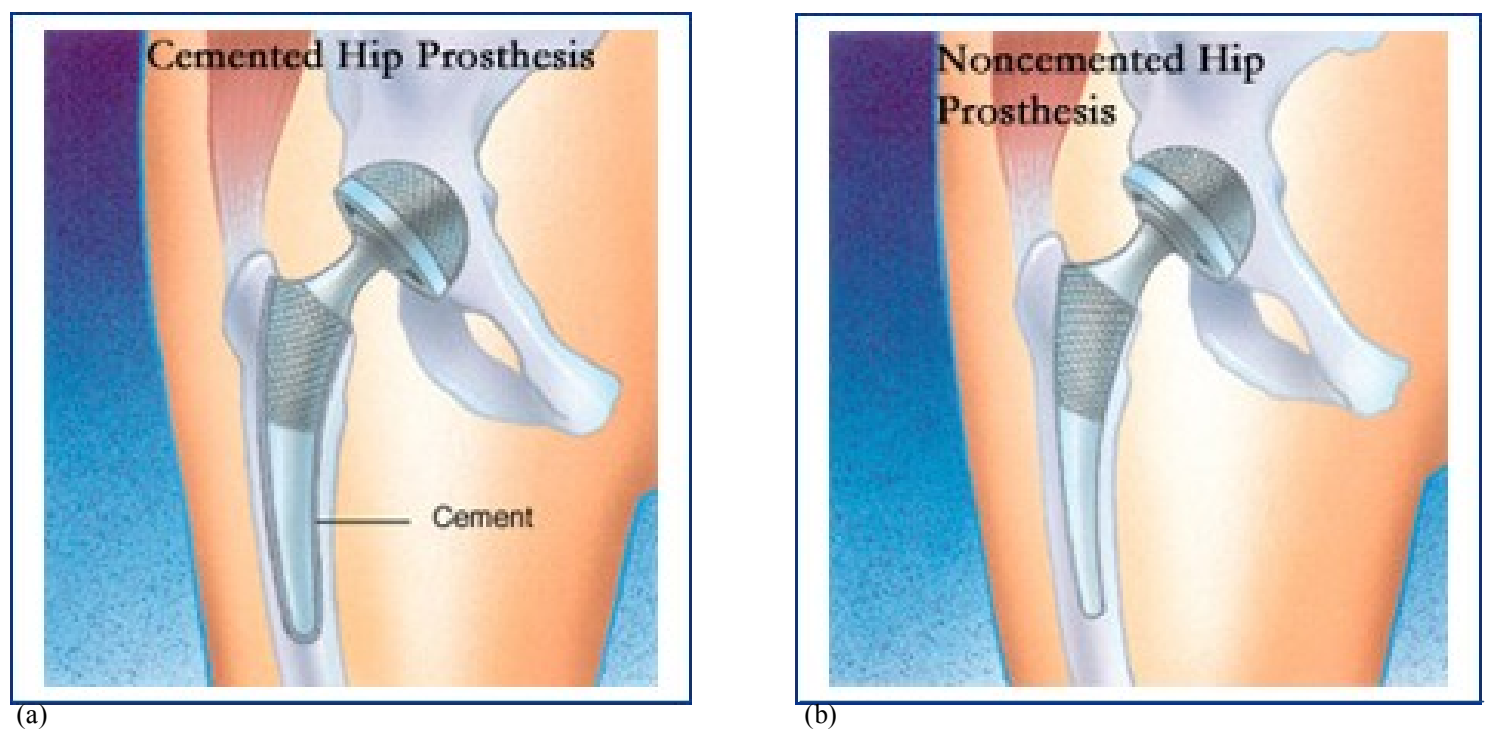

Figure 1.4: Hip prostheses: (a) Cemented, (b) Cementless. [3]

\subsubsection{Femoral Stem Sizes, Tapers, and Textures}

As previously stated, cementless stems are expected to have less aseptic loosening when compared with cemented stems. The added textures and thermally sprayed porous-coatings assists for bone ingrowth to better secure the implant. It is taken that the bond between bone resorption and the prosthesis is far greater than that of the bond between PMMA and a coated or uncoated stem. Figure 1.5 provides examples of femoral stems with varying tapers, textures, and coatings. Figures $1.5 \mathrm{a}$ and $\mathrm{b}$ are uncoated stems that would be used in a cemented THA since the PMMA filler requires no porosity for ingrowth. Figure $1.5 \mathrm{c}$ is a coated stem that can 
be used for either surgery, but may be better suited for a cemented THA since the texture is not porous enough to allow for optimal bone ingrowth. Figures $1.5 \mathrm{~d}-\mathrm{f}$ are textured stems for a cementless THA in that there is enough porosity in the polymeric coating for bone resorption. The tapers of Figures 1.5a-f are all different shapes and sizes that depend on the distance and angles of the patient's actual hip.

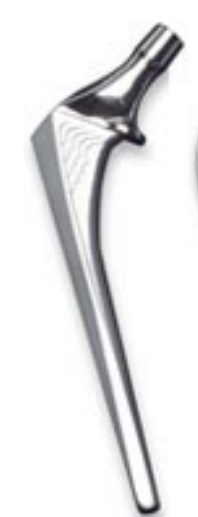

(a)

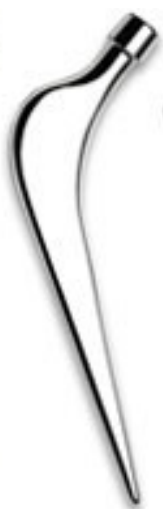

(b)

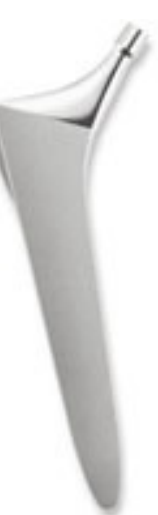

(c)

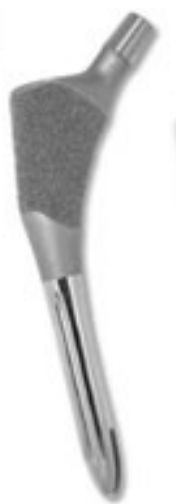

(d)

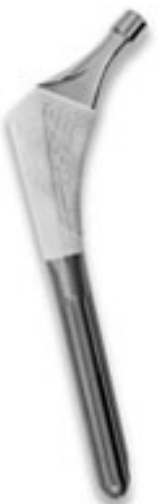

(e)

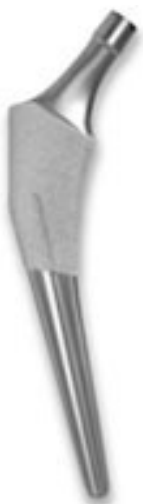

(f)

Figure 1.5: Femoral stems: (a) and (b) Uncoated, (c) Coated, (d)-(f) Porous-coated. [19]

\subsubsection{Post-Surgery Expectations}

Hip replacements are traumatic surgeries to people of all ages, especially the frail. A total hip joint replacement takes approximately 2 to 4 hours of surgical time and requires a 6 week to 6 month recovery with minimal activities to ensure healthy rehabilitation [4,5]. Older patients tend to have cemented THAs since the recovery time is faster as opposed to waiting for new bone ingrowth to occur as in cementless THAs [4]. An example of an implanted cementless THA can be seen in the radiograph of Figure 1.6. In a primary (i.e., first-time) hip replacement the parts typically weigh 1-2 pounds but can weigh up to 5 pounds, which is more than the 
weight of the bone removed $[1,20]$. Men and patients who weigh more than $165 \mathrm{lb}$ have higher rates of failure [1]. Overall, the chance of a hip replacement lasting 20 years is approximately $80 \%$ [1]. More than likely, patients can expect to have revision surgeries to correct fractured devices or to relieve new pain and/or inflammation.

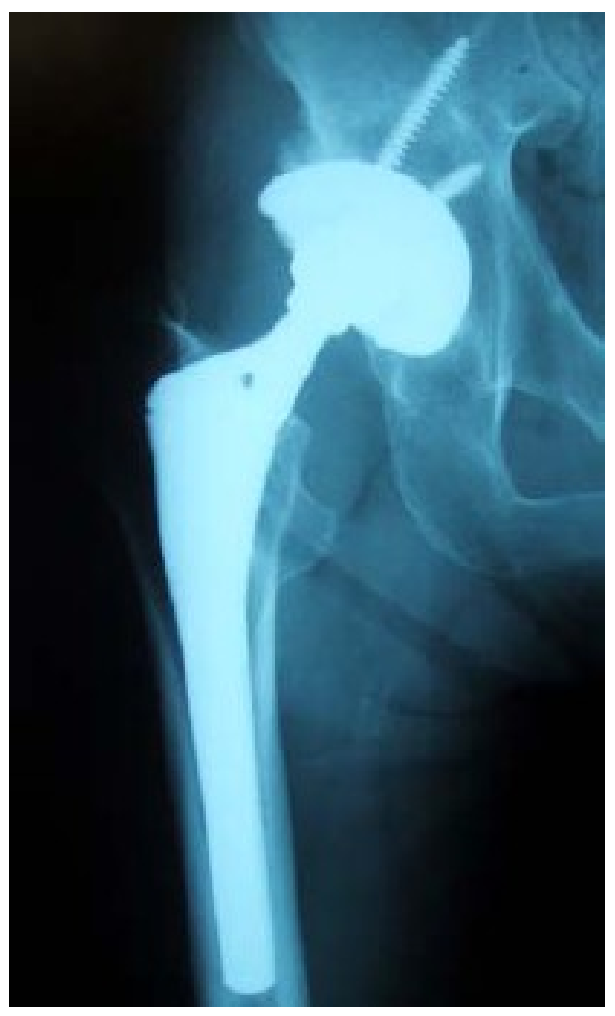

Figure 1.6: Radiograph of an implanted cementless THA. [21]

\subsection{Objectives}

This research focused on failed hip implant components with an emphasis on the interaction between the metallic femoral heads and the ultra high molecular weight polyethylene (UHMWPE) liners from the acetabular cups. Typical problems found between the femoral head and liner, are wear, possible corrosion product, defects, and fractures. The overall goal of this 
research is to perform failure analysis and materials characterization to determine the causes for premature failure of the aforementioned components.

The objectives are separated into three main categories: acquisition of background information, macro level analysis: non-destructive evaluation (NDE), and micro level analysis: Destructive evaluation (DE). Non-destructive analysis techniques such as visual examination and dye penetrant inspection are used in failure analysis to observe surface defects and physical properties of the sample. DE is the further analysis of the mechanical properties and microstructural characteristics of the sample whether by machining, metallography, or sample failures created by tensile-testing, etc. The selected techniques performed throughout this research specifically analyzed all possible aspects of the components to determine every flaw. The failure analysis performed on the failed implant components included: 
Table 1.3: Thesis objectives

\begin{tabular}{|c|c|c|}
\hline \multirow{2}{*}{$\begin{array}{l}\text { Acquisition of Background } \\
\text { Information }\end{array}$} & - Patients & - Background \\
\hline & - Components & $\begin{array}{l}\text { - Find the manufacturers } \\
\text { - Acquire mechanical and physical properties }\end{array}$ \\
\hline \multirow[t]{5}{*}{$\begin{array}{l}\text { Macro Level Analysis: } \\
\text { Nondestructive Evaluation } \\
\text { (NDE) }\end{array}$} & - Visual Examination & $\begin{array}{l}\text { - Gather component dimensions } \\
\text { (i.e., lengths, widths, diameters) } \\
\text { - Locate macroscopic scratches, abrasive wear, } \\
\text { and plastic deformation, on the UHMWPE liners } \\
\text { and femoral heads }\end{array}$ \\
\hline & $\begin{array}{l}\text { - X-Ray Fluorescence } \\
\text { (XRF) }\end{array}$ & $\begin{array}{l}\text { - Attain elemental weight percentages for each } \\
\text { component }\end{array}$ \\
\hline & $\begin{array}{l}\text { Fourier Transform } \\
\text { Infrared Spectroscopy } \\
\text { (FTIR) }\end{array}$ & $\begin{array}{l}\text { - Concrete support for previous elemental } \\
\text { compositions } \\
\text { - Find molecular intensities for carbon-carbon } \\
\text { and carbon-hydrogen bonds }\end{array}$ \\
\hline & $\begin{array}{l}\text { - Dye Penetrant } \\
\text { Inspection (DPI) }\end{array}$ & $\begin{array}{l}\text { More clearly define macroscopic scratches, } \\
\text { abrasive wear, and plastic deformation, on the } \\
\text { UHMWPE liners }\end{array}$ \\
\hline & - Optical Microscopy & $\begin{array}{l}\text { - Provide microstructural images of the metallic } \\
\text { femoral heads }\end{array}$ \\
\hline \multirow[t]{2}{*}{$\begin{array}{l}\text { Micro Level Analysis: } \\
\text { Destructive Evaluation } \\
\text { (DE) }\end{array}$} & - Metallography & $\begin{array}{l}\text { - Examine material and alloy component cross- } \\
\text { sections } \\
\text { - Ensure all components have correct } \\
\text { microstructures } \\
\text { - Find defects, areas of wear and fatigue, cracks, } \\
\text { and plastic deformation }\end{array}$ \\
\hline & $\begin{array}{l}\text { - Scanning Electron } \\
\text { Microscopy (SEM) }\end{array}$ & $\begin{array}{l}\text { - Search for areas of wear on UHMWPE liners } \\
\text { - Locate areas of wear and defects } \\
\text { - Acquire elemental sprectra of foreign } \\
\text { bodies and unknown deposits }\end{array}$ \\
\hline
\end{tabular}




\subsection{Overview of Following Thesis Chapters}

Further backgrounds for each of the biomaterials used in this research (i.e., stainless steels, cobalt-based alloys, and polyethylene) and the failure modes of hip implant components will be provided in Chapter 2. Chapter 3 contains the experimental procedures for each failure analysis technique listed in the above objectives. In Chapter 4, the results from each test will be exhibited and discussed, followed by the summary and conclusions in Chapter 5. 


\section{Chapter 2: Background}

Mechanical properties and characteristics of biomaterials associated with total hip replacements (THRs) have much improved since the first orthopedic surgeries. As mentioned in the previous chapter, metals, alloys, ceramics, and polymers, compromise of the diverse components in hip prostheses. The following sections will provide in-depth backgrounds of the aforementioned biomaterials and the strict requirements that each component must meet before implantation.

\subsection{Stainless Steel}

Stainless steel is a diverse alloy that has continued to facilitate the applications in many fields. Largely due to its ease of fabrication and desirable assortment of mechanical properties and corrosion behavior, stainless steel is the predominant implant alloy [8]. The elemental compositions of austenitic stainless steel grades, according to the American Iron and Steel Institute (AISI), are displayed in Table 2.1. The substantial corrosion resistance required by joint replacement components can be found within the 300 -series [22]. To be considered "stainless," steel requires the addition of $\mathrm{Cr}$ to enhance corrosion resistance by forming a $\mathrm{CrO}_{2}$ passive layer on the surface of the steel. The lower the $\mathrm{C}$ content in the stainless steel, the more corrosion resistant the alloy is to the physiological saline in the human body [8]. With this reasoning, it has been recommended by the American Society of Testing and Materials (ASTM) that 316L should be the principal alloy for implant fabrication in comparison with other SS grades [8]. Other alloying elements include nickel which is used to increase corrosion resistance in more 
aggressive environments and molybdenum which improves localized corrosion resistance against pitting, fretting, and crevice corrosion [23].

Table 2.1: Composition of austenitic stainless steels (balance \% iron). [8]

\begin{tabular}{|lccccc|}
\hline AISI & $\% \mathrm{C}$ & $\% \mathrm{Cr}$ & $\% \mathrm{Ni}$ & $\% \mathrm{Mn}$ & $\%$ other elements \\
\hline 301 & 0.15 & $16-18$ & $6.0-8$ & 2.0 & $1.0 \mathrm{Si}$ \\
304 & 0.07 & $17-19$ & $8.0-11$ & 2.0 & $1-\mathrm{Si}$ \\
$316,18-8 \mathrm{sMo}$ & 0.07 & $16-18$ & $10.0-14$ & 2.0 & $2-3 \mathrm{Mo}, 1.0 \mathrm{Si}$ \\
$316 \mathrm{~L}$ & 0.03 & $16-18$ & $10.0-14$ & 2.0 & $2-3 \mathrm{Mo}, 0.75 \mathrm{Si}$ \\
$430 \mathrm{~F}$ & 0.08 & $16-18$ & $1.0-1.5$ & 1.5 & $1.0 \mathrm{Si}, 0-6 \mathrm{Mo}$ \\
\hline
\end{tabular}

Mechanical properties of biomaterials sometimes require additional characteristics to fully duplicate the structure intended for replacement. In situations where the original cast, wrought, or forged alloy requires a physical or chemical alteration, heat treatments such as annealing, cold working, and hot forging, can be of service [24]. As 316 and 316L are the most widely used stainless steel alloys in surgical implant fabrication, ultimate tensile strengths, yield strengths, and elongations, for such heat treated alloys are listed in Table 2.2 [8]. The overall advantages to stainless steel include good hot-and cold-working mechanical properties, good machinability, and low cost [25]. Though SS maintains fine biocompatibility and properties, there is a tendency to fall short in the viewpoint of fatigue resistance because of low proportional limits that lead to initiation and propagation of fatigue cracks [22]. Biomaterials with improved fatigue resistances are titanium and titanium-alloys, cobalt-alloys, and the stainless steel 400series [22]. 
Table 2.2: Mechanical properties of stainless steels in surgical implants. [8]

\begin{tabular}{|llccc|}
\hline Material & \multicolumn{1}{c}{ Condition } & $\begin{array}{c}\text { Ultimate Tensile Strength } \\
(\mathrm{MPa})\end{array}$ & $\begin{array}{c}\text { Yield Strength } \\
(\mathrm{MPa})\end{array}$ & $\begin{array}{c}\text { Elongation in } \\
\text { 2 in., min. \% }\end{array}$ \\
\hline 316 & Annealed & 515 & 205 & 40 \\
& Cold finished & 620 & 310 & 35 \\
& Cold worked & 860 & 690 & 12 \\
$316 \mathrm{~L}$ & Annealed & 505 & 195 & 40 \\
& Cold finished & 605 & 295 & 35 \\
& Cold worked & 860 & 690 & 12 \\
\hline
\end{tabular}

As all biomaterials eventually fail, the key failure modes associated with stainless steel are wear, fatigue, and corrosion. The mechanism of wear, which will be further discussed in a later chapter, involves the break-down of a softer surface due to contact with another harder surface. The following case represents the effects of wear particles on stainless steel. Upon a second revision surgery of a 54 year old THR patient, severe deformation of the stainless steel femoral head was discovered [26], Figure 2.1. The substantial and rapid abrasion of the stainless steel occurred because released alumina particles (from the previous ceramic head) in the surrounding tissue and joint cavity came between the PE liner and stainless steel [26]. This case goes to show that the wear of some biomaterials can be the ultimate cause of failure for others. As far as corrosion is concerned, research has revealed that the fretting corrosion product of austenitic steel can cause undesirable reactions in both the implant and the human body [25]. From these corrosion products, Xulin and Ito et al. discovered nickel concentrations as high as $2 \%$ in tissues around retrieved stainless steel orthopedic implants by histological analysis [25]. Aside from implant failures due to fabrication and manufacture, a healthy and none-toostrenuous lifestyle is the optimal setting for stainless steel implants with increased lifetimes. 


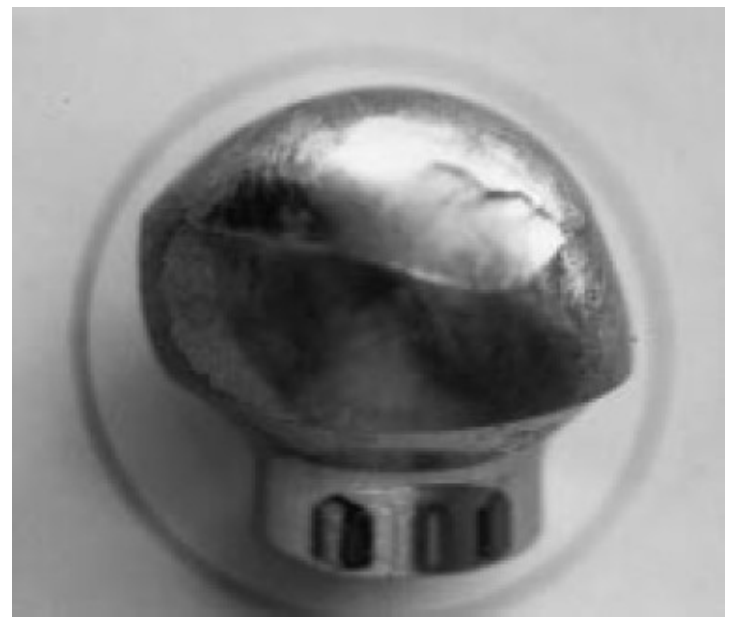

Figure 2.1: Severe deformation of a stainless steel femoral head caused by PE and alumina wear debris at the interface between the cup and femoral head. [26]

\subsection{Cobalt-Based Alloys}

Ever since the use of stainless steel as the first biomaterial in THR surgeries, biomedical manufacturers have aimed research at the production of additional alloys with superior mechanical properties [3]. Presently, cobalt-based alloys are among the safest biomaterials for orthopedic prostheses, because of their excellent corrosion properties and mechanical strength [27]. The main attribute of cobalt-based alloys is its corrosion resistance in chloride environments, which is due to alloying additions and the formation of the chromium oxide $\mathrm{Cr}_{2} \mathrm{O}_{3}$ passive layer [28].

Orthopedic implants fabricated with cobalt-alloys can be cast, wrought, or forged [8]. An example of a metal-metal modular junction between a cast cobalt-alloy femoral stem and a cast cobalt-alloy femoral head is shown in Figure 2.2. The exceptional mechanical properties and corrosion resistances of cobalt-alloys originate from the specific weight percentages of base elements and alloy additions in their compositions. According to Table 2.3, casting and forging 
bars made with cobalt-based alloys with low quantities of nickel are designated as F75 and F799, and alloys with larger nickel content are designated as F90 and F562 [29]. Compared to the wrought alloys, cobalt-based casting alloys are characterized by higher contents of high melting metals such as chromium, tungsten, tantalum, titanium, and zirconium, and by higher carbon contents [30]. In all designations, molybdenum produces finer grains which results in higher strength and silicon and manganese improve oxidation resistance $[8,30]$.

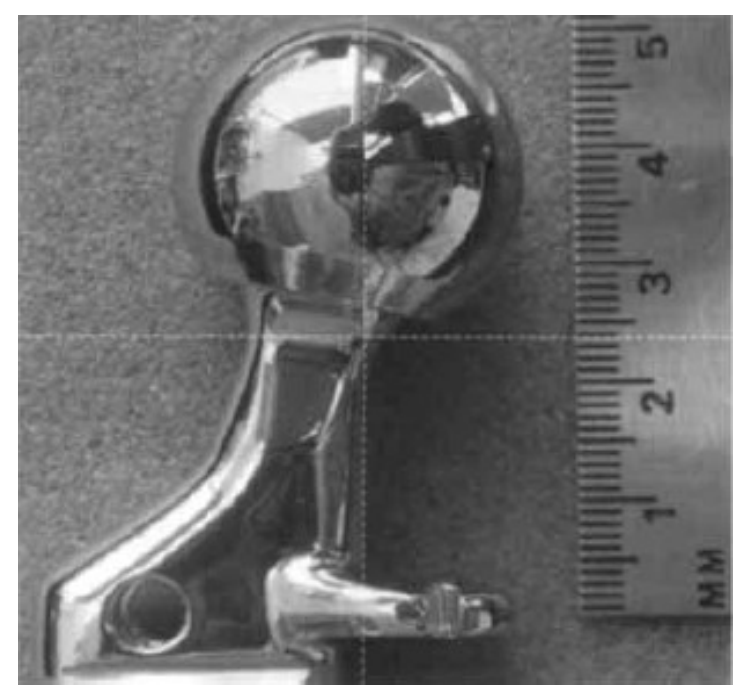

Figure 2.2: Cast cobalt-alloy femoral stem with a cast cobalt-alloy femoral head. [31] 
Table 2.3: Chemical compositions of cobalt-based alloys for biomedical implants. [28]

\begin{tabular}{|c|c|c|c|}
\hline Material & ASTM & Common Trade Names & Composition (wt.\%) \\
\hline $\mathrm{Co}-\mathrm{Cr}-\mathrm{Mo}$ & F75 & Vitallium & 58.9-69.5 Co \\
\hline \multirow[t]{7}{*}{ Cast } & & Haynes-Stellite 21 & $27.0-30.0 \mathrm{Cr}$ \\
\hline & & Protasul-2 & 5.0-7.0 Mo \\
\hline & & Micrograin-Zimaloy & $\max 1.0 \mathrm{Mn}$ \\
\hline & & & $\max 1.0 \mathrm{Si}$ \\
\hline & & & $\max 2.5 \mathrm{Ni}$ \\
\hline & & & $\max 0.75 \mathrm{Fe}$ \\
\hline & & & $\max 0.35 \mathrm{C}$ \\
\hline Co-Cr-Mo & F799 & Forged Co-Cr-Mo & 58-59 Co \\
\hline \multirow[t]{8}{*}{ Forged } & & Thermomechanical Co-Cr-Mo & $26.0-30.0 \mathrm{Cr}$ \\
\hline & & FHS & 5.0-7.00 Mo \\
\hline & & & $\max 1.00 \mathrm{Mn}$ \\
\hline & & & $\max 1.00 \mathrm{Si}$ \\
\hline & & & $\max 1.00 \mathrm{Ni}$ \\
\hline & & & $\max 1.5 \mathrm{Fe}$ \\
\hline & & & $\max 0.35 \mathrm{C}$ \\
\hline & & & $\max 0.25 \mathrm{~N}$ \\
\hline Co-Cr-W-Ni & F90 & Haynes-Stellite 25 & 45.5-56.2 Co \\
\hline \multirow[t]{9}{*}{ Wrought } & & Wrought Co-Cr & $19.0-21.0 \mathrm{Cr}$ \\
\hline & & & $14.0-16.0 \mathrm{~W}$ \\
\hline & & & $9.0-11.0 \mathrm{Ni}$ \\
\hline & & & $\max 3.00 \mathrm{Fe}$ \\
\hline & & & $1.00-2.00 \mathrm{Mn}$ \\
\hline & & & $0.05-0.15 \mathrm{C}$ \\
\hline & & & $\max 0.04 \mathrm{P}$ \\
\hline & & & $\max 0.40 \mathrm{Si}$ \\
\hline & & & $\max 0.03 \mathrm{~S}$ \\
\hline \multirow{9}{*}{$\begin{array}{l}\text { Co-Ni-Cr-Mo-Ti } \\
\text { Wrought }\end{array}$} & F562 & MP $35 \mathrm{~N}$ & 29-38.8 Co \\
\hline & & Biophase & $33.0-37.0 \mathrm{Ni}$ \\
\hline & & Protasul-1( ) & $19.0-21.0 \mathrm{Cr}$ \\
\hline & & & 9.0-10.5 Мо \\
\hline & & & $\max 1.0 \mathrm{Ti}$ \\
\hline & & & $\max 0.15 \mathrm{Si}$ \\
\hline & & & $\max 0.010 \mathrm{~S}$ \\
\hline & & & $\max 1.0 \mathrm{Fe}$ \\
\hline & & & $\max 0.15 \mathrm{Mn}$ \\
\hline
\end{tabular}


The typical microstructure of cobalt-based alloys consists of a cobalt-rich solid-solution matrix containing carbides (i.e., $\mathrm{Cr}_{7} \mathrm{C}_{3}$, and $\mathrm{M}_{23} \mathrm{C}_{6}$ ) within the grains and at grain boundaries, where chromium, tungsten, tantalum, silicon, zirconium, nickel, and cobalt, may be present in a single carbide particle $[28,30]$. Table 2.4 provides the mechanical properties of heat treated, surgical grade cobalt-alloys. Early versions of cobalt-based alloys used for hip implants contained relatively high carbon contents $(0.2 \%)$, and were typically produced by investment casting [27]. Depending on the casting method, the manufacturing process has the ability to produce at least three microstructural features that can strongly influence implant properties, both positively and negatively [28]. The features include: (1) if not the typical F75 microstructure, then the formation of interdendritic regions that become solute (chromium, molybdenum, cobalt) rich and contain carbides, while dendrites become depleted in chromium and richer in cobalt, (2) dendrite formation and relatively large grain sizes that decrease yield strength, and (3) casting defects [28]. Although fabrication of cast materials may result in microscopic voids within their structures, techniques such as hot isostatic pressing (HIPing) can be applied for full densification of the material to improve mechanical properties [32].

More recently, low-carbon wrought versions of cobalt-based alloys have excellent mechanical properties and corrosion resistance and tend to be stronger than cast alloys [27,32]. Similar to cast alloys, hot forging or HIPing of components significantly reduces the number shrinkage voids and alters the grain structures leading to superior mechanical and fatigue properties [32]. 
Table 2.4: Mechanical properties of heat treated Co-based alloys. [33]

\begin{tabular}{|c|c|c|c|c|c|c|c|c|c|c|}
\hline \multirow{2}{*}{$\begin{array}{l}\text { Material: } \\
\text { Condition: }\end{array}$} & \multirow{2}{*}{\begin{tabular}{|c|} 
Cast \\
CoCrMo \\
AN
\end{tabular}} & \multicolumn{3}{|c|}{$\begin{array}{l}\text { Wrought } \\
\text { CoCrMo }\end{array}$} & \multicolumn{2}{|c|}{$\begin{array}{c}\text { Wrought } \\
\text { CoNiCrMo }\end{array}$} & \multicolumn{2}{|c|}{$\begin{array}{c}\text { Wrought } \\
\text { CoNiCrMoFe }\end{array}$} & \multicolumn{2}{|c|}{$\begin{array}{c}\text { Wrought } \\
\text { CoNiCrMoWFe }\end{array}$} \\
\hline & & AN & $\mathrm{CW}$ & HW & AN & CWA & $\mathrm{CW}$ & CWA & AN & $\mathrm{CW}$ \\
\hline Density $\left(\mathrm{g} / \mathrm{cm}^{3}\right)$ & 7.8 & 9.15 & 9.15 & - & - & - & - & - & - & - \\
\hline E (tensile) (GPa) & 200 & 230 & 230 & - & - & - & - & - & - & - \\
\hline Hardness (Hv) & 300 & 240 & 450 & 28 & - & - & - & - & - & - \\
\hline$\sigma_{0.2 \%}(\mathrm{MPa})$ & 455 & 310 & 1000 & 700 & $241-449$ & 1585 & - & $1240-1450$ & 275 & 1310 \\
\hline$\sigma_{\text {UTS }}(\mathrm{MPa})$ & 665 & 860 & 1500 & 1000 & $793-1000$ & 1795 & $1515-1795$ & $1860-2275$ & 600 & 1172 \\
\hline Elong. (min. \%) & 8 & 30 & 9 & 12 & 50 & 8 & - & $1.0-17$ & 50 & 12 \\
\hline
\end{tabular}




\subsection{Polymers}

From the wide selection of metals, alloys, ceramics, and composites, polymers represent the largest class of biomaterials [28]. Specific to acetabular components in THRs, ultra high molecular weight polyethylene (UHMWPE) has been the choice bearing material since its debut in 1962 [34]. UHMWPE is a homopolymer formed from ethylene $\left(\mathrm{C}_{2} \mathrm{H}_{4}\right)$, in which a single molecular chain can consist upwards of 200,000 ethylene repeat units (namely, 400,000 carbon atoms) [34]. Based on an exceptionally large molecular size, the superior mechanical properties for UHMWPE are compared with other polymers in Table 2.5. UHMWPE has high abrasion resistance, low friction, high impact strength, excellent toughness, low density, ease of fabrication, biocompatibility, and biostability [35].

Table 2.5: Thermoplastic Resins [33]

\begin{tabular}{|c|c|c|c|c|c|c|c|c|}
\hline Material: & $\begin{array}{c}\text { PE } \\
\text { (UHMW) }\end{array}$ & $\begin{array}{c}\text { PE } \\
\text { (UHMW) }\end{array}$ & $\begin{array}{c}\mathrm{PE} \\
(\mathrm{UHMW})\end{array}$ & $\begin{array}{c}\text { PE } \\
\text { (UHMW) }\end{array}$ & $\begin{array}{c}\text { PLA } \\
\text { (STCP) }\end{array}$ & PMMA & $\begin{array}{c}\text { PSF } \\
\text { High N2 }\end{array}$ & $\begin{array}{c}\text { PEEK } \\
\text { High N2 }\end{array}$ \\
\hline Condition & MM & EX & $\mathrm{CM}$ & $\mathrm{HC}$ & $\mathrm{CM}$ & $\mathrm{CM}$ & IM & IM \\
\hline Density $\left(\mathrm{g} / \mathrm{cm}^{3}\right)$ & $0.927-0.944$ & $0.927-0.944$ & $0.93-0.944$ & - & - & 1.186 & $1.23-1.25$ & $1.28-1.32$ \\
\hline $\mathrm{E}$ (tensile) (GPa) & - & 1.24 & 1.36 & 2.17 & $4.0-5$ & $2.6-3.2$ & $2.3-3.2$ & $3-8.3^{*}$ \\
\hline Hardness (Sh. D) & 60 & 60 & 62 & 66 & - & - & - & - \\
\hline$\sigma_{\mathrm{y}}(\mathrm{MPa})$ & $19-21$ & $19-28$ & $19-29$ & 28 & - & - & $65-96$ & 70 \\
\hline$\sigma_{\mathrm{UCS}}(\mathrm{MPa})$ & - & - & - & - & - & $80-125$ & - & - \\
\hline$\sigma_{\text {UTS }}(\mathrm{MPa})$ & $27-35$ & $37-47$ & $27-40$ & - & $50-60$ & $50-75$ & 740 & $90-152$ \\
\hline Elong. (min. \%) & 300 & $250-300$ & 350 & 230 & 3-Feb & $2.0-10$ & 35 & $4.9^{* *}$ \\
\hline $\begin{array}{r}\text { Notes: IM: injecti } \\
\text { crystallinit } \\
\\
\text { acid stereo }\end{array}$ & $\begin{array}{l}\text { lded; MM: m } \\
\text { (UHMWPE): } \\
\text { ymer; PMMA }\end{array}$ & $\begin{array}{l}\text { led, machinec } \\
\text { ra high molec } \\
\text { olymethyl me }\end{array}$ & $\begin{array}{l}\text { EX: extruded; } \\
\text { lar weight pol } \\
\text { lacrylate; PSF }\end{array}$ & $\begin{array}{l}\text { M: compres } \\
\text { thylene; PL } \\
\text { olysulfone; }\end{array}$ & $\begin{array}{l}\text { on molded; } \\
\text { (STCP): pc } \\
\text { flexural; * }\end{array}$ & $\begin{array}{l}\text { HC: high } \\
\text { llactic } \\
\text { at yield. }\end{array}$ & & \\
\hline
\end{tabular}

The fabrication of UHMWPE orthopedic implants involves the consolidation of crosslinked resin powder into a rod, followed by machining into the final shape as displayed in Figure 2.3 [34]. Clinical results have indicated that although crosslinking improves wear resistance, it may also provide adverse effects [36]. Before the components are sent to vendors, 
they are packaged and sterilized to ensure no bacterial contamination of the UHMWPE components before implantation. Currently, gamma radiation in a reduced oxygen environment is the choice method of sterilization [34]. Due to the strict requirements of sterilization, only high-density PE can be used in such biomedical applications because low-density material cannot withstand the high temperatures [28].
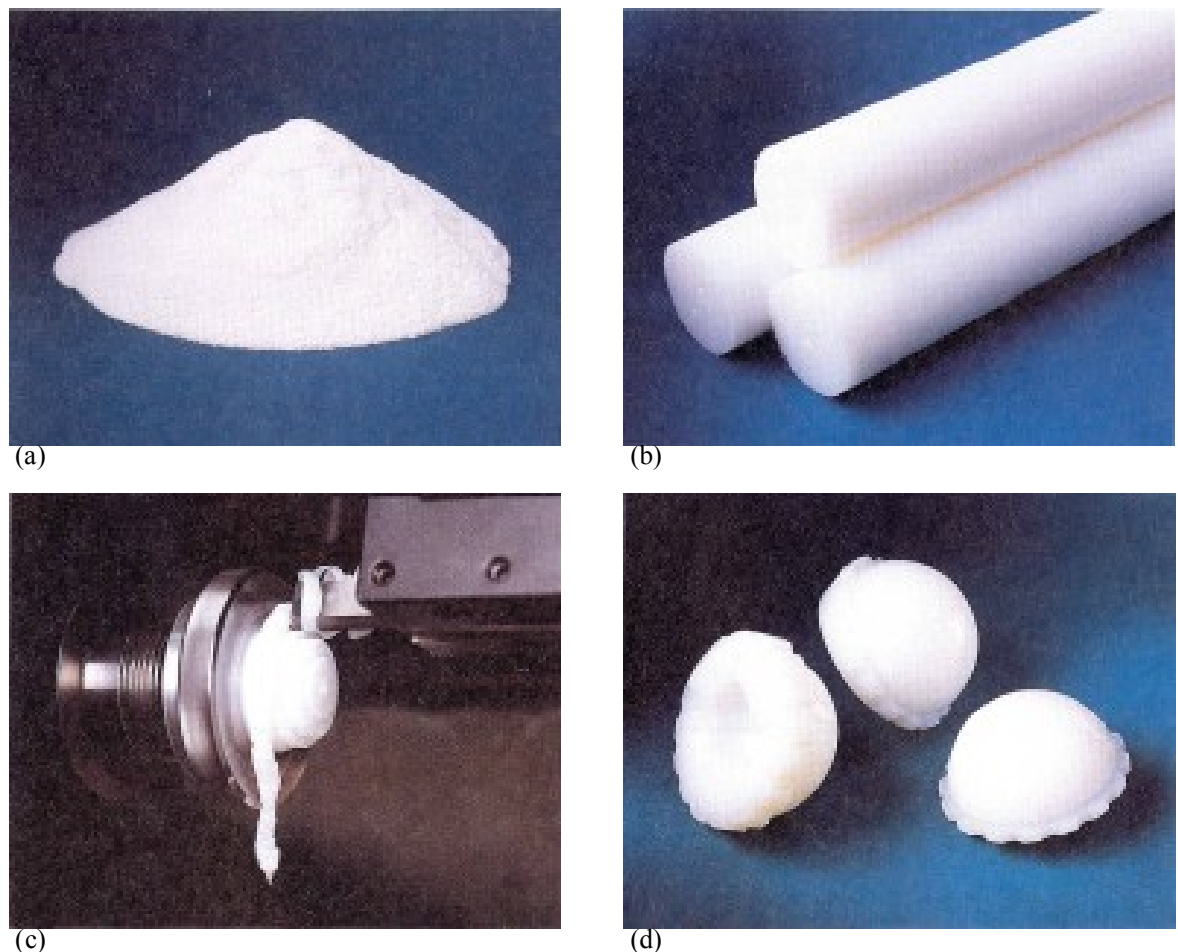

Figure 2.3: Processing steps in the manufacture of UHMWPE implants: (a) Resin powder, (b) Semifinished rods that have been consolidated from the resin powder, (c) Machining of the UHMWPE rods on a lathe, (d) UHMWPE acetabular components after machining. [34]

\subsection{Wear}

Though advances in biomaterial fabrication have allowed for implants to possess longer lifetimes, it is inevitable that the implants will fail due to wear. Wear is the erosion of material 
surfaces on one solid surface by the action of another surface [37]. The wear mechanisms that continue to affect hip components, are adhesive wear, abrasive wear, and fatigue wear, and will be further discussed in this chapter.

\subsubsection{Adhesive Wear}

Adhesive wear occurs when two smooth bodies are slid over each other and fragments are pulled off one surface, thus adhering to the other due to the strong adhesive forces between the atoms [37]. The interface of the femoral head and PE liner is a prime area where adhesive wear occurs. Over a period of time, loose particles (i.e., three-body particles) come between the articulating surfaces and have the ability to create wear tracks such as those in Figure 2.4. If there is poor lubricant, or no lubricant, in the interface, the adhesion between the two surfaces will rapidly increase and the formation of wear scars may occur, with the possibility of overheating due to friction [38].

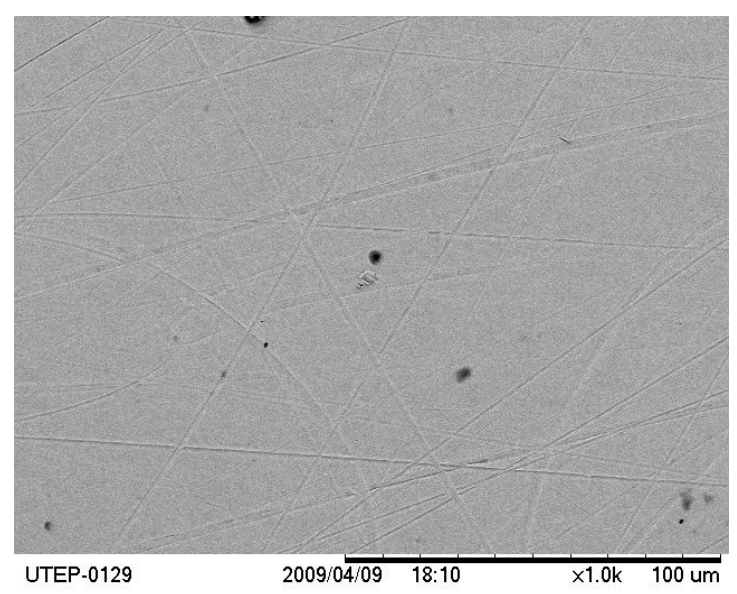

Figure 2.4: Wear tracks on Patient $\mathrm{W}$ femoral head at a magnification of 1000x. 
In efforts to reduce boundary interaction between the femoral head and PE liner, DePuy Orthopaedics, Inc. has created fluid film lubrication for their most recent implant series. Research performed by DePuy allowed scientists and engineers to compare surface interactions between several modes of lubrication, Figure 2.5. The first analysis of boundary lubrication, Figure 2.5a, depicts considerable amount of direct interaction that occurs between the surfaces, where the lubrication is from the synovial fluid [39]. Without an extensive amount of cushion between the femoral head and PE liner, it is the mode of boundary lubrication that is typically seen in total hip replacements (THRs). The mixed lubrication mode, Figure 2.5b, has a load that is partially supported by the lubricating fluid, but still contains direct interaction between surfaces [39]. The final image, Figure 2.5c, is that of the newest fluid film lubrication (proprietary composition). The bearing surfaces are fully separated and the load is fully supported by the lubricating fluid, which measurably lowers wear rates [39]. The fluid film layer produced by DePuy combats against abrasive wear since the lubricant layer is thicker than particle sizes that can be generated [38]. Though research continues to evaluate the lifetimes of such fluid films, this new technology will hopefully end abrasive wear of such components and the possibility of wear particles entering surrounding tissues. 

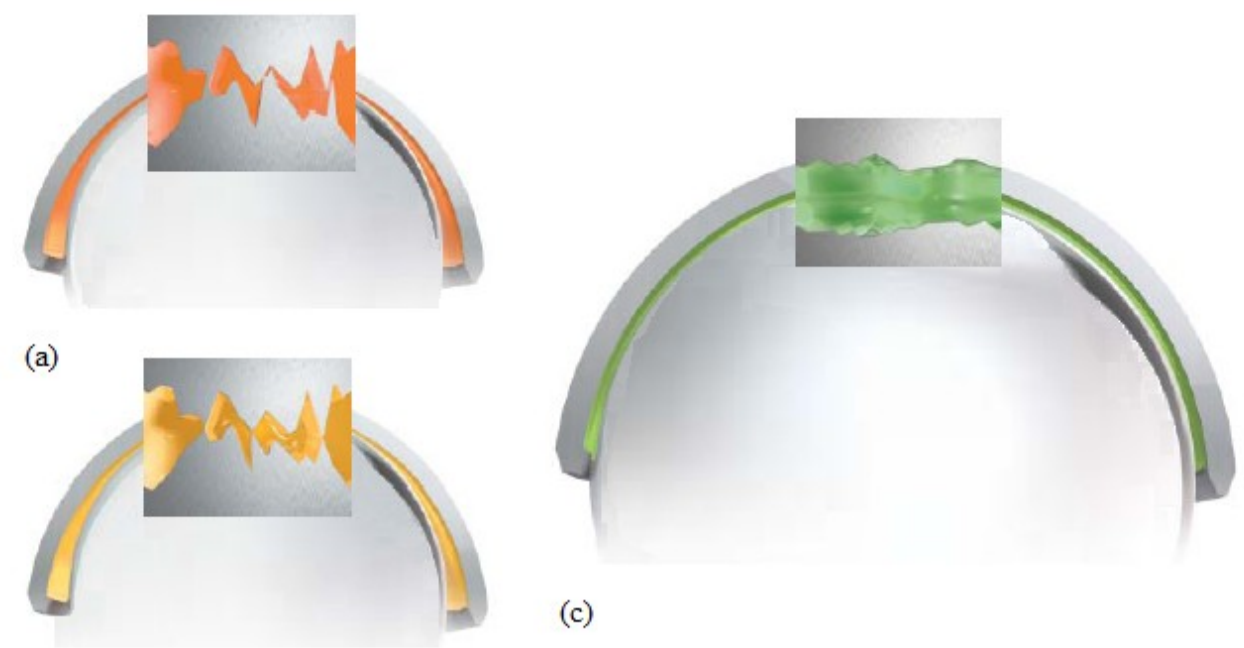

(b)

Figure 2.5: Bearings exhibiting different lubrication modes: (a) Boundary lubrication, (b) Mixed lubrication, (c) Fluid film lubrication. [39]

\subsubsection{Abrasive Wear}

The second wear mode is that of abrasive wear. This mechanical damage is the wear of a soft surface produced by a "plowing" of the surface by large asperities in the harder counter surface [33]. Particle transfer and roughened counterfaces create wear particles that eventually lead to the mechanism of abrasive wear. Metal particles can be produced by wear at the articulating surface by: (1) three-body wear, (2) abrasion due to movement at the prosthesis-bone interface of cementless prostheses, (3) abrasion at the prosthesis-cement and cement-bone interfaces of cemented prostheses, and (4) metal-metal articulation of modular prostheses [40]. Abrasive wear has the ability to be a consequence of adhesive wear or environmental effects [41]. Although abrasive wear is expected in articulating interfaces, it also plays a role in the supposedly fixed interfaces of modular devices [33]. 


\subsubsection{Fatigue Wear}

Fatigue wear (i.e., surface fracture) is the wear of a solid surface caused by fracture arising from material fatigue $[33,38]$. This mechanism is often caused by stresses produced by: (1) asperities that exceed the endurance limit for the softer of the material pair, (2) design of devices that are too thin in comparison to the magnitude of the contact stress and its contact area, and (3) free particles [33]. In further detail, free particles such as bone or polymethyl methacrylate (PMMA) have the ability to produce three-body wear. Figure 2.6 provides a schematic of the production of thin films caused by loose particles that come between articulating surfaces. In terms of biomaterials, as the metal moves on the polymer, the softer polymer shears off and the metal then picks up a coating of the polymer [33]. The formation of a stable film at the counterface leads to a change in the wear rate of the polymer [38]. If the film is unstable, it can bridge across the asperities on the surface of the metal, replacing metal-polymer contact with polymer-polymer contact, thereby increasing the actual contact area and reducing local stresses [33]. Debris in wear processes has been given considerable attention because it can build up between the sliding surfaces and increase the number of interfaces from one to two [38].

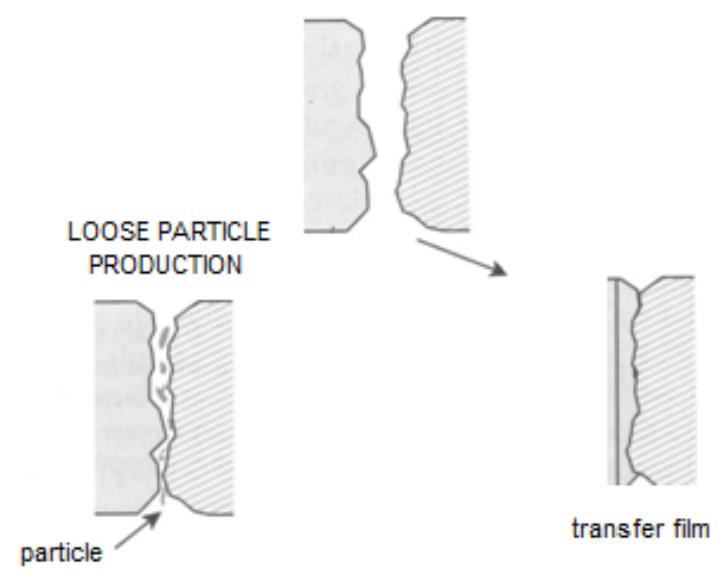

Figure 2.6: Transfer film vs. Particle production [33] 


\subsubsection{Wear Characteristics}

In subgroups of the chief wear mechanisms, damage modes such as burnishing, pitting, scratching, delamination, and plastic flow, can quite often be found on THA components [34]. Such damage modes were found in research performed by Ohnsorge et al. at the Department of Orthopaedic Surgery in the University of Aachen, Germany. Over a period of 13 years, 148 total hip arthroplasty (THA) cases were studied and controlled, concluding with 111 prostheses sufficient enough for clinical and radiologic follow-ups due to various reasons [42]. Upon final follow-up appointments, 47 of the reviewable $111 \mathrm{x}$-rays revealed prostheses with decentralized heads, suggesting a considerable amount of PE wear [42]. As stress can hold a key factor in PE damage, Figure 2.7 displays an insert explanted after 6 years that revealed material loss at the inner circumference with an analogously floating prosthetic head [42]. Through this macroscopic image, multiple surface scratches can be viewed and dull areas on both the PE liner and ceramic femoral head suggest issues of friction [42].

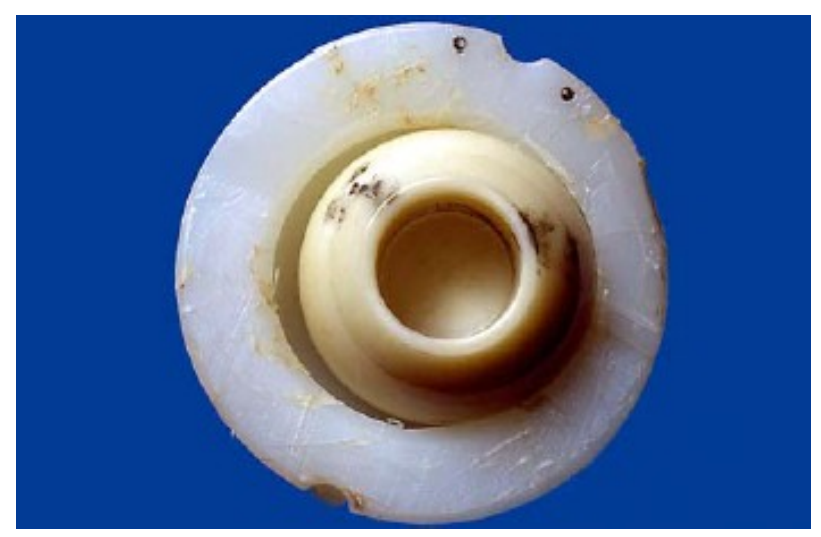

Figure 2.7: PE wear with articular gap formation. [42] 
From the same Ohnsorge study, another insert explanted after 10 years revealed PE at the rim and at the bottom of the liner to be discolored and brittle [42]. Figure 2.8 provides concrete evidence of plastic flow at the center of rotation, burnishing (polished areas), delamination and multiple cracks on the rim of the insert, and predominant asymmetric cold flow of PE near the holes in the metal backing [42]. Similarly accounted for in THA components are fatigue cracks that result in the removal of material in chunks or flakes as soon as the cracks grow to the surface of the polymer [38].

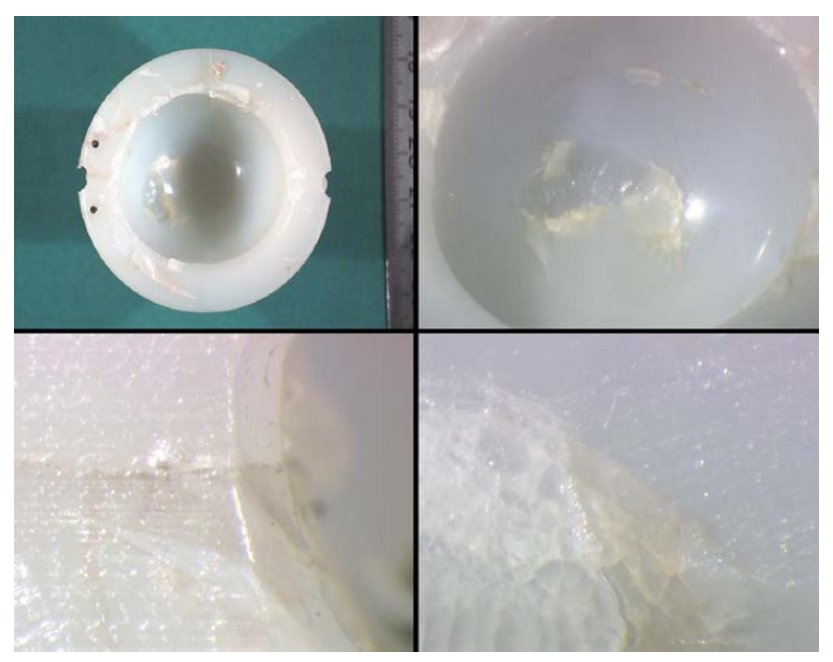

Figure 2.8: PE insert looking brittle in the rim, showing multiple continuous cracks, local polishing, and subsurface delamination of the articular surface. [42]

\subsubsection{Biological Wear}

Aside from mechanical wear associated with implants, wear also has the ability to negatively influence the immune system of THA recipients. In this context, it has been recognized as the main biological mechanism leading to implant failure [43]. All types of wear debris induce a foreign-body reaction in regenerating capsular tissues and interface tissues 
between the bone and implant [44]. The most common metal sensitizers found in biomaterials are nickel, cobalt, and chromium, and hypersensitivity can spur from titanium and vanadium [43]. Research performed at the Yamagata University School of Medicine in Japan focused on interface biology and implant-related osteolysis in which wear particles were found in neighboring prosthesis tissues [44]. Biological analyses on a tissue sample from the interface of a loose total hip joint with periprosthetic loosening displayed foreign-bodies, Figure 2.9 [44]. As metals are indestructible, chronic inflammation of the surrounding prosthesis area may take effect due to the release of such ions and molecules $[43,45]$.

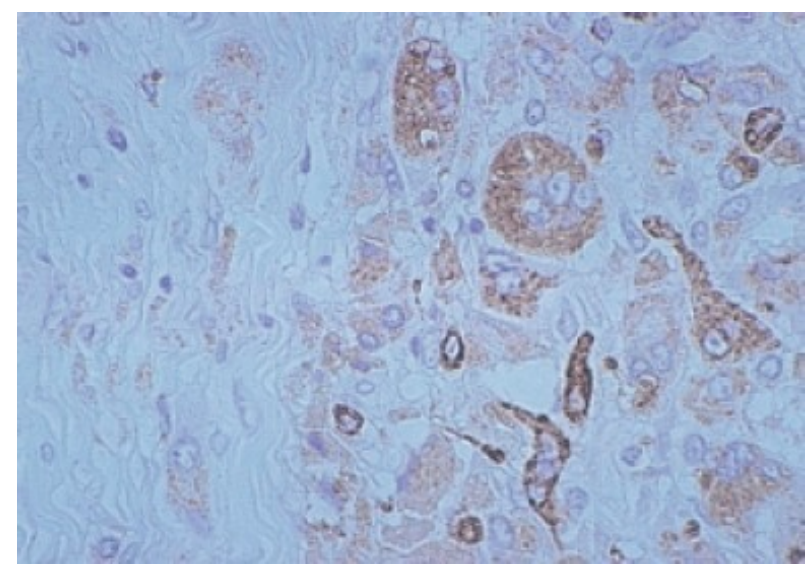

Figure 2.9: Metallic- or ceramic-type giant cells from the interface of a loose total hip joint. [44]

The biggest problem of UHMWPE in THRs is the production of wear particles, which tend to become points of bacterial infection and can act as three-body particles [38]. It is possible that more than 51 billion polymer particles are produced each year and after the elimination of most of these particles by the body's host response, large numbers of them still remain in the body tissues, Figure 2.10 [35]. Aside from physical wear particles, toxic unreacted 
free radicals and unreacted monomer precursors, created during the sterilization process, can also be released into the body $[34,46]$.

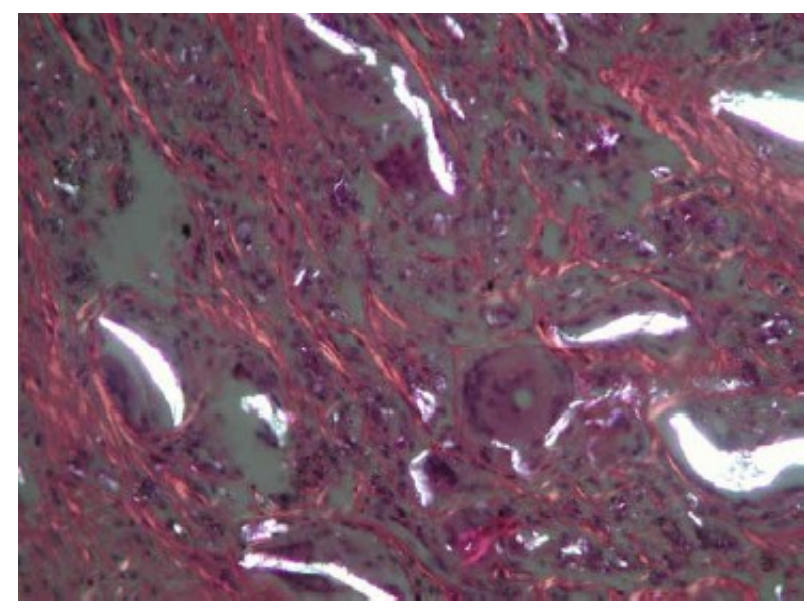

Figure 2.10: PE wear particles in the surrounding tissue of an implant. [42]

\subsection{Corrosion}

To function successfully, it is essential for metallic biomaterials to possess adequate corrosion resistance against the aggressive environment of the human body $[8,47]$. Though corrosion accounts for the destructive attack of a metal by chemical or electrochemical reaction with its environment, there are occasional, but rare component failures $[33,48]$. If and when metallic implants fail due to corrosion, immense concentrations of corrosion products are released in the body and react with the tissue fluids, dissolved gases, inorganic, and organic ions [8]. The remainder of this section entails further background of the foremost corrosion damages that affect THR prostheses, which are uniform and galvanic corrosion, crevice corrosion, pitting corrosion, and fretting corrosion. 


\subsubsection{Environment}

The human body contains synovial fluid, which is a watery dialysate of blood plasma containing electrolytes, cells, proteins, and mucopolysaccaride, which stands at a temperature of $37^{\circ} \mathrm{C}$ [41]. Nearby tissue fluids likely contain water, dissolved oxygen, proteins, and various ions such as chloride and hydroxide [47]. It is these fluids that provide for the lubrication of implant surfaces in THAs. The acidic nature of synovial fluid is due to the addition of long chain polymers (hyaluronic acid), which also accounts for the viscosity of the fluid [41]. Other acids found in the synovial fluid are protein bound sialic acid, N-acetylneuraminic acid, and hexoses and hexosamine [41].

Upon insertion, no matter the surface (soft or hard tissue) the implant makes contact with, the implant is rapidly coated with a 1-10 nm thick protein layer, most often from blood plasma [49]. As implants remain in the body for extended periods of time, they may become isolated from surrounding tissues by a 50-250 $\mu \mathrm{m}$ thick fibrous encapsulation [49]. In efforts to prevent corrosion, most alloys used for orthopedic prostheses form passive films to prevent oxidation from taking place [50]. These films consist of metal oxides, which form spontaneously on the surface of the metal in such a way that they prevent transport of metal ions and electrons across the film [50].

\subsubsection{Uniform and Galvanic Corrosion}

Reactions of metals with aqueous environments are electrochemical in nature [8]. In a standard electrochemical (or galvanic) cell, the apparatus involves a cathode, anode, electrolyte, 
and current. With the addition of a current, electrons pass from the positive cation to the negative anion, and the production of ions are released into an electrolyte. The electrode at which chemical reduction occurs is called the cathode and the electrode at which chemical oxidation occurs is called the anode [48].

According to the standard electrochemical series for selected metals in Table 2.6, the more positive the potential of a metal, the more noble (cathodic) it is. In contrast, as the potential decreases for any such metal, the behavior is more active (anodic). The corrosion resistances of metals owe their resistance to very positive equilibrium potentials, indicating that the chemical driving force for oxidation either is very small and negative or is positive [50]. However, metals that are commonly used in orthopedics have more negative potentials, indicating that, from a chemical driving force perspective, they are much more likely to corrode [50]. Figure 2.11 presents the galvanic series for metals and alloys in seawater. This series is well fitted for the corrosion of implants in vivo, in that the environment of the body is equally as harmful as seawater with its plethora of chlorides. The difference between the standard electrochemical series and the galvanic series is that the galvanic series ranks the nobility of alloys as well. In terms of the three most commonly used metallic implants (stainless steel, cobalt-based alloys, and titanium-based alloys), stainless steel is the least corrosion resistant, suffering frequently from interface corrosion [8]. In a modular device, it is possible for a stainless steel femoral head to corrode by galvanic corrosion due to the higher potential of the attached titanium stem [26]. 
Table 2.6: Standard Electrochemical Series for selected metals. [48]

\begin{tabular}{lc}
\hline Electrode $\mathrm{Reaction}$ & $\begin{array}{c}\text { Standard Potential, } \phi^{\circ} \\
\text { in volts at } 25^{\circ} \mathrm{C}\end{array}$ \\
\hline $\mathrm{Au}^{3+}+3 e^{-}=\mathrm{Au}$ & 1.50 \\
$\mathrm{Pt}^{2+}+2 e^{-}=\mathrm{Pt}$ & -1.2 \\
$\mathrm{Pd}^{2+}+2 e^{-}=\mathrm{Pd}$ & 0.987 \\
$\mathrm{Hg}^{2+}+2 e^{-}=\mathrm{Hg}$ & 0.854 \\
$\mathrm{Ag}^{+}+e^{-}=\mathrm{Ag}$ & 0.800 \\
$\mathrm{Hg}^{2+}+2 e^{-}=2 \mathrm{Hg}$ & 0.789 \\
$\mathrm{Cu}^{+}+e^{-}=\mathrm{Cu}$ & 0.521 \\
$\mathrm{Cu}^{2+}+2 e^{-}=\mathrm{Cu}$ & 0.342 \\
$2 \mathrm{H}^{+}+2 e^{-}=\mathrm{H} 2$ & 0.000 \\
$\mathrm{~Pb}^{2+}+2 e^{-}=\mathrm{Pb}$ & -0.126 \\
$\mathrm{Sn}^{2+}+2 e^{-}=\mathrm{Sn}$ & -0.136 \\
$\mathrm{Mo}^{3+}+3 e^{-}=\mathrm{Mo}$ & -0.2 \\
$\mathrm{Ni}^{2+}+2 e^{-}=\mathrm{Ni}$ & -0.250 \\
$\mathrm{Co}^{2+}+2 e^{-}=\mathrm{Co}$ & -0.277 \\
$\mathrm{Tl}^{+}+e^{-}=\mathrm{Tl}$ & -0.336 \\
$\mathrm{In}^{3+}+3 e^{-}=\mathrm{In}$ & -0.342 \\
$\mathrm{Cd}^{2+}+2 e^{-}=\mathrm{Cd}$ & -0.403 \\
$\mathrm{Fe}^{2+}+2 e^{-}=\mathrm{Fe}$ & -0.440 \\
$\mathrm{Ga}^{3+}+3 e^{-}=\mathrm{Ga}$ & -0.53 \\
$\mathrm{Cr}^{3+}+3 e^{-}=\mathrm{Cr}$ & -0.74 \\
$\mathrm{Zn}^{2+}+2 e^{-}=\mathrm{Zn}$ & -0.763 \\
$\mathrm{Cr}^{2+}+2 e^{-}=\mathrm{Cr}$ & -0.91 \\
$\mathrm{Nb}^{3+}+3 e^{-}=\mathrm{Nb}$ & -1.1 \\
$\mathrm{Mn}^{2+}+2 e^{-}=\mathrm{Mn}$ & -1.18 \\
$\mathrm{Zr}^{4+}+4 e^{-}=\mathrm{Zr}$ & -1.53 \\
$\mathrm{Ti}^{2+}+2 e^{-}=\mathrm{Ti}$ & -1.63 \\
$\mathrm{Al}^{3+}+3 e^{-}=\mathrm{Al}$ & -1.66 \\
$\mathrm{Hf}^{4+}+4 e^{-}=\mathrm{Hf}$ & -1.70 \\
$\mathrm{U}^{3+}+3 e^{-}=\mathrm{U}$ & -1.80 \\
$\mathrm{Be}^{2+}+2 e^{-}=\mathrm{Be}$ & -1.85 \\
$\mathrm{Mg}^{2+}+2 e^{-}=\mathrm{Mg}$ & -2.37 \\
$\mathrm{Na}^{+}+e^{-}=\mathrm{Na}$ & -2.71 \\
$\mathrm{Ca}^{2+}+2 e^{-}=\mathrm{Ca}$ & -2.87 \\
$\mathrm{~K}^{+}+e^{-}=\mathrm{K}$ & -2.93 \\
$\mathrm{Li}^{+}+e^{-}=\mathrm{Li}$ & -3.05 \\
\hline &
\end{tabular}




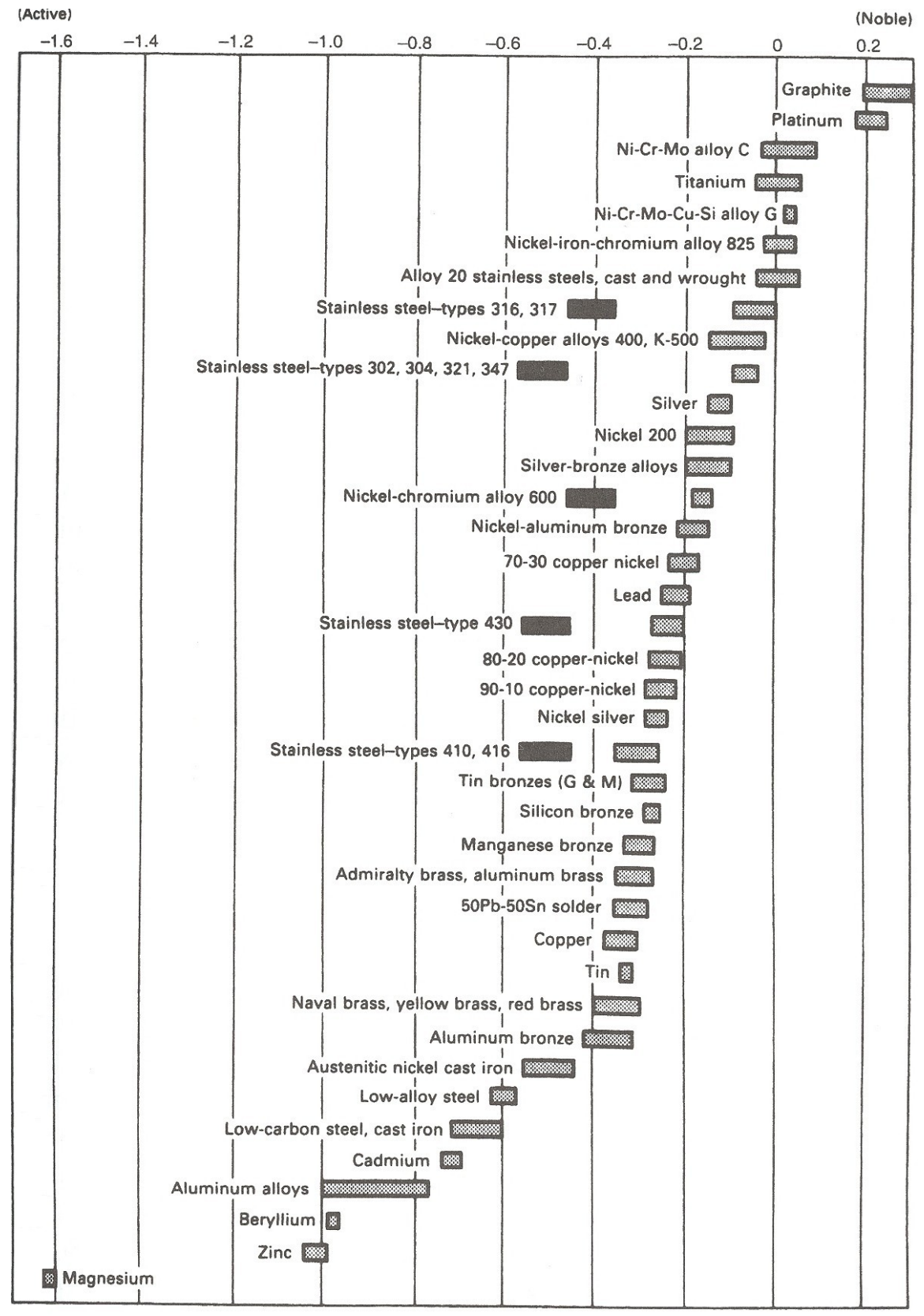

Figure 2.11: Galvanic Series of some commercial metals and alloys in seawater. [48] 


\subsubsection{Crevice Corrosion}

Though the benefits of modular replacement devices outweigh most consequences in ease of sizing and construction, modularity has come to produce a range of apparent crevice and related corrosion effects [33]. Most literature involving analyses of retrieved implants tends to observe corrosion damage in the neck-taper regions of femoral components. Crevice corrosion, Figure 2.12, initiates with uniform or galvanic corrosion until $\mathrm{O}_{2}$ is consumed in the crevice [51]. The extremely low oxygen concentrations of the crevice lead to cathodic reduction of water [8]. As $\mathrm{pH}$ increases, hydrolysis of $\mathrm{M}^{+}$occurs to maintain equilibrium between $\mathrm{M}^{+}$and $\mathrm{M}(\mathrm{OH})_{2}[51]$. Due to large charge imbalance, high electrolyte conductivity, and a larger cathodic area outside the crevice, there is a higher rate of attack at the anode [48]. The decrease in $\mathrm{pH}($ increase in $\mathrm{H}+$ ) and the addition of $\mathrm{Cl}^{-}$then stabilizes $\mathrm{M}^{+}$in solution [50]. The process of crevice corrosion continues in the further decrease of $\mathrm{pH}$ and the build-up of $\mathrm{Cl}^{-}$in the anodic area [51].

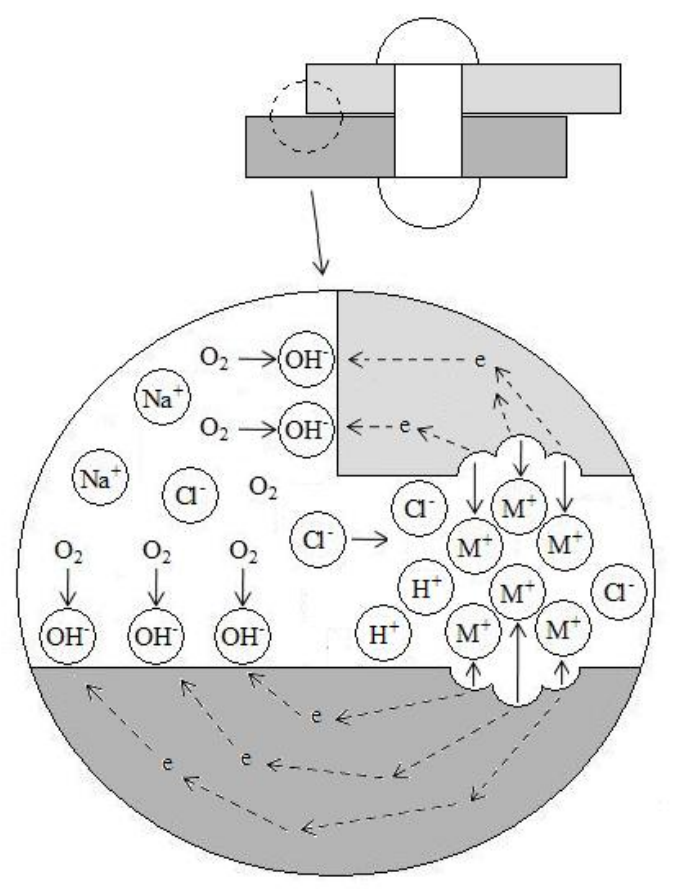

Figure 2.12: Crevice corrosion in a $\mathrm{NaCl}$ environment. [51] 
Biomaterials implanted in the body are able to undergo crevice corrosion through the close-range contact between two similar or dissimilar metals/alloys, as previously mentioned. Further in depth, by using metal-on-metal conical taper connections, severe corrosive attack tends to occur at the taper connections of modular joint replacement components [50]. Figure 2.13 illustrates the locations of corrosion products from a modular hip prosthesis studied by Jacobs et al. [50]. The area labeled "A" represents a thin interfacial layer of mixed oxides and chlorides within the crevice and "B" points to thick deposits of chromium-orthophosphate hydrate-rich corrosion products around the opening of the crevice [50]. Unexpectedly, it was found that the principal corrosion products were also located at the surfaces of the polyethylene liners [50]. Related research performed by Gilbert et al. revealed that 16 to $35 \%$ of 148 retrieved total hip implants showed signs of moderate-to-severe corrosive attack in the head-neck taper connection [52]. Similar to the femoral components analyzed in this thesis, Gilbert's research involved Ti-6Al-4V stems with cobalt-chrome femoral heads and cobalt-chrome stems with cobalt-chrome femoral heads [52].

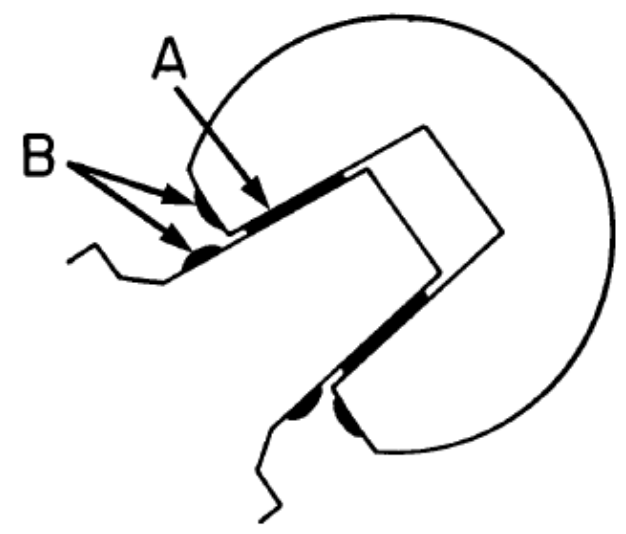

Figure 2.13: Principal corrosion products in the taper connections identified as: $\mathrm{A}=$ mixed oxides and chlorides and $\mathrm{B}=$ chromium-orthophosphate hydrate-rich material. [50] 


\subsubsection{Pitting Corrosion}

The mechanism of pitting is the same as crevice corrosion as shown in Figure 2.14. The anodic area can form due to inclusions, deposits of debris or scale, residual stresses, or by asperities of another surface [53]. Because the small anodic area of the pit is surrounded by a much larger cathodic area, corrosion can be very detrimental. This localized corrosion could even be difficult to detect because there is very little weight loss or gain and it is possible for the pit to be masked by corrosion product [53].

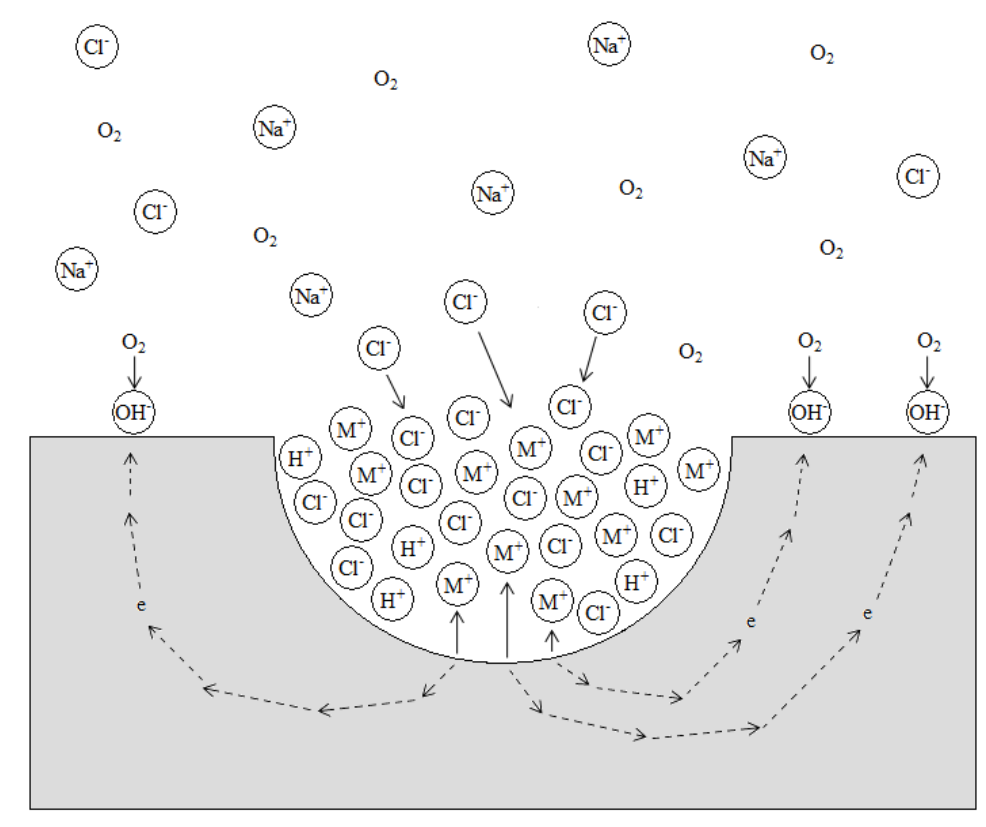

Figure 2.14: Autocatalytic processes in a corrosion pit. [53]

Relating to biomaterials, pitting resulting from crevice corrosion is favored whenever a stainless steel is covered by an organic or inorganic film [48]. With the removal of this passive layer, the pit is exposed to the hostile environment of the body where pitting and crevice corrosion can initiate. In an SEM image of a stainless steel femoral head studied in this thesis, 
Figure 2.15, pitting can be observed in the outer regions of the plastic deformation indicated by the red arrows.

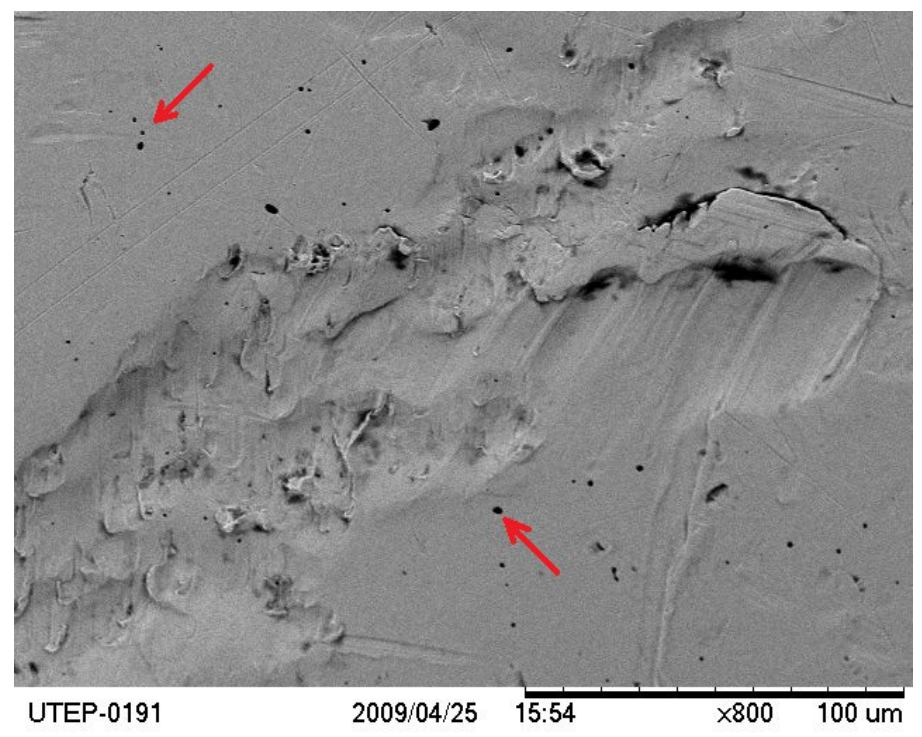

Figure 2.15: Patient $U$ femoral head with pits at a magnification of $800 x$.

\subsubsection{Fretting Corrosion}

In modular junctions, micromotions $(<100 \mu \mathrm{m})$ induced by cyclic loading occur between components [31]. As the motions increase, removal of passive layers exposes the substrate to the corrosive environment of the body [38]. If the exposed surface is softer and/or more chemically reactive than the counter surface, an expected increase in corrosion rates, wear rates, weight loss, and pit volume, will occur $[33,38]$. This is the process of fretting corrosion. Based on galvanic corrosion that can occur from fretting corrosion, material selection should most definitely play an important role in modular junctions [31]. 
Clinical studies have revealed that this mechanically assisted corrosion has a tendency to affect the tapers of the head-neck and mid-shaft region of the femoral stem [54]. Research performed by Gilbert et al. found corrosion product and scars indicative of fretting corrosion at these specific junctions, Figure 2.16. With the continuation of corrosion, large amounts of metal can be released into the body [31].

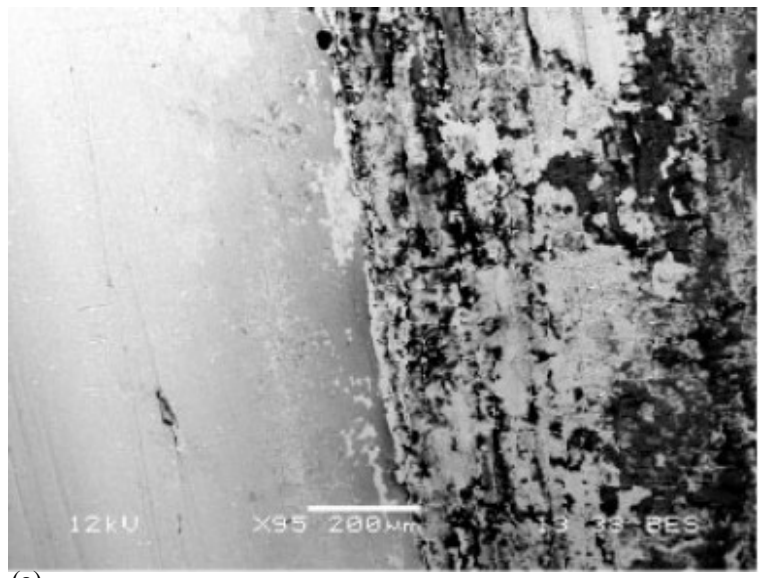

(a)

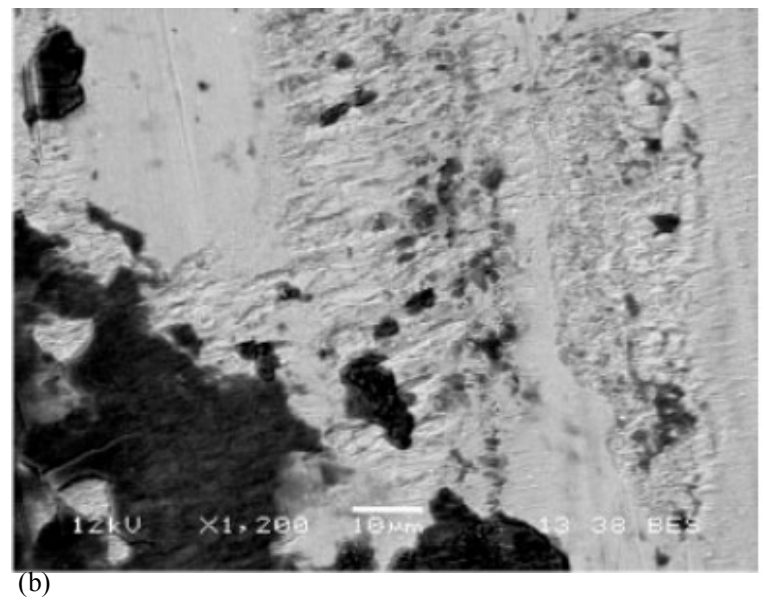

Figure 2.16: Backscattered electron images of a $6 \mathrm{~mm}$ stainless steel neck taper after testing: (a) Corrosion product at low magnification of $95 \mathrm{x}$, (b) Fretting corrosion attack at higher magnification of 1200x. [54] 


\section{Chapter 3: Experimental Procedures}

This researcher was provided with three sets of acetabular components from Dr. Richard Westbrook of the El Paso Orthopaedic Surgery Group and a fourth set from a surgeon in Mexico City, Mexico. Three sets contained UHMWPE liners and metallic femoral head components and the fourth set of components contained a ceramic acetabular socket and metallic femoral head.

\subsection{Visual Examination}

Visual examination of all components, Figures 3.1-3.4, was necessary to locate macroscopic surface flaws. Upon visual examination of the UHMWPE, areas of abrasive wear, plastic flow, scratches, and possible cracks, were seen. The surfaces of the femoral heads revealed minute scratches most likely formed from the years of movement inside the socket and burnishing from contact with the femoral stem. The socket of the acetabular shell displayed worn areas with burnishing.

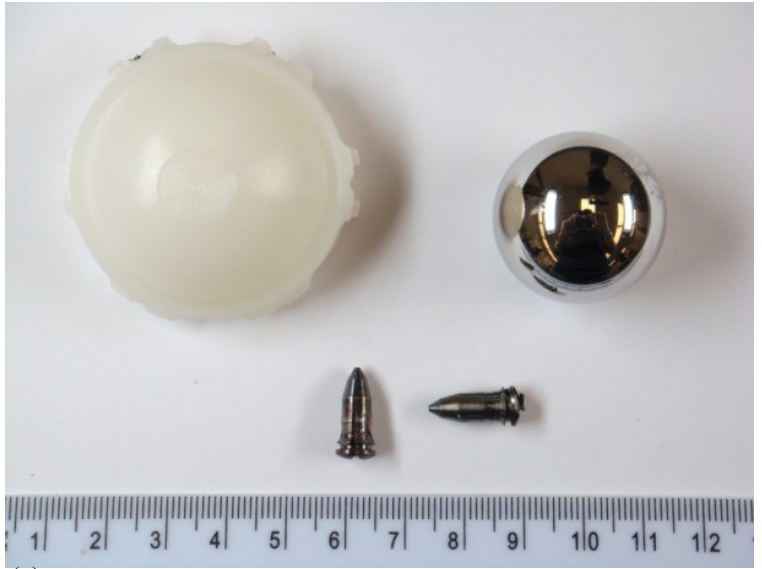

(a)

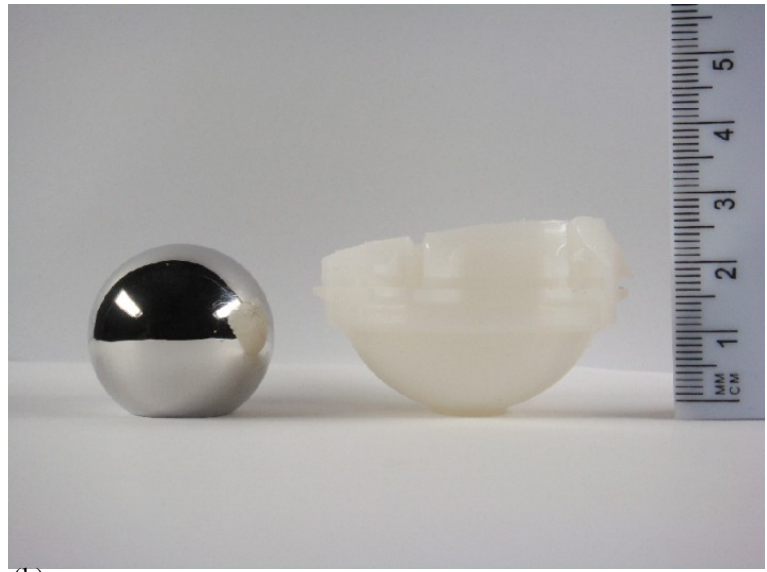

(b)

Figure 3.1: Patient E liner, head, and screws. 


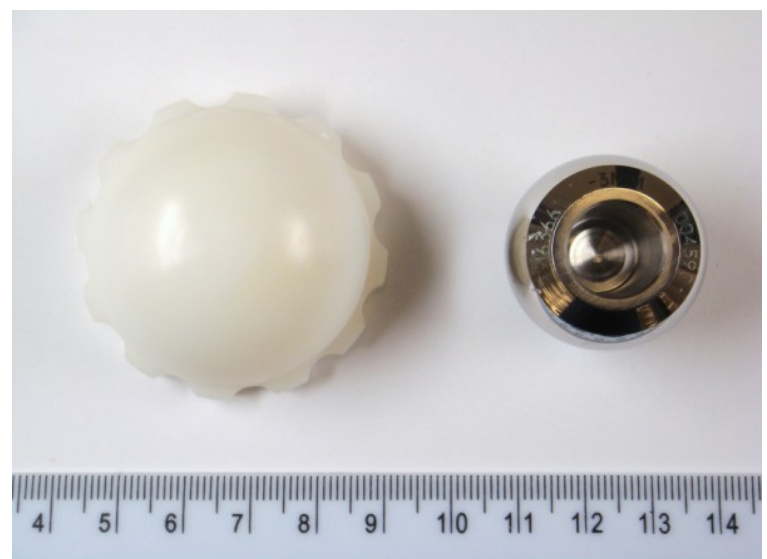

(a)

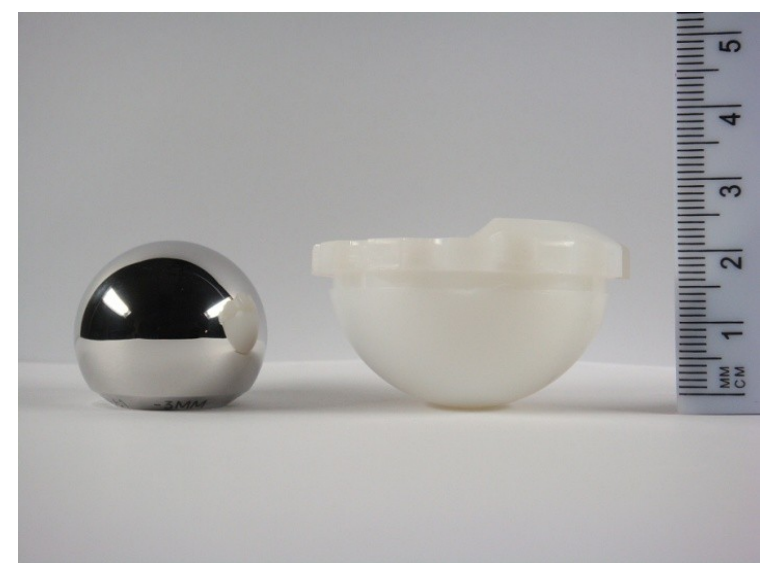

(b)

Figure 3.2: Patient W liner and head.

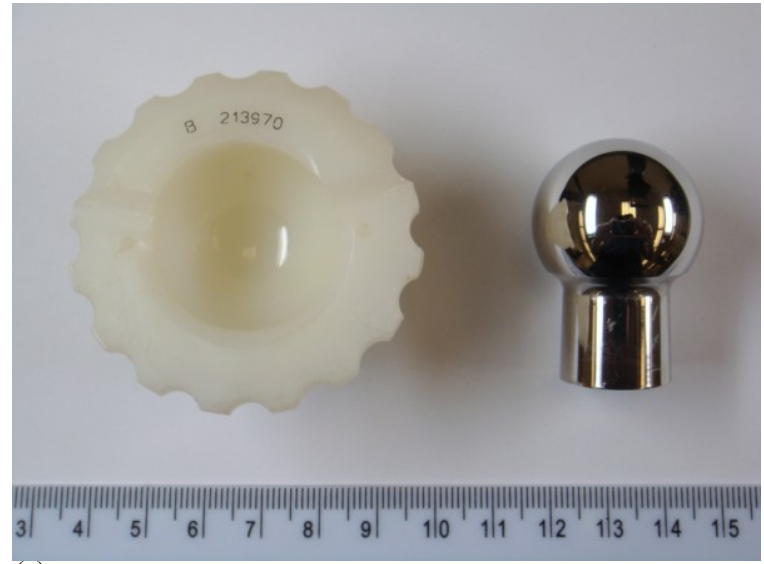

(a)

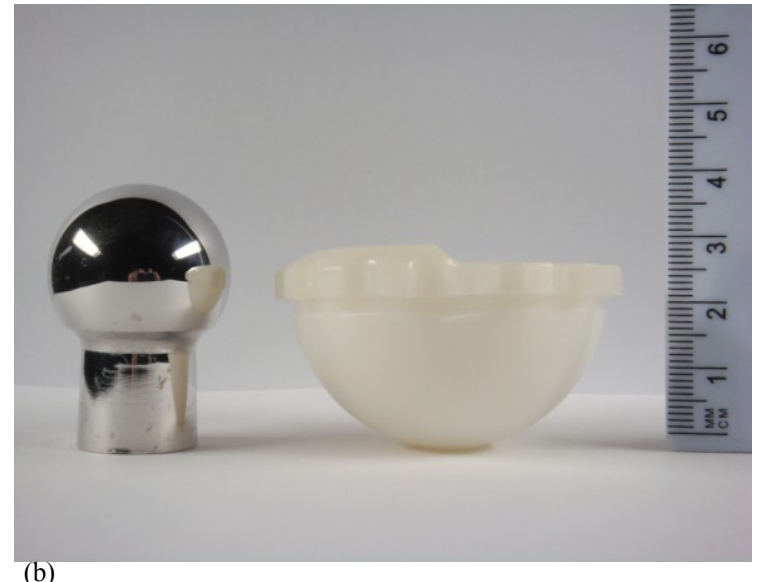

(b)

Figure 3.3: Patient $\mathrm{H}$ liner and head with an increased neck length.

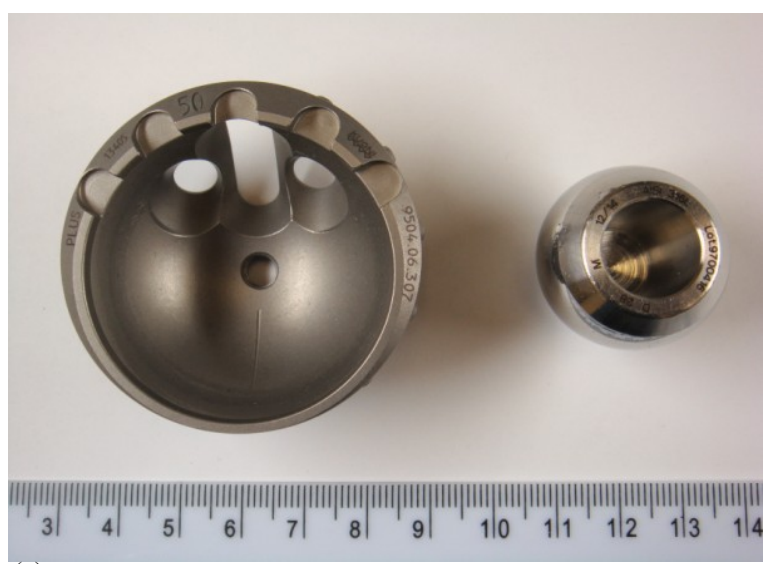

(a)

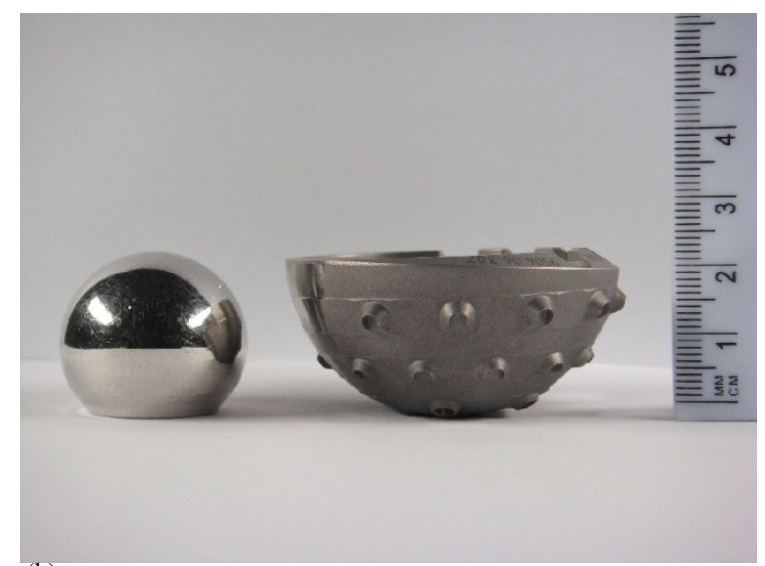

(b)

Figure 3.4: Patient U acetabular socket and head. 


\subsection{Ultrasonic Cleaning}

Utilizing a Branson 8510 Ultrasonic, cleaning was performed on the acetabular shell, femoral heads, and UHMWPE liners to remove excess surface particles and biohazard waste remaining from the revision surgery, as seen in the before and after images in Figure 3.5. The proper personal protective equipment (PPE) required were goggles, gloves, and a lab coat. To clean the femoral heads, the ultrasonic tub was filled with 1-1.5 inches of water and $300 \mathrm{~mL}$ of ethanol was used as the cleaning agent. The specimens were then placed in the beaker and cleansed for 15 minutes each. Before each component was cleaned, a new beaker of ethanol was required.

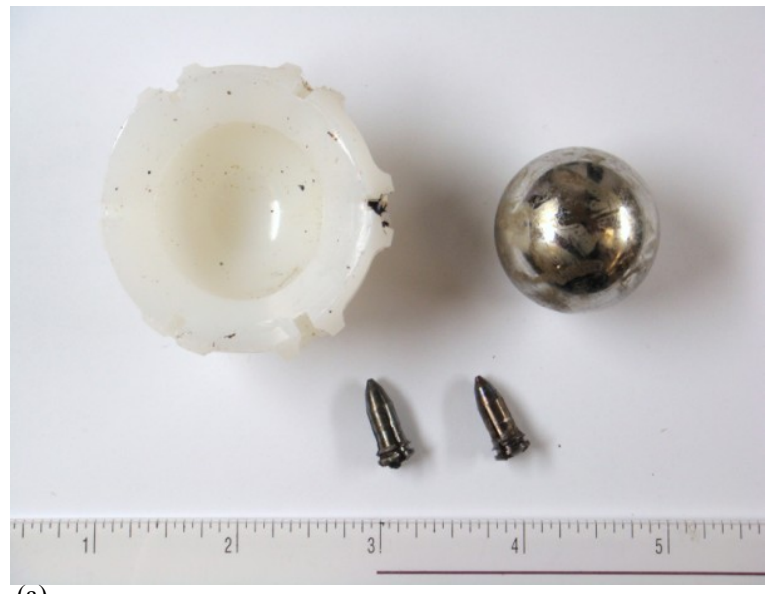

(a)

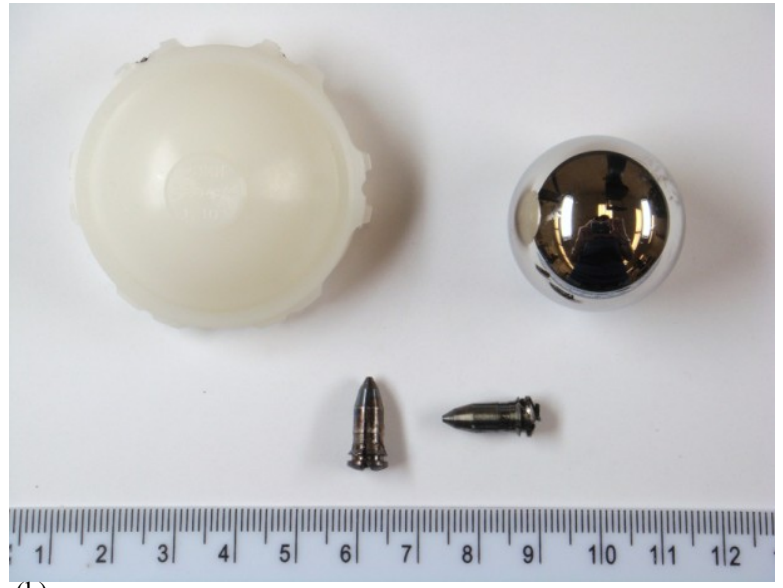

(b)

Figure 3.5: Patient E components: (a) as-received femoral head and liner, before ultrasonic cleaning, (b) after ultrasonic cleaning.

For the initial ultrasonic cleaning of the UHMWPE liners, the same basic instructions as previously stated were followed, the only difference was the replacement of ethanol with deionized water. The purpose of using water was to ensure that the UHMWPE would not react 
with the ethanol. After the initial visual examination the components were cleaned for 15 minutes each to discard surface grit. A second ultrasonic cleansing was performed after the dye penetrant inspection (DPI) to remove the excess dye, Figure 3.6. Since the dye was water-based, the components required an ultrasonic bath of 20 minutes and an extra soak for 40 minutes. As stated before, each component required a new beaker of fresh deionized water.

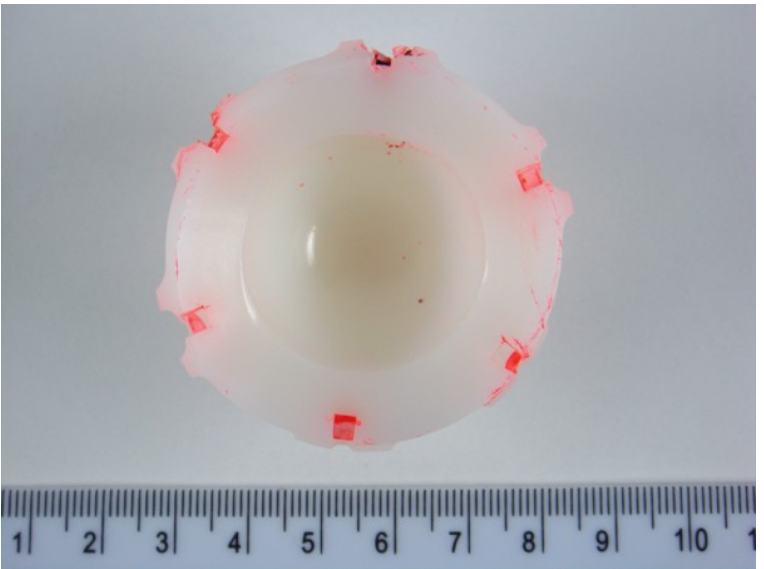

(a)

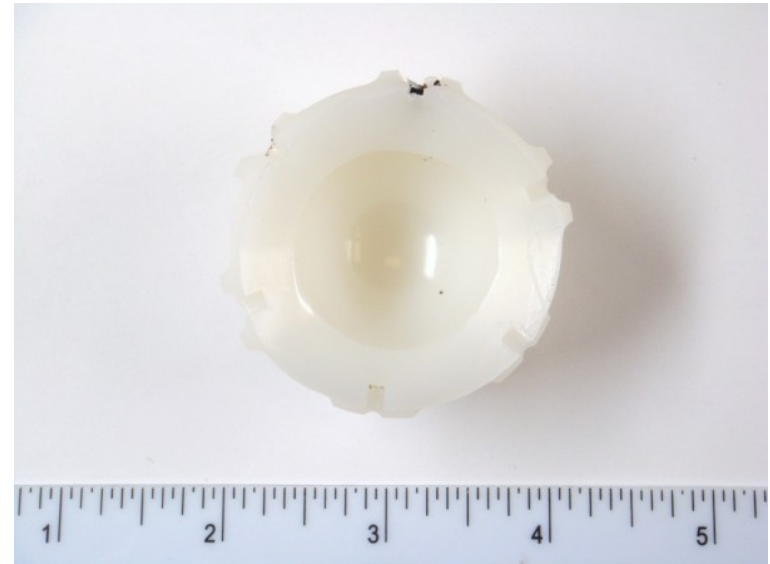

(b)

Figure 3.6: Patient E liner (a) Dye Penetrant Inspection (DPI), (b) After ultrasonic.

\subsection{X-Ray Fluorescence (XRF)}

$\mathrm{X}$-ray fluorescence $(\mathrm{XRF})$ is a form of non-destructive evaluation (NDE) that allows the user to acquire elemental compositions of alloys. With an Innov-X Systems Handheld XRF Analyzer, elemental compositions of the 4 femoral heads and acetabular shell were acquired. The device was simply aimed at the components for several seconds, at a short distance. 


\subsection{Fourier Transform Infrared Spectroscopy (FTIR)}

Attenuated Total Reflection Infrared Spectroscopy (ATR-IR), an FTIR accessory, is an internal reflection used for simplifying the analysis of solids, powders, pastes, gels, and liquids [55]. As illustrated in Figure 3.7, the sample sits on top of a Zinc Selenide (ZnSe) and diamond crystal with a high refractive index. The basic process involves an infrared beam sent up the crystal, reflected in the crystal, and back towards the detector. When the beam is reflected in the crystal, it penetrates into the sample by a few microns [55].

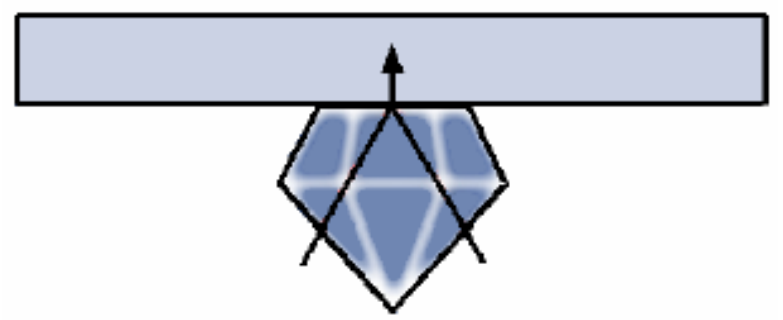

Figure 3.7: Principle of Universal ATR operation. [55]

ATR-IR was performed with a Perkin Elmer Spectrum 100 FT-IR fitted with a Universal ATR Sampling Accessory. Since the accessory allows for the analysis of large samples, the UHMWPE liners did not need to be sectioned. After the liner was cleaned with ethanol, it was placed on the crystal, held in place with the pressure knob, and a transmittance spectrum was collected. After collection of the data, the crystal and top plates were cleaned with methanol and a cotton bud and allowed to fully dry before the next component was analyzed. It is necessary to clean the crystal in a current of warm air to ensure no residue contaminates the analysis. The insertion and removal procedure was repeated for the remaining UHMWPE components. 


\subsection{Dye Penetrant Inspection (DPI)}

DPI is a technique that allows the user to view surface cracks and other macroscopic flaws. The DPI was used on the UHMWPE components since the white bodies of the liners make it difficult to see surface defects. The dye mixture involved a 5:1 ratio of water to a waterbased dye (in $\mathrm{mL}$ ). With a small foam-tipped brush, the entire surface of the liner was coated with a thin layer of the mixture and allowed to sit and dry for five minutes. During the 5 minutes the dye penetrated all surface defects due to capillary action. Finally, with a soft polishing cloth and cotton buds, the surface dye was removed, leaving only the dye that seeped into scratches, cracks, other surface defects, Figure 3.8.

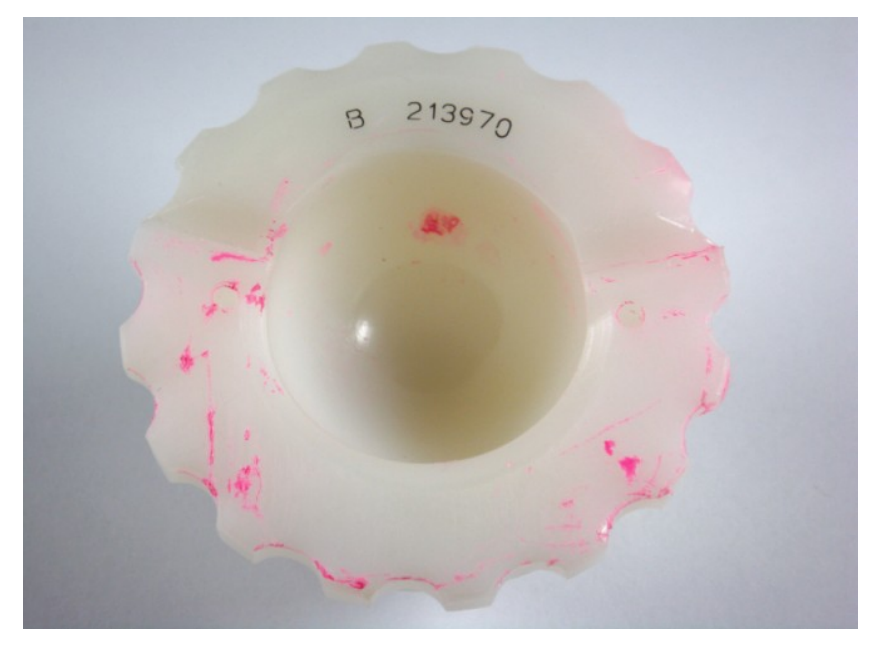

Figure 3.8: Patient H, UHMWPE liner after Dye Penetrant Inspection (DPI).

\subsection{Carbon Coating}

To view metals and materials in the SEM, the specimen must be electrically conductive. For materials that are not metallic, the SEM provides an image in which the specimen charges 
and no clear images can be recorded without significantly modifying the microscope parameters. Since the SEM image relies on electrons to scan the specimen surface, the UHMWPE components need to be carbon coated with a conductive element. The coatings were achieved with an automatic Pelco CC-7A SEM Carbon Coater. A coating time of 6 seconds and voltage of $3.5 \mathrm{kV}$ provided the ideal carbon coating thickness of approximately $10 \mathrm{~nm}$ on each of the UHMWPE liners.

\subsection{Metallography}

The purpose of metallography on the femoral heads was to investigate microstructures and to get a closer look at possible failure initiation spots and other pertinent damage. The entire metallographic process required the samples to be sectioned, mounted, ground/polished, cleaned, and etched.

\subsubsection{Sectioning}

En route to metallography, the femoral heads were sectioned with an Allied 80-40060, rubber-bonded blade with silicon carbide mineral, on an Allied-Power Cut 10 abrasive saw. A 6061-T6 aluminum, custom made specimen holder was required to section the samples. Based on the spherical dimensions of the femoral heads, it would have been difficult to safely secure the components during machining. The circumferential portion of the holder allowed for all the pressure to safely be located at the diameter of the heads. The image in Figure 3.9 displays the sectioning set-up, complete with the specimen holder. Both femoral heads (i.e., cobalt-chrome 
and stainless steel) were axially sectioned, as seen in Figure 3.10, to ensure similar geometries during further testing.

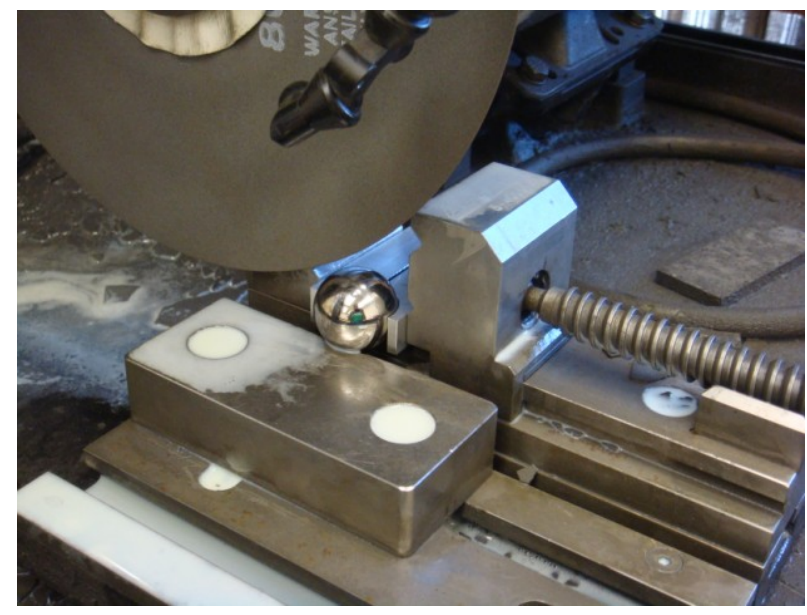

Figure 3.9: Sectioning of Patient E femoral head.
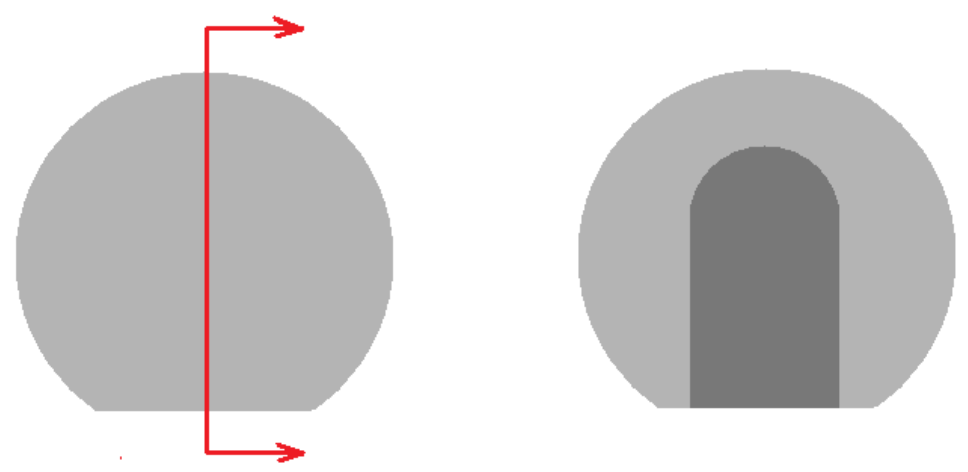

Figure 3.10: Femoral head cross-section displaying the hollow-centered, tapered bore.

\subsubsection{Grinding and Polishing}

Initially, the sectioned samples were placed in mounting rings in preparation for the KoldMount. In a 2:1 volumetric ratio, two parts KoldMount mounting material (powder) with one part KoldMount self-curing liquid were mixed for 30 seconds or until the mixture formed a 
homogenized slurry solution. The slurry was poured in the mounting rings and allowed to cure overnight, followed by removal of the samples from the mounting rings. The mounted cobaltbased alloy and stainless steel samples were wet ground from 220 to 600 grit silicon carbide paper and polished down to $1 \mu \mathrm{m}$ with a polycrystalline diamond suspension. The electrolytic etchant used for the cobalt-based alloy was $2 \% \mathrm{CrO}_{3}$ in water $\left(\mathrm{H}_{2} \mathrm{O}\right)$. Utilizing a Buehler ElectroMet Etcher and a stainless steel probe, the sample was etched with 3 volts for 10 seconds. The microstructure was inspected with an Olympus PME3 Optical Microscope at the El Paso Natural Gas (EPNG) Metallography Laboratory. The etchant used for the stainless steel specimen was Kallings \#2, which composed of $100 \mathrm{~mL}$ hydrochloric acid $(\mathrm{HCl}), 100 \mathrm{~mL}$ methanol, and $5 \mathrm{~g}$ cupric chloride $\left(\mathrm{CuCl}_{2}\right)$. The stainless steel required a swab for a few seconds. The stainless steel microstructure was inspected with a Reichert MEF4M Optical Microscope.

\subsection{Scanning Electron Microscopy (SEM)}

SEM was performed on all components with a Hitachi TM-1000 Tabletop Microscope, Hitachi S-4800 SEM, and an FEI Quanta 400 SEM at an accelerating voltage range of 1-20kV and current of 1-25mA. Three microscopes were used throughout the research because some components were too large for the chamber of the tabletop microscope and for the acquisition of energy dispersive x-ray spectroscopy (EDS) spectra. Through SEM, the shell and the cobalt-

alloy and stainless steel femoral heads were characterized by microstructural features and by surface and subsurface failure modes, Figure 3.11a. Microscopy of the UHMWPE liners focused on surface wear mechanisms, Figure 3.11b. 

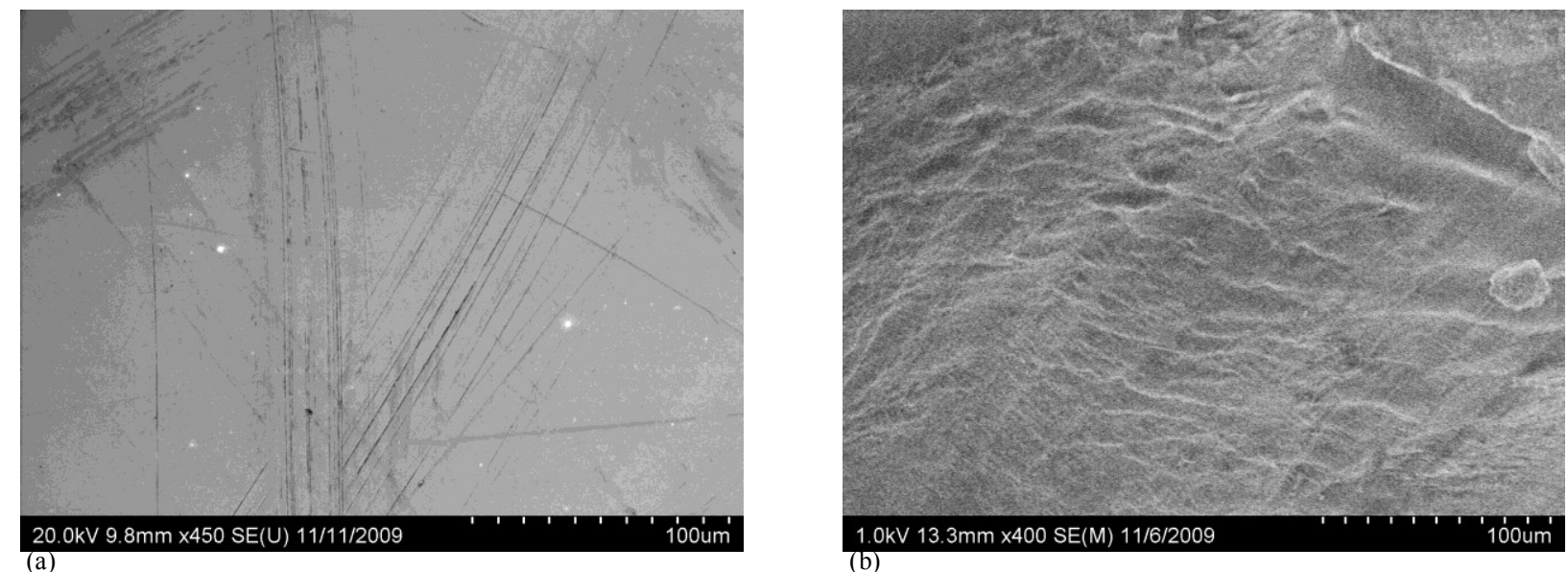

Figure 3.11: (a) Patient E femoral head with wear tracks at a magnification of 450x, (b) Patient $\mathrm{W}$ liner, area with plastic flow at a magnification of 400x. 


\section{Chapter 4: Results and Discussion}

In collaboration with The El Paso Orthopaedic Surgery Group, The Department of Metallurgical and Materials Engineering at the University of Texas at El Paso receives failed implant components on which failure analysis is performed. Dr. Richard Westbrook of El Paso Orthopaedic Surgery Group provided the researcher with three sets of acetabular components and the respective patient backgrounds, while a fourth set came from Mexico City, Mexico. Throughout the study, the implants are referred to by first letter of the last name of the patient followed by the specific component (i.e., Patient E femoral head). Failure analysis of the hip implant components was aimed at identifying crack initiation spots, characteristic failure modes, and surface flaws that ultimately led to THA revision surgeries.

\subsection{Patient and Component Backgrounds}

As previously stated, three of the four cases studied came with their respective patient backgrounds. Table 4.1 provides the components' details of implant lifetimes, dimensions, manufacturers, and patient information, where all information is in reference to the date of the revision surgeries. The first case, Patient E, involved a 69 year old male whose duration of implantation was 12 years. The manufacturer, DePuy Orthopaedic, Inc., produced the S-ROM total hip arthroplasty (THA) components, in which the femoral head has an outer diameter (OD) of $28 \mathrm{~mm}$ with an offset of $6 \mathrm{~mm}$ (i.e., 28+6) and an UHMWPE liner inner diameter (ID) of $28 \mathrm{~mm}$. Though two screws accompanied the components, they were not analyzed. The second case, Patient $\mathrm{W}$, involved a 77 year old female who required revision hip surgery after 10 years 
from the initial THA. The manufacturer, Biomet, produced the $28 \mathrm{~mm}$ OD femoral head with an offset of $3 \mathrm{~mm}$ and an UHMWPE liner ID of $28 \mathrm{~mm}$. The illustration in Figure 4.1 should hopefully give the reader a better understanding of the offset length between the femoral head and the femoral stem. The third case, Patient $\mathrm{H}$, was an 85 year old male whose implant lifetime exceeded 10 years. The Biomet femoral head has an OD of $28 \mathrm{~mm}$ with an increased neck length and an offset of $9 \mathrm{~mm}$ and an UHMWPE liner ID of $28 \mathrm{~mm}$ with a 12/14 taper.

Patient $U$ was the only case in which full patient and component background was provided. Before the primary THA, the patient was a 57 year old woman, 5'2", and a weighed 140 pounds. In terms of medical history, Patient $U$ was diagnosed with diabetes at age 44 and a THA of the left hip was required due to stage II osteoporosis. At the 3 year post-surgery followup appointment, x-ray radiographs displayed aseptic mechanical loosening of the femoral stem. Though no osteolysis or diabetes infections were found in the surrounding tissues of the implant during the revision surgery, all components were replaced with newer models. The retrieved components were manufactured by Stemcup Medical Products AG. The Kuoni-model femoral head has a $28 \mathrm{~mm}$ OD, the UHMWPE liner an ID of $28 \mathrm{~mm}$ (though not provided), and an acetabular shell with an ID of approximately $60 \mathrm{~mm}$. Due to research requirements from the manufacturer, the UHMWPE liner was sent back to the company for further research and analyses. 
Table 4.1: Details of the four cases in this study.

\begin{tabular}{|c|c|c|c|c|c|c|}
\hline $\begin{array}{l}\text { Case } \\
\text { Designation }\end{array}$ & $\begin{array}{l}\text { Patient Information } \\
\text { at Retrieved Surgery }\end{array}$ & $\begin{array}{l}\text { Reference } \\
\text { Number }\end{array}$ & $\begin{array}{l}\text { Initial } \\
\text { Surgery }\end{array}$ & $\begin{array}{l}\text { Duration of } \\
\text { Implantation }\end{array}$ & Manufacturer & $\begin{array}{l}\text { Components } \\
\text { at Retrieval }\end{array}$ \\
\hline Patient W & $\begin{array}{l}\text { Female } \\
77 \text { years }\end{array}$ & ЕР00052104 & 1997 & 10 years & Biomet & $\begin{array}{l}\text { Femoral Head } \\
163661 \text { 3MM } 004590 \\
\text { UHMWPE Liner } \\
\text { 28MM B987250 }\end{array}$ \\
\hline Patient $\mathrm{H}$ & $\begin{array}{c}\text { Male } \\
85 \text { years }\end{array}$ & EP00052238 & - & $10+$ years & Biomet & $\begin{array}{l}\text { Femoral Head } \\
163665+9 \text { MM } 531180 \\
\text { UHMWPE Liner } \\
\text { B } 213970\end{array}$ \\
\hline Patient U & $\begin{array}{l}\text { Female } \\
60 \\
5 ' 2^{\prime \prime} \\
148 \mathrm{lbs}\end{array}$ & - & - & 3 years & $\begin{array}{l}\text { Stemcup Medical } \\
\text { Products AG }\end{array}$ & $\begin{array}{l}\text { Femoral Head } \\
\text { D.28 M 12/14 AISI 316L } \\
\text { Lot } 9700416 \\
\text { Acetabular Shell } \\
\text { Plus } 1340550 \text { KUONI } \\
9504.06 .307\end{array}$ \\
\hline
\end{tabular}




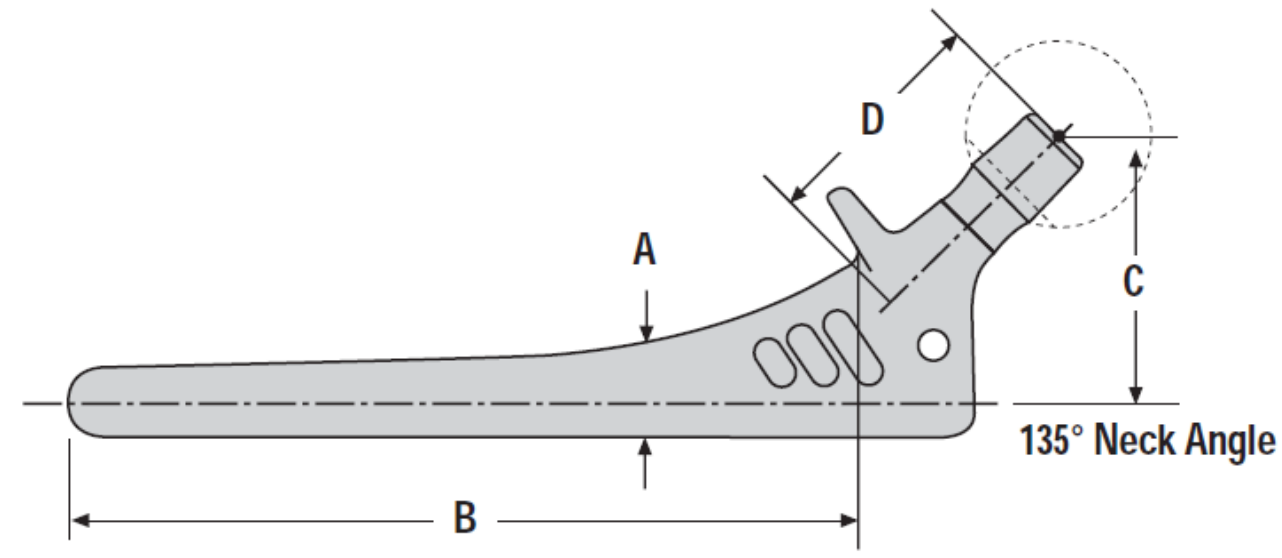

Figure 4.1: Hip implant sections: A-stem size, B-stem length, C-offset, D-neck length. [56]

\subsection{Visual Examination}

Upon visual examination of the Patient E components in Figure 3.1, the liner had many surface scratches and areas of plastic deformation on the outer rim. In the socket two fixed, metallic particles were also located. The femoral head was fairly unimpaired save for an area heavily situated with scratches and a possible surface deposit. The hollow of the femoral head (i.e., bore) also displayed burnishing. Patient W liner, Figure 3.2a, had a large area of plastic deformation on the surface of the liner with few scratches. Though wear tracks were visible on the femoral head, Figure 3.2, nothing atypical was discovered. The Patient H liner in Figure 3.3 was the only component with an area of visible abrasive wear in the socket where the liner is in direct contact with the femoral head. The outer rim of the liner also displayed an area of plastic deformation. The corresponding Patient $\mathrm{H}$ femoral head displayed only a few scratches and burnishing of the increased neck area. The Patient $U$ femoral head in Figure 3.4 had the greatest amount of damage. The surface was completely dulled from the overwhelming amount of surface scratches and defects. Many areas of the femoral head displayed large indentions similar 
to those created by Brinell or Rockwell Hardness Testing. In the socket of the acetabular shell, a ring of burnishing and areas of deformation were observed.

\subsection{X-Ray Fluorescence (XRF)}

With the use of an Innov-X Systems Alpha-2000A Handheld XRF Analyzer, it was found that the three sets of implants from the El Paso Orthopaedic Surgery Group (Patients E, W, and H) are all Co-based alloys, specifically alloy F75 with cobalt, chromium, and molybdenum as the main components, Table 4.2. The fourth component, Patient $\mathrm{U}$ femoral head, is a $316 \mathrm{~L}$ stainless steel. The Patient $U$ acetabular shell is a $99.53 \%$ pure titanium component with an extra alloying addition of Fe. The XRF values obtained were compared with reference compositions of the specific alloys to ensure correct compositions.

Table 4.2: Elemental compositions of femoral heads and acetabular shell.

\begin{tabular}{|c|c|c|c|c|c|c|c|c|}
\hline Component & $\mathrm{Ti}$ & $\mathrm{Cr}$ & $\mathrm{Fe}$ & Co & $\mathrm{Mn}$ & Mo & $\mathrm{Ni}$ & $\mathrm{Cu}$ \\
\hline \multicolumn{9}{|c|}{ - Femoral Head } \\
\hline Patient E & - & 27.97 & - & 64.78 & 0.70 & 6.02 & 0.53 & - \\
\hline Patient W & - & 28.55 & - & 64.57 & 0.94 & 0.56 & - & - \\
\hline Patient $\mathrm{H}$ & - & 27.06 & - & 65.32 & 0.97 & 6.10 & 0.56 & - \\
\hline Patient U & - & 17.68 & 67.61 & - & 1.30 & 2.17 & 10.83 & 0.40 \\
\hline \multicolumn{9}{|c|}{ - Acetabular Shell } \\
\hline Patient U & 99.53 & - & 0.47 & - & - & - & - & - \\
\hline
\end{tabular}

\subsection{Fourier Transform Infrared Spectroscopy (FTIR)}

The infrared (IR) spectrum for polyethylene is grouped within the alkenes. The spectrum provides wavenumbers $\left(\mathrm{cm}^{-1}\right)$ for the $\mathrm{C}-\mathrm{C}$ and $\mathrm{C}-\mathrm{H}$ bonds found within the ethylene $\mathrm{C}_{2} \mathrm{H}_{4}$ 
homopolymer chain. The experimental Attenuated Total Reflection (ATR) spectra values do not exactly match with the reference values as the reference is for polyethylene (in general) and not specifically for UHMWPE. The main characteristic trough of the reference polyethylene spectrum in Figure 4.2 is that of the $\mathrm{C}-\mathrm{H}$ stretch bond found in the higher wavenumber range of 2853-2962 $\mathrm{cm}^{-1}$ [57]. The two smaller troughs, located in the fingerprint region, coincide with the C-C stretch bond at approximately $1492.23 \mathrm{~cm}^{-1}$ and the $\mathrm{C}-\mathrm{H}$ bending bond in the range of approximately $723.30-749.51 \mathrm{~cm}^{-1}$. Each trough is caused because energy is being absorbed from the particular frequency of infrared radiation to excite the molecular bonds to a higher state of vibration [57]. Table 4.3 displays the comparison of the reference polyethylene IR transmittance spectrum, Figure 4.2, with the six main trough values obtained for the liners of Patient $\mathrm{E}$ in Figure 4.3, Patient $\mathrm{W}$ in Figure 4.4, and Patient $\mathrm{H}$ in Figure 4.5. The IR spectra acquired by the Fourier Transform Infrared (FTIR) universal ATR sampling accessory slightly varied due to different intensities since the force gage was set in a range of 32-44 N. 


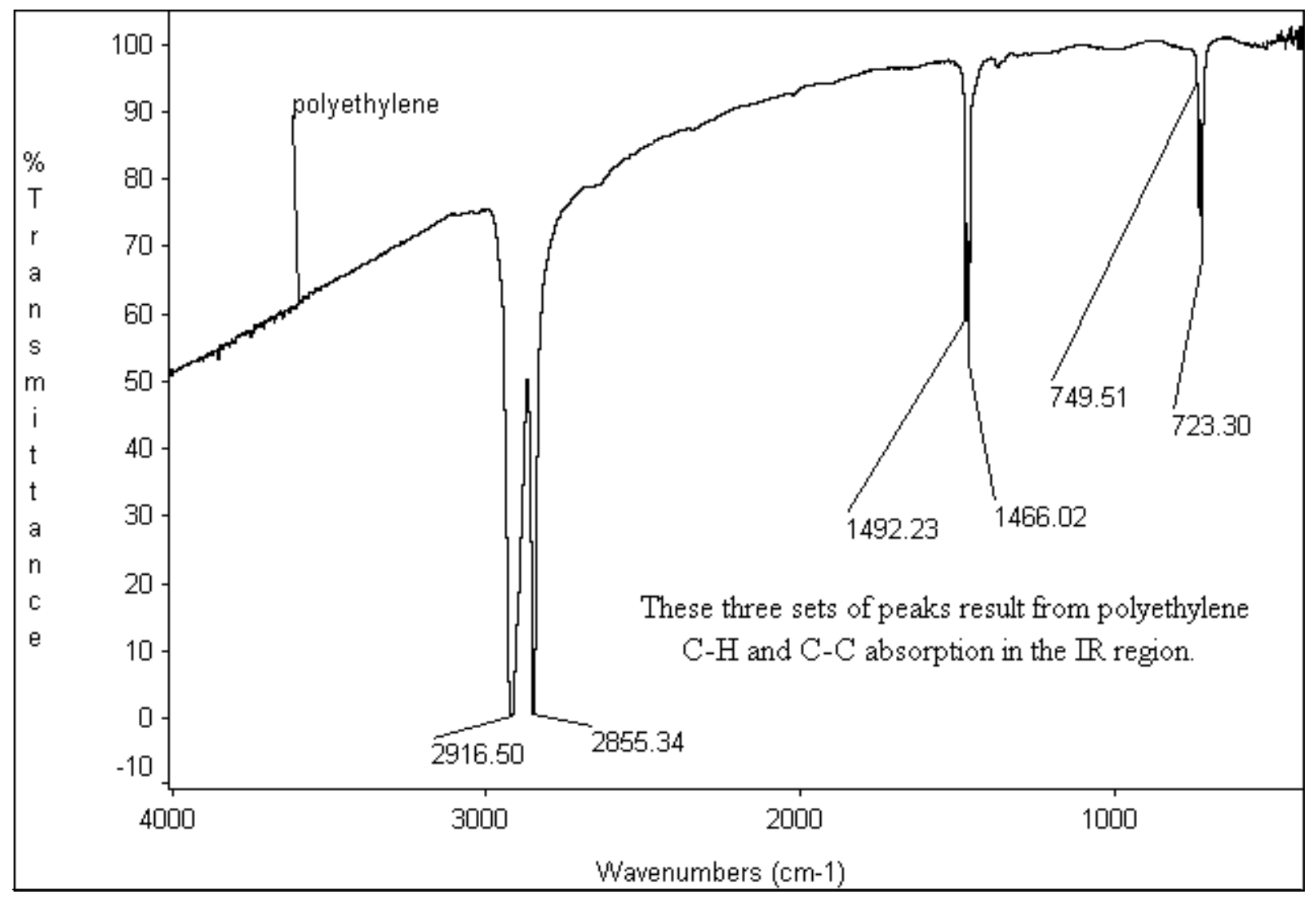

Figure 4.2: Polyethylene infrared (IR) transmittance spectrum, wavenumber reference. [58] 


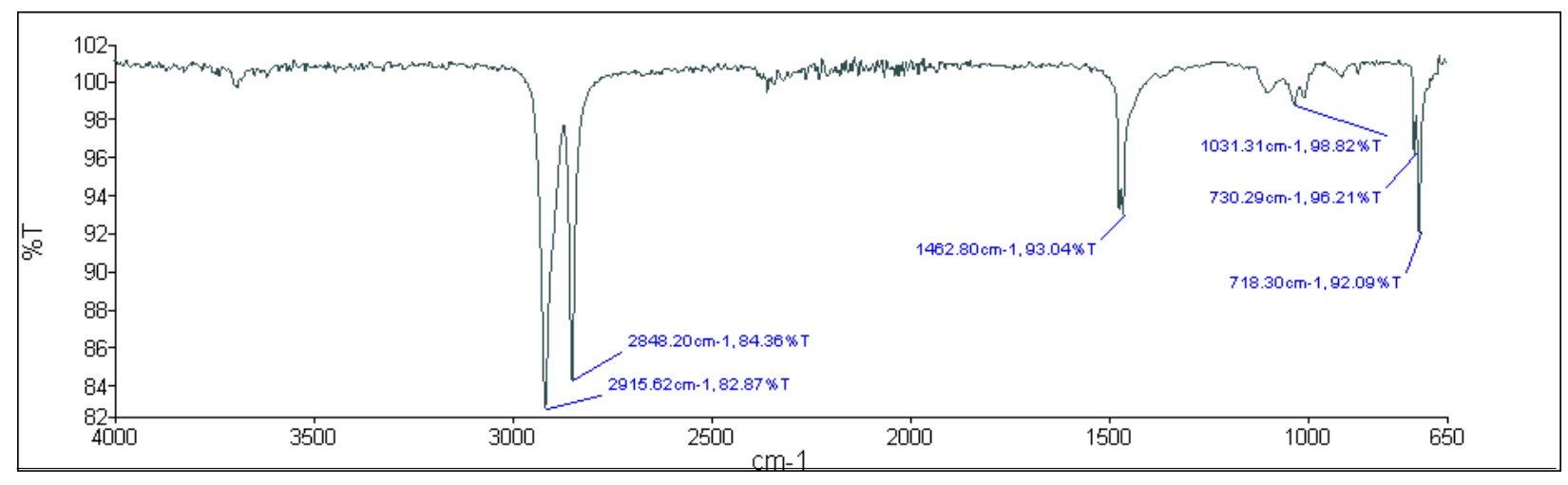

Figure 4.3: Patient E liner, IR transmittance spectrum.

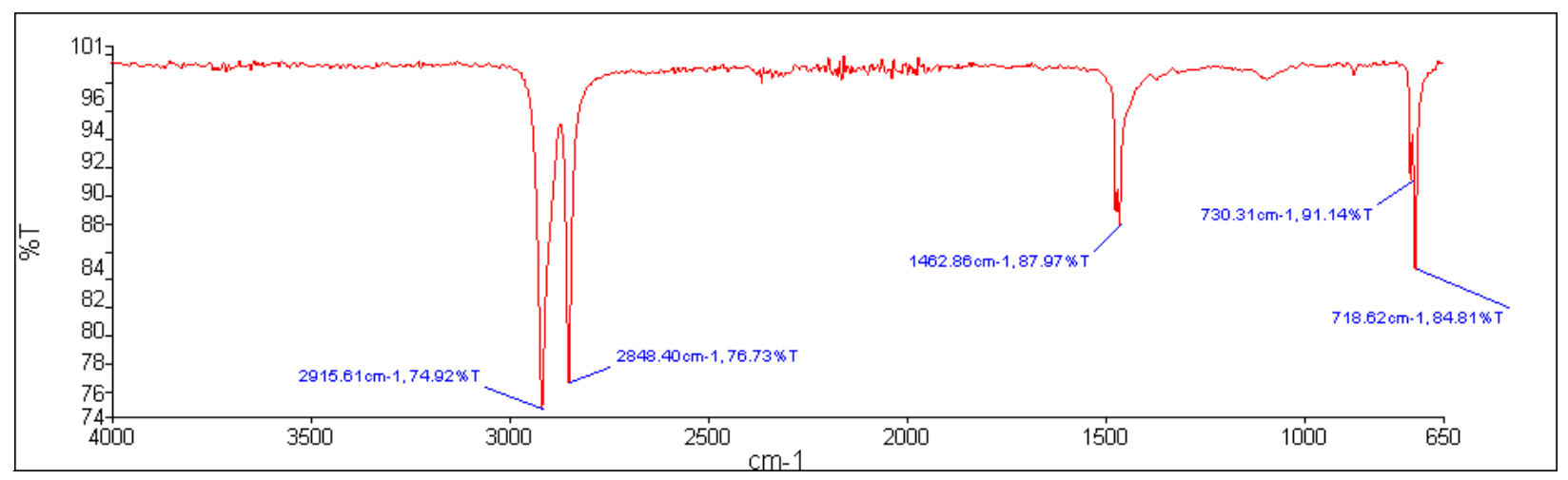

Figure 4.4: Patient W liner, IR transmittance spectrum.

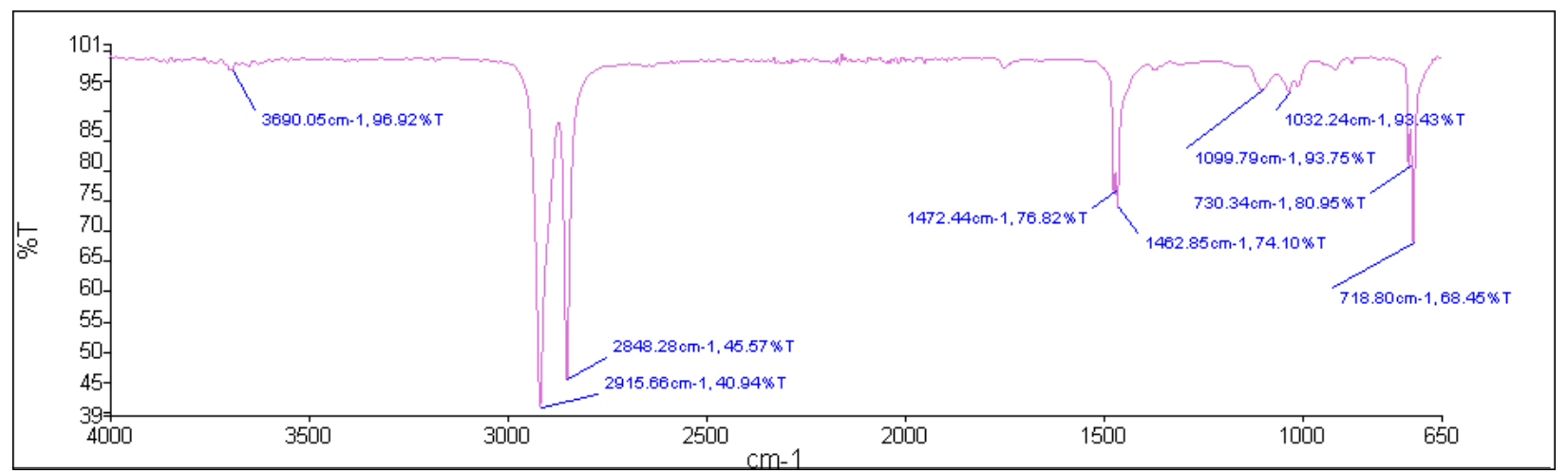

Figure 4.5: Patient H liner, IR transmittance spectrum. 
Table 4.3: Comparison of the reference wavenumber values with experimental wavenumber values.

\begin{tabular}{|lcccccc|}
\hline Transmittance & \multicolumn{7}{c|}{ Wavenumbers $\left(\mathrm{cm}^{-1}\right)$} \\
Spectra & Trough 1 & Trough 2 & Trough 3 & Trough 4 & Trough 5 & Trough 6 \\
Reference & 2916.50 & 2855.34 & 1492.23 & 1466.02 & 749.51 & 723.30 \\
Patient E & 2915.62 & 2848.20 & - & 1462.80 & 730.29 & 718.30 \\
Patient W & 2915.61 & 2848.40 & - & 1462.86 & 730.31 & 718.62 \\
Patient H & 2915.66 & 2848.28 & 1472.44 & 1462.85 & 730.34 & 718.80 \\
\hline
\end{tabular}

\subsection{Dye Penetrant Inspection (DPI)}

The use of dye penetrant inspection (DPI) on the UHMWPE liners was essential because it not only enhanced surface defects already viewed during the visual examination, but it clearly brought out unnoticeable deformations as well. The red, water-based dye provided a great contrast to the white PE substrate. The damage sustained by the PE for all components involved abrasive wear and plastic deformation.

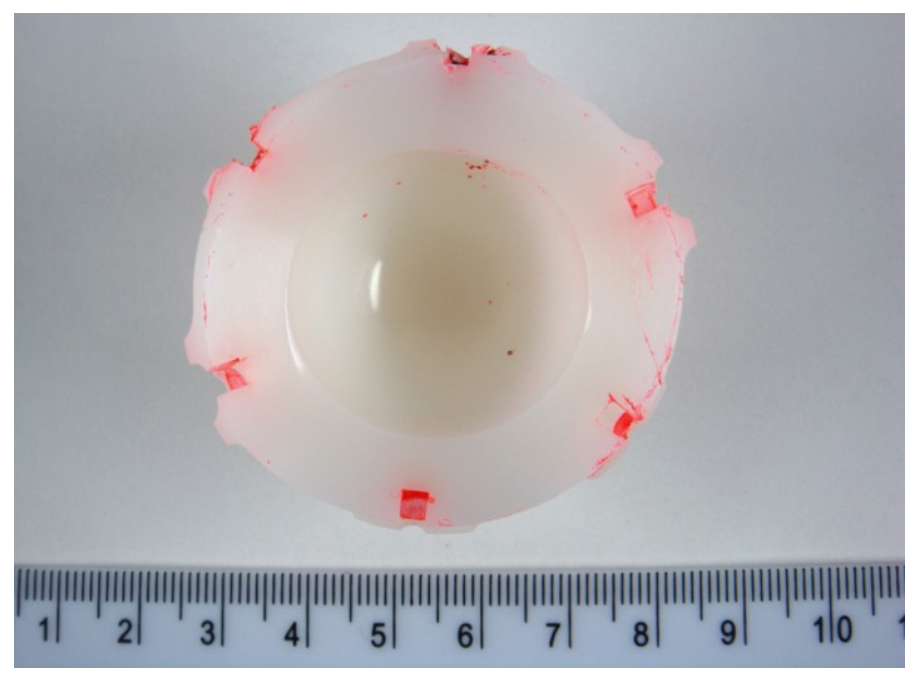

Figure 4.6: Patient E liner with dimensional reference 
Completely unnoticeable during the initial visual examination, indentations were found in the socket region of the liner, Figures 4.6 and 4.7. Each indentation had a similar diameter and depth. Upon further investigation, two small metallic "rods" were situated inside of the PE. It is possible that these metallic rods are actually wear particles that became entrapped in the interface between the PE liner and the femoral head.
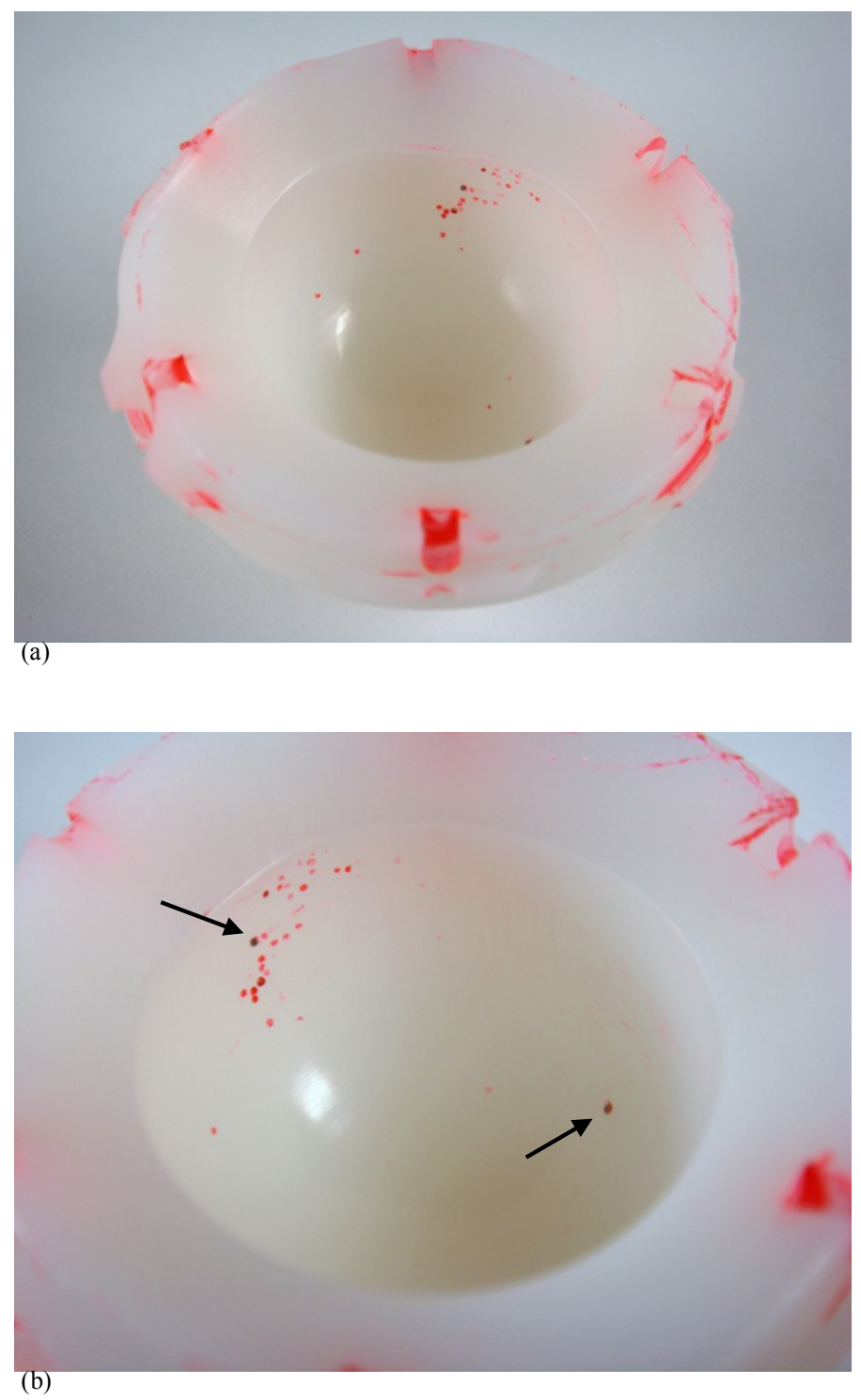

Figure 4.7: Patient E liner: (a) indentations, (b) close up image of indentations and two foreign, metallic particles indicated with arrows. 
Plastic deformation occurred in the areas where the PE liner locks with the ceramic acetabular shell. Figure $4.8 \mathrm{a}$ and $\mathrm{b}$ displays the severe deformation of these regions. Though the center should remain hollowed out, the PE was so plastically deformed that material came together and flapped over itself. Figure 4.8c and d displays another similar area with deformation on the sprocket portion of the rim.

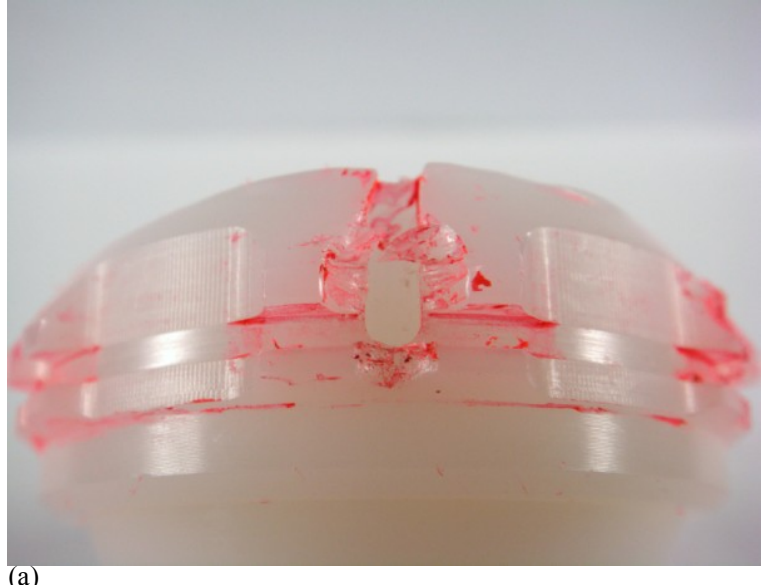

(a)

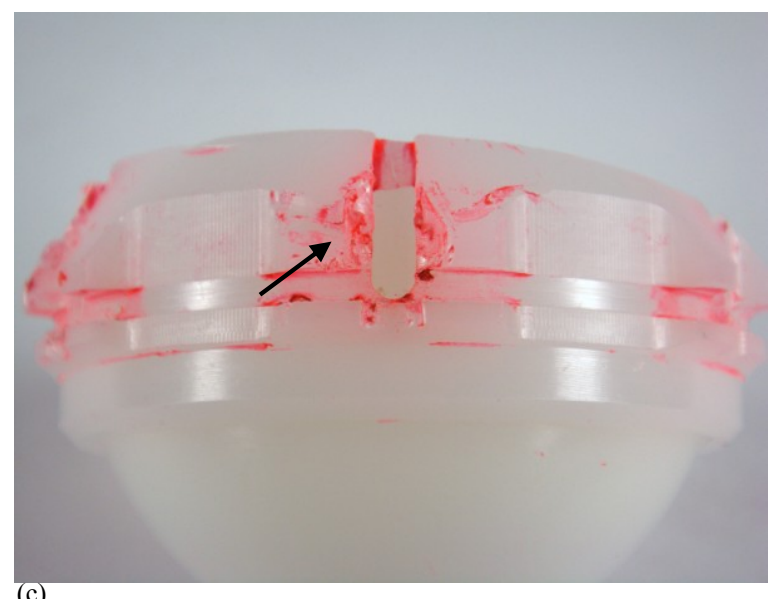

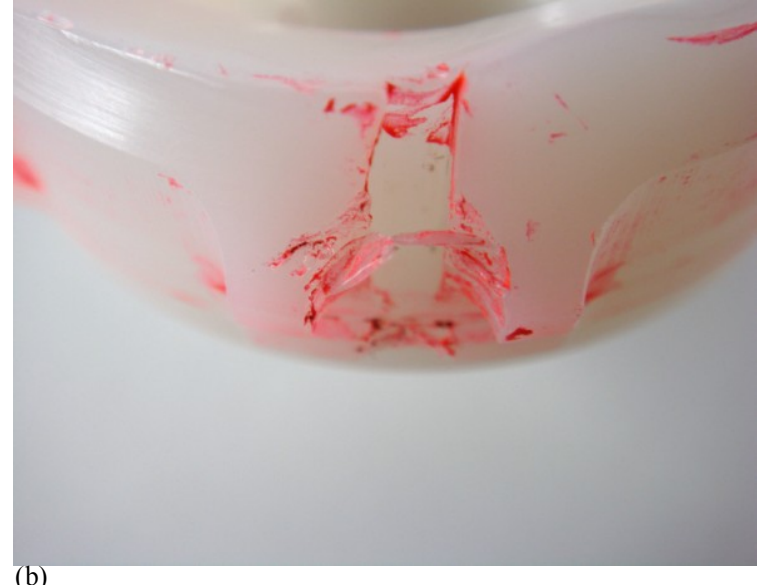

(b)

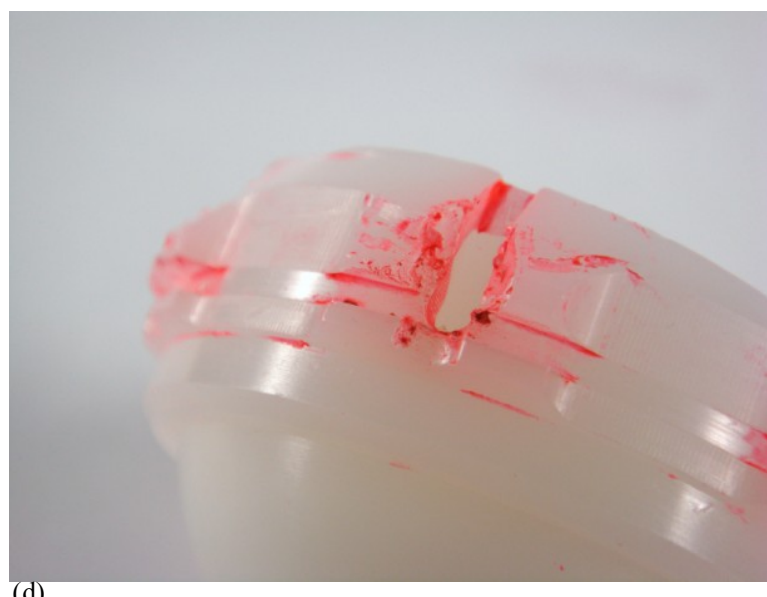

(d)

Figure 4.8: Patient E liner: (a) frontal view of plastic deformation, (b) deformed material that flapped towards the center from the two sides, (c) deformed sprocket with plastic flow indicated by arrow, (d) right-hand view. 
The largest amount of damage sustained was on the proximal region of the Patient W liner. As indicated by the arrow in Figure $4.9 \mathrm{~b}$, the deformed area is in a place that makes no contact with the femoral head. On the underside, where the liner makes contact with the acetabular shell, DPI revealed a deep crack which is pointed by the arrow in Figure 4.10.

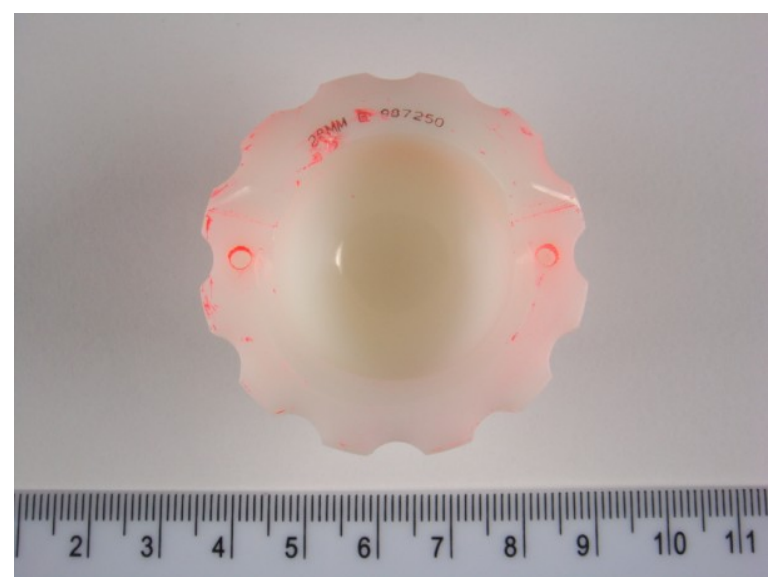

(a)

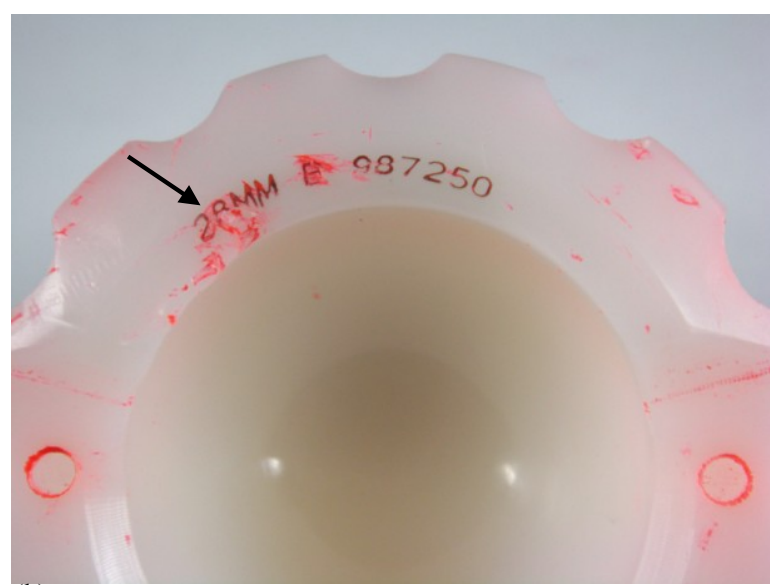

(b)

Figure 4.9: Patient $\mathrm{W}$ liner: (a) with dimensional reference, (b) closer image of surface deformation.

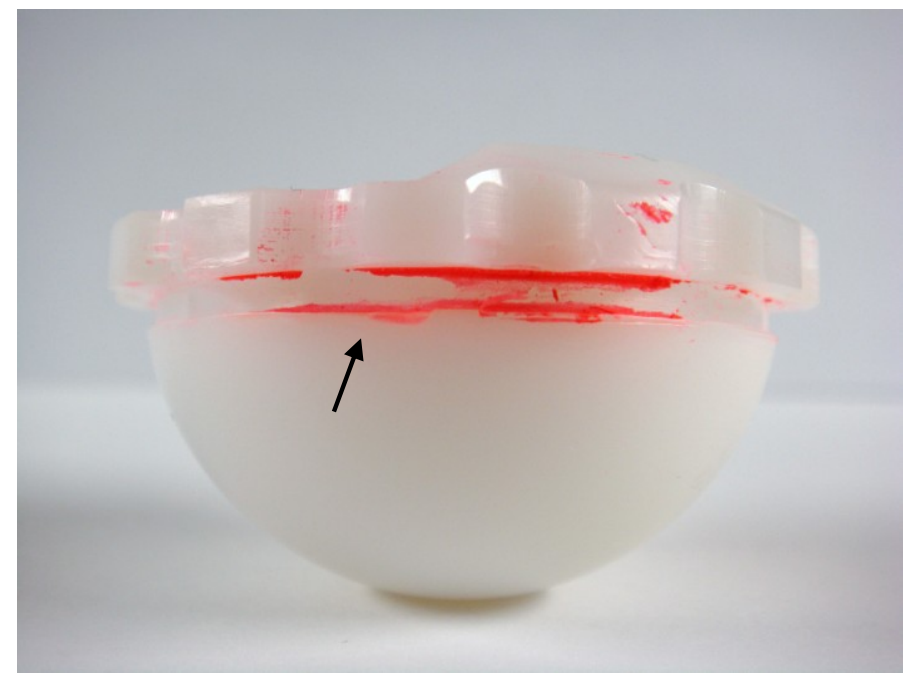

Figure 4.10: Patient W liner with radial crack 
Similar to Figure 4.10, more rim damage was found on the other side of the component, Figure 4.11. The capillary action of the red dye clearly presents hash marks in at least 3 directions. It is obvious that the deformed area sits lower than the surrounding "sprocket" arms. Plastic flow of the PE is also evident in the downward sloping crack. Beneath the hash marks is a puncture in the PE. As the PE and acetabular shell are only in contact with the bone/cement, the damage sustained may have been due to implant insertion or retrieval by the surgeon.
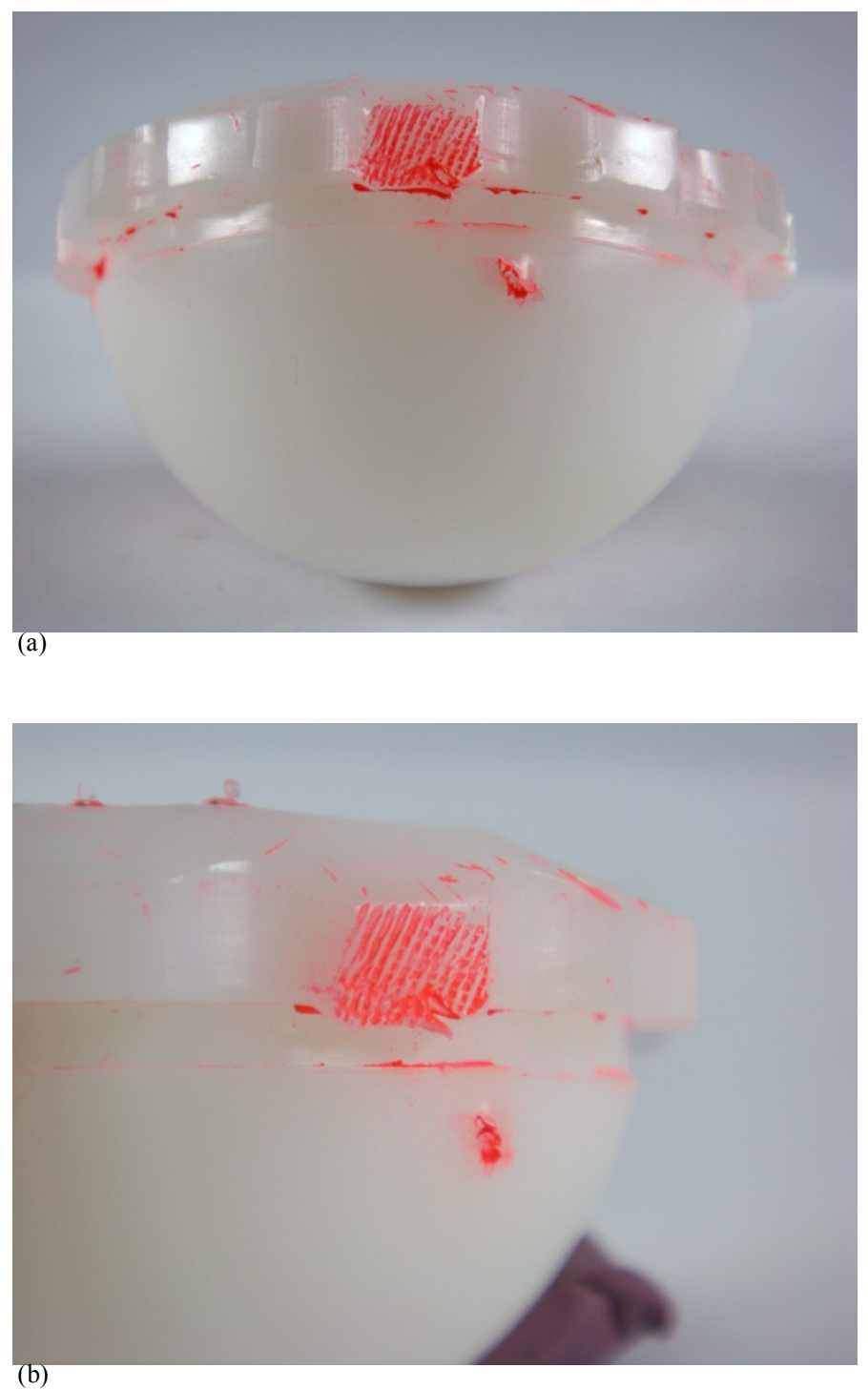

Figure 4.11: Patient $\mathrm{W}$ liner: (a) frontal view of rim deformation and puncture, (b) side view. 
Scratches and plastic flow of the rim can be seen in Figure 4.12a. The Patient H liner was the component that truly displayed abrasive wear of the socket. Clearly visible throughout the visual examination, the dye brings more focus to the large wear spot indicated in Figure 4.12b. To the left of this defect and closer to the rim, is a smaller wear spot. The Patient $\mathrm{H}$ liner had the largest amount of surface scratches, abrasions, and plastic flow.
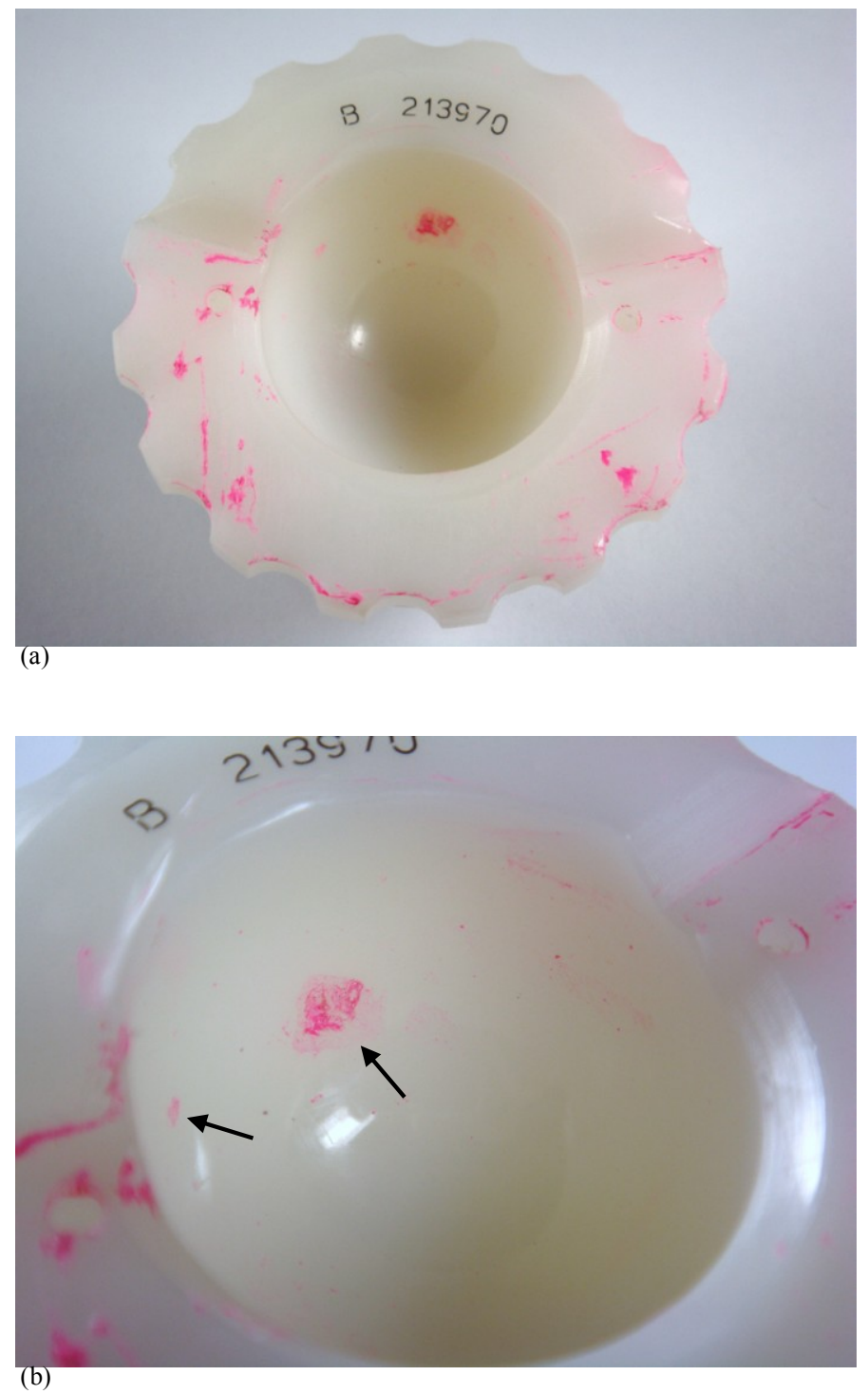

Figure 4.12: Patient $\mathrm{H}$ liner: (a) vast amount of surface abrasions and large abrasive wear area, (b) abrasive wear. 
Deformation of the outer rim was a similar feature in all three PE liners. Figure 4.13 indicates a large area of plastic flow and a radial crack. In service, bending and flexing loads continuously act upon the acetabular components every time the patient walks, runs, sits, etc. It is possible that such repeated actions may have produced such a crack and plastic flow.
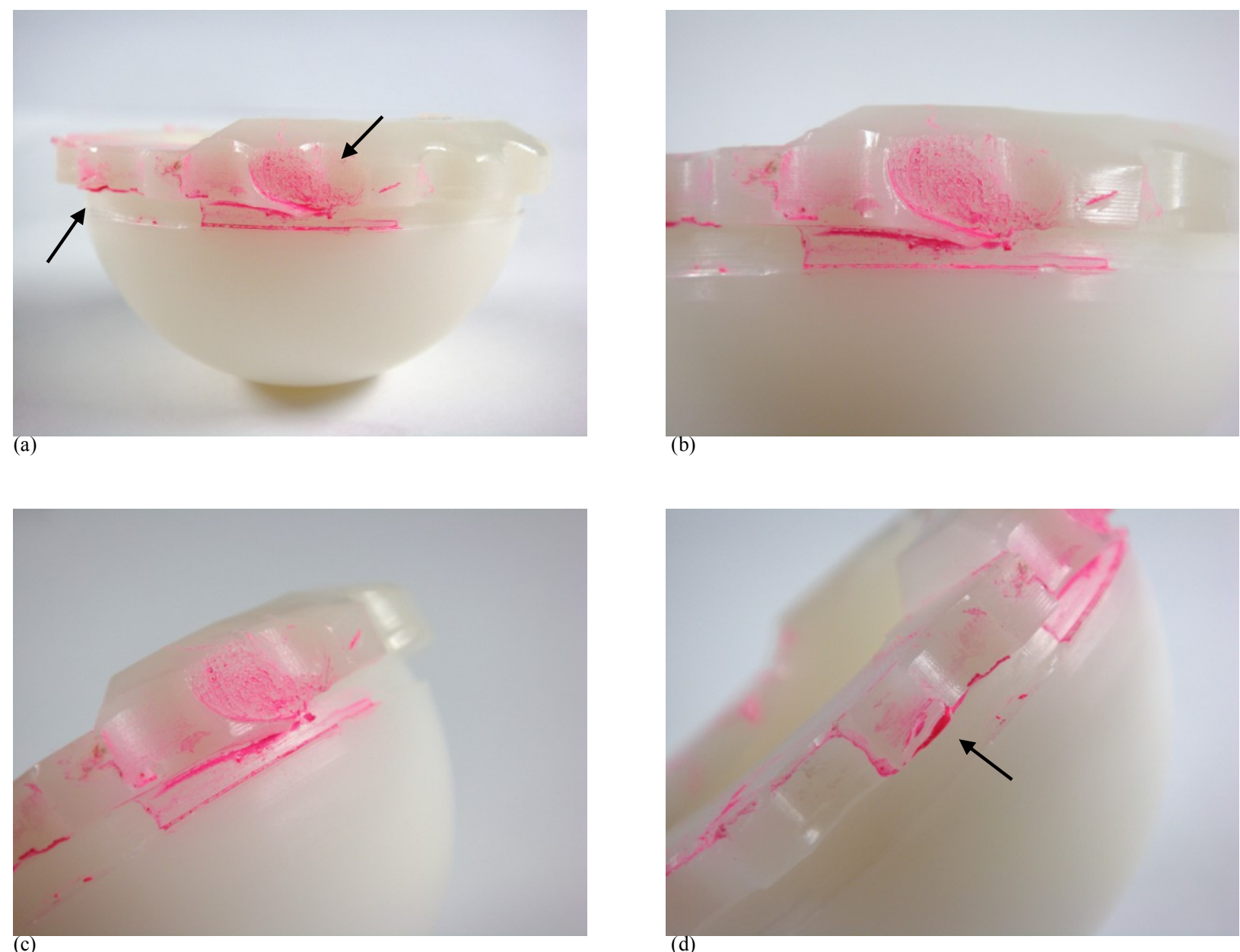

Figure 4.13: Patient $\mathrm{H}$ liner: (a) plastic deformation, plastic flow, and radial crack, (b) closer image of plastic deformation, (c) side view of plastic deformation, (d) side view of radial crack. 


\subsection{Metallography}

As three of the four femoral heads were cobalt-based alloys, one implant was selected to present the microstructure. Based upon the elemental weight percentages in the compositions acquired by XRF, the three femoral heads fell under the ASTM designation of an F75 casting alloy. Characteristic to the F75 specification, the microstructure for the Patient E section of the femoral head displayed dispersed carbides, Figure 4.14a and b. As casting defects are known to arise in cast products, Figure $4.14 \mathrm{~b}$ and c displays a fairly large casting defect of densely connected carbides.
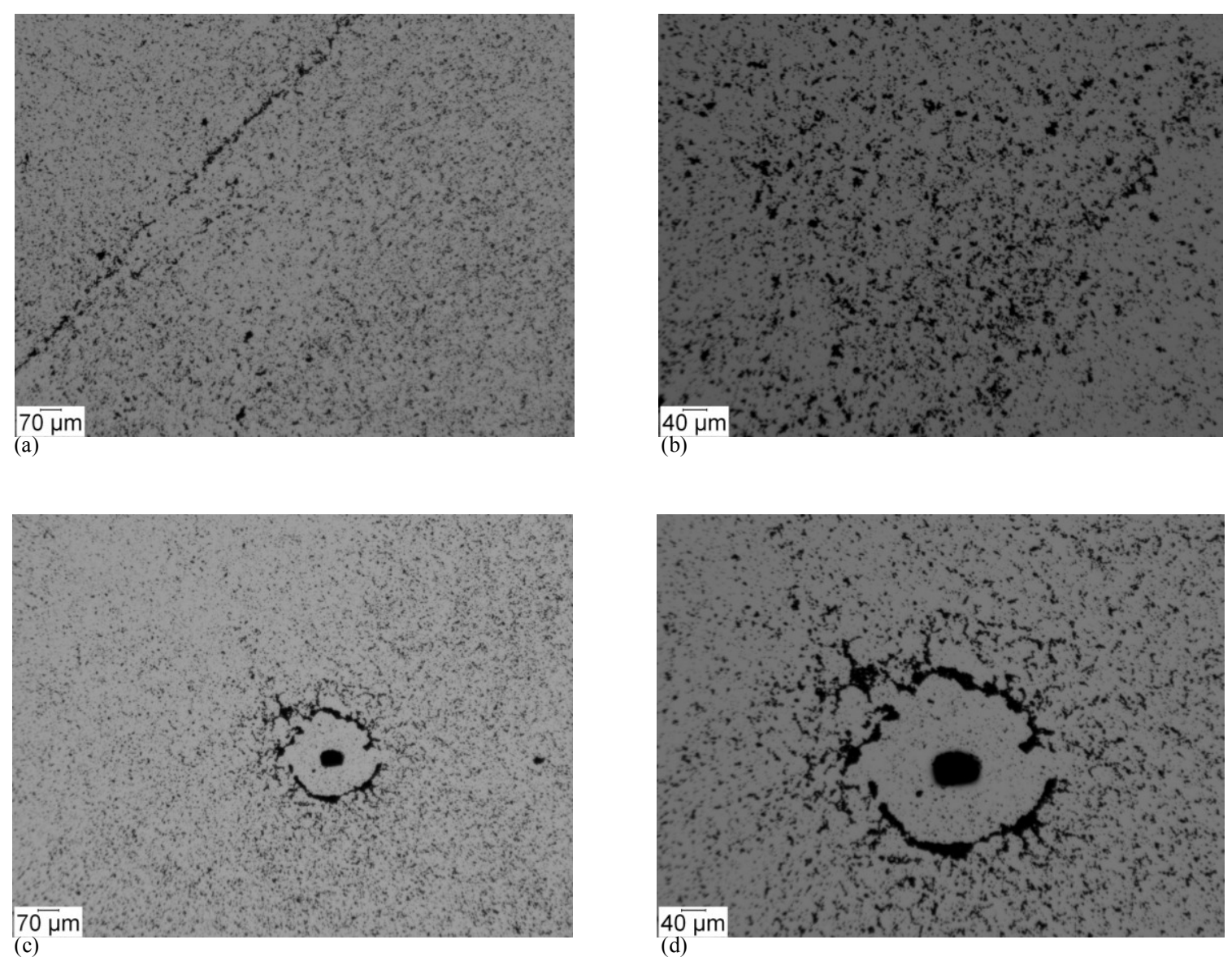

(c)

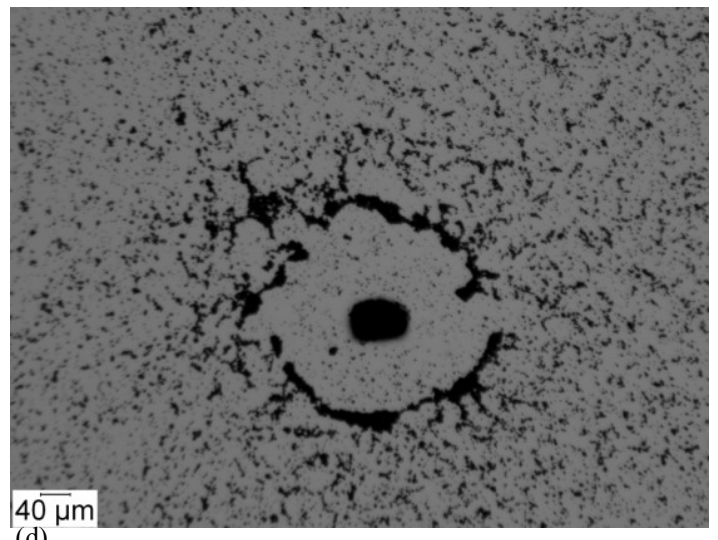

(d)

Figure 4.14: Patient E cobalt-alloy femoral head: (a) and (b) dispersed carbides, (c) and (d) casting defect. 
Initially found during the visual examination of the components, the engravings on the Patient U femoral head, Figure 3.4a, indicated the component as a 316L stainless steel. The composition produced by XRF confirmed the elemental weight percentages with 316L. As seen in Figure 4.16, the microstructure for this surgical alloy consisted of variable grain sizes with annealing twins. In order for the formation of twins, the alloy must have undergone an annealing heat treatment.
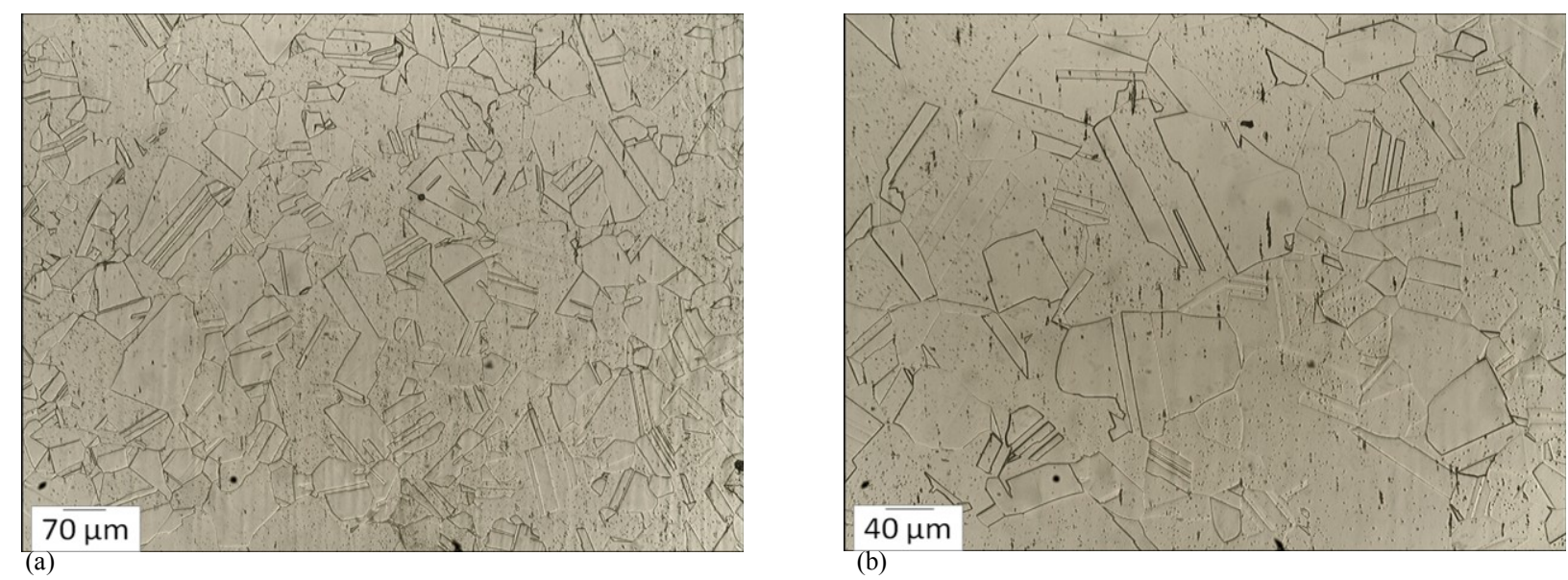

Figure 4.15: Patient $U$ stainless steel femoral head with variable grain sizes and annealing twins at a magnification of: (a) 200x, (b) 400x.

\subsection{Scanning Electron Microscopy (SEM)}

After a thorough visual examination of each of the PE liners, it seemed as though there was an insufficient amount of component damage which could have led to retrieval during the revision surgery. Upon this realization, SEM was used to characterize damage modes associated with wear, fatigue, and possible corrosion. It is of the utmost importance to remember that when a harder surface makes contact with a softer surface, over time it should be the softer surface that 
wears away. When particles with higher hardness than that of the femoral head and PE come between the contact surfaces, it may result in wear of both components.

\subsubsection{Ultra High Molecular Weight Polyethylene (UHMWPE) Liners}

The most unique case of the PE liners was the Patient E liner for its large amounts of wear tracks, indentations, and foreign particles (further discussed in a later section). Many wear tracks were found within the base of the socket, Figure 4.16a. Though the component was repeatedly ultrasonically cleaned, embedded surface debris remained throughout the base of the socket. Still in the socket region, though closer to rim surface, circular impressions with large wear tracks were observed, Figure 4.16b. The similar diameters of the wear tracks to that of the impression diameters was close enough to suggest that this damage was the result of a third-body particle.
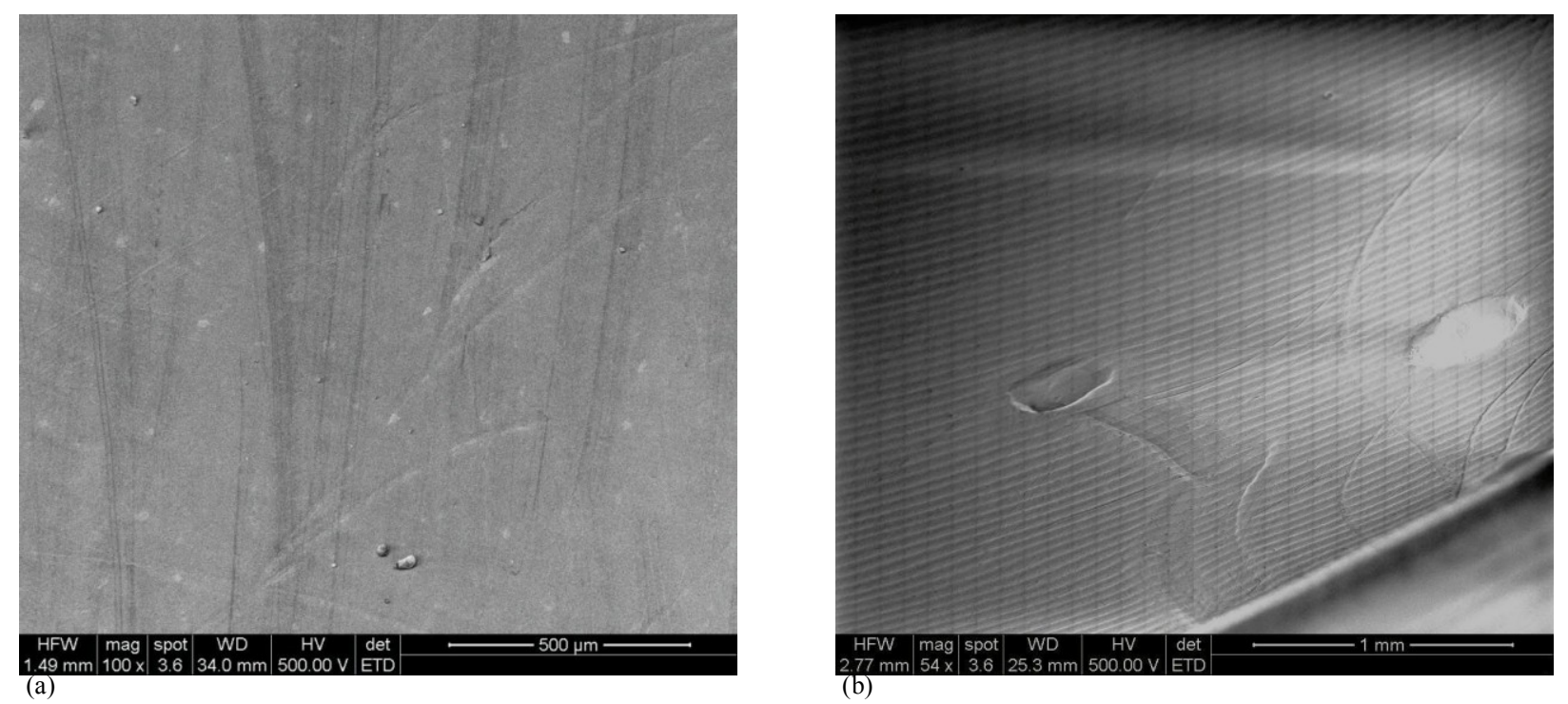

Figure 4.16: Patient E liner: (a) wear tracks and surface debris, (b) impressions with wear tracks. 
In a region close to the previously seen impressions, indentations we observed as well. The rim surface is on the right side of the image in Figure 4.17a and is indicated by the arrow. In a close-up image of the indentation in Figure 4.17b, plastic flow was observed on the left half of the indentation. According to the micron marker, the diameter of the indentation is approximately $400 \mu \mathrm{m}$ and the depth is well in excess of $200 \mu \mathrm{m}$.

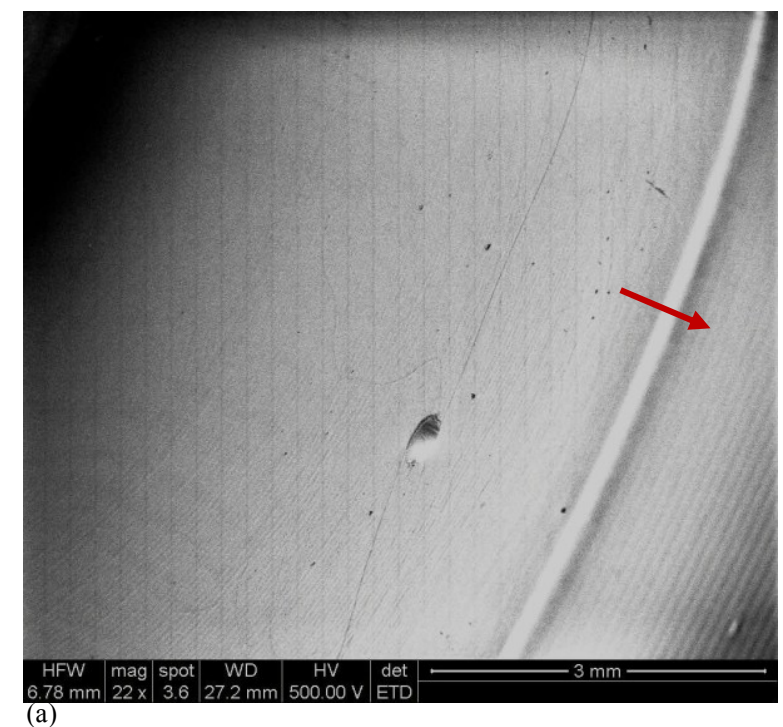

Figure 4.17: Patient E liner: (a) indentation, (b) closer image of indentation with plastic flow.

Although the PE liners were carbon coated to relieve surface charging, the combination of a large amount of non-conducting material with a large depth of focus made it difficult to obtain a crisp image in some of the micrographs. The image in Figure 4.18a was taken on the very bottom of the socket. In this large region, embedded surface debris was found, along with oddly shaped wear tracks in the top of the image, and the metallic foreign particle. The foreign particle in Figure 4.18b had a rod-like shape, in which wear tracks were visible on the surface in a diagonal direction. The particle faced a lateral load as indicated by the plastic flow lines. 


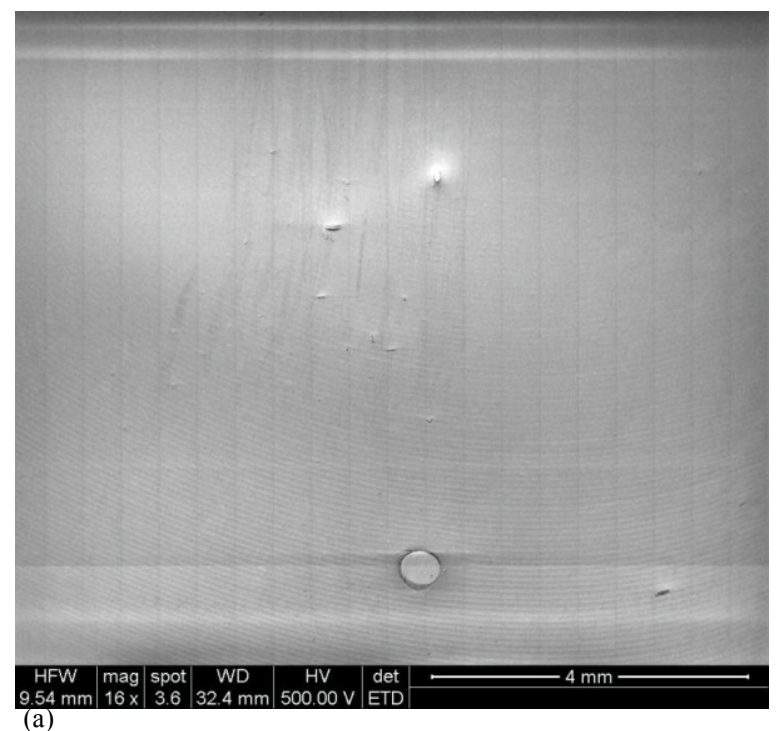

Figure 4.18: Patient E liner: (a) surface debris, wear tracks, and foreign particle, (b) foreign particle with wear tracks

In reference to location of the Patient $\mathrm{E}$ liner, the indentations and foreign particle observed in Figure 4.19 are the same indentations as in Figure 4.7b. The indentations appear to have similar diameters and different depths of penetration. It is difficult to assign a shape to the foreign particle in Figure 4.19b. It may be possible that the particle was spherical but as it was in constant sliding contact with the femoral head, the surface may have worn flat. In a different case, the particle shares similar features with a cup-cone fracture surface. The two plastic flow lines indicate that this particle faced lateral loads as well.

The indentations in Figure 4.20a, illustrates varying diameters and depths of penetration and wear tracks that either led to or away from these unique areas. The complex morphologies viewed in Figures 4.20a and b, both led the researcher to believe that the foreign particle either plowed or was impressed into the Patient E liner. 


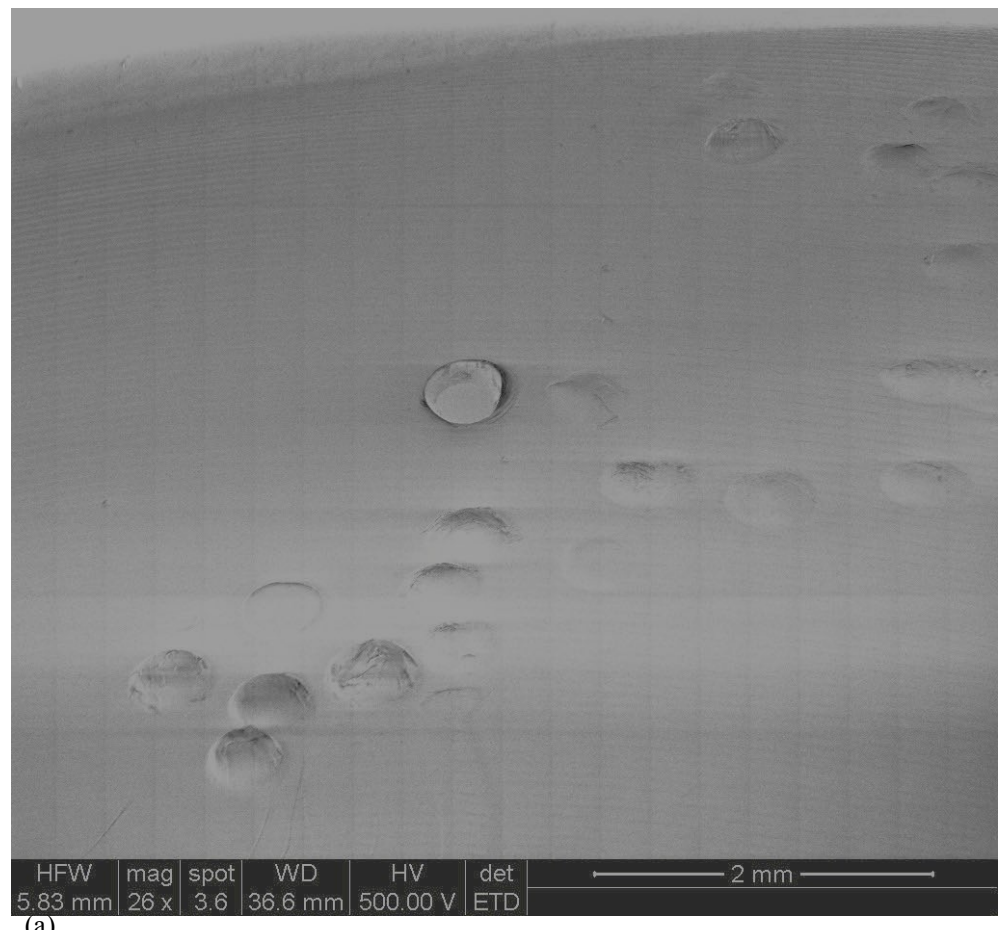

(a)

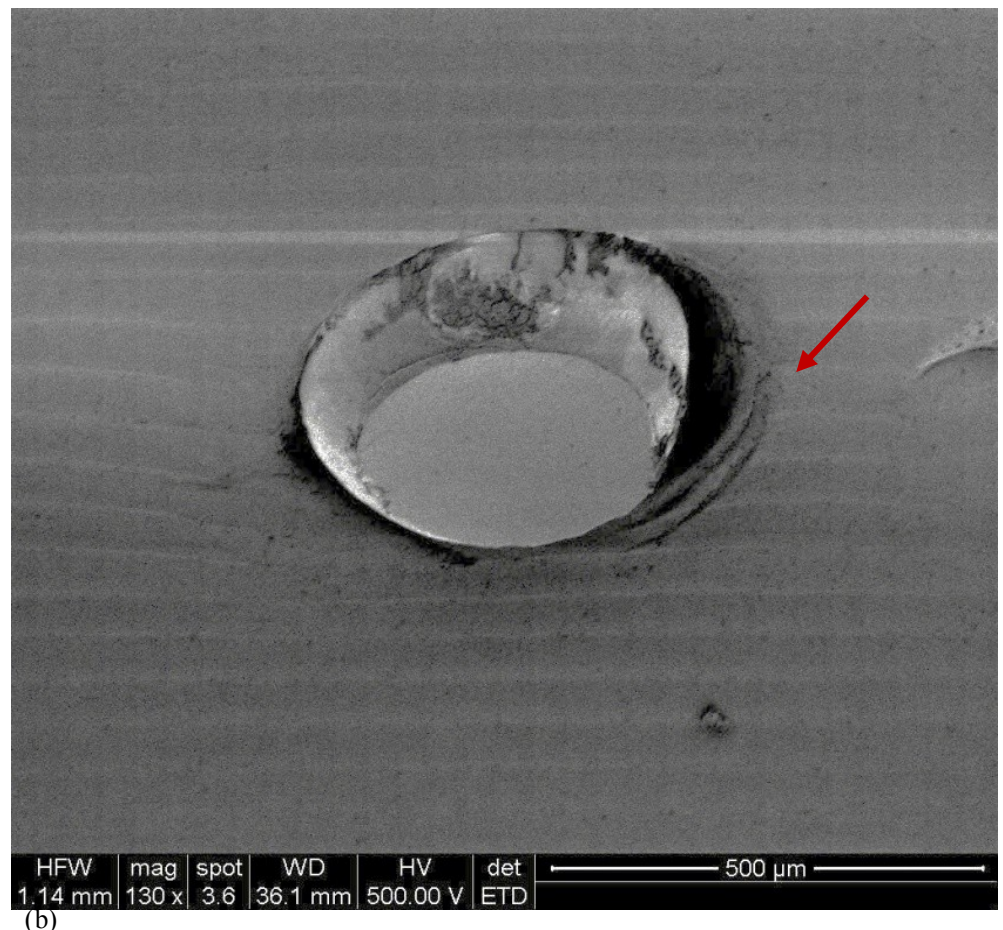

Figure 4.19: Patient E liner: (a) indentations and foreign particle, (b) foreign particle with plastic flow. 


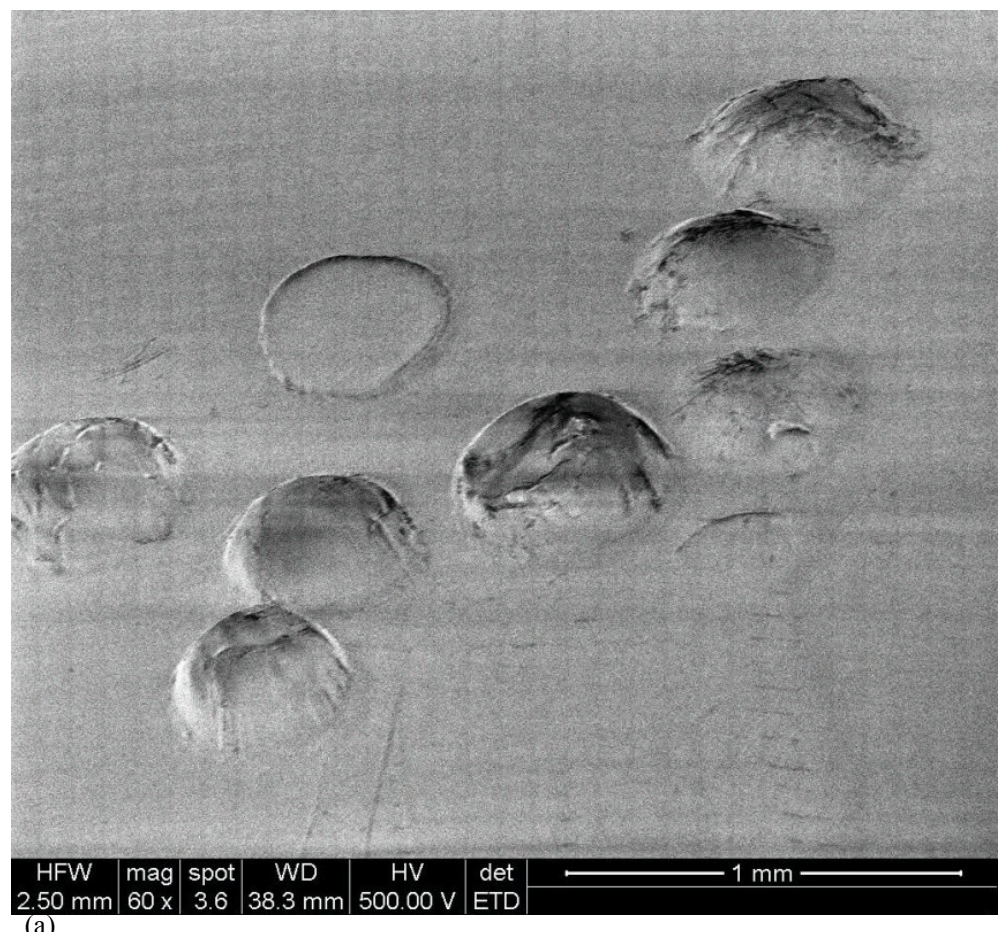

(a)

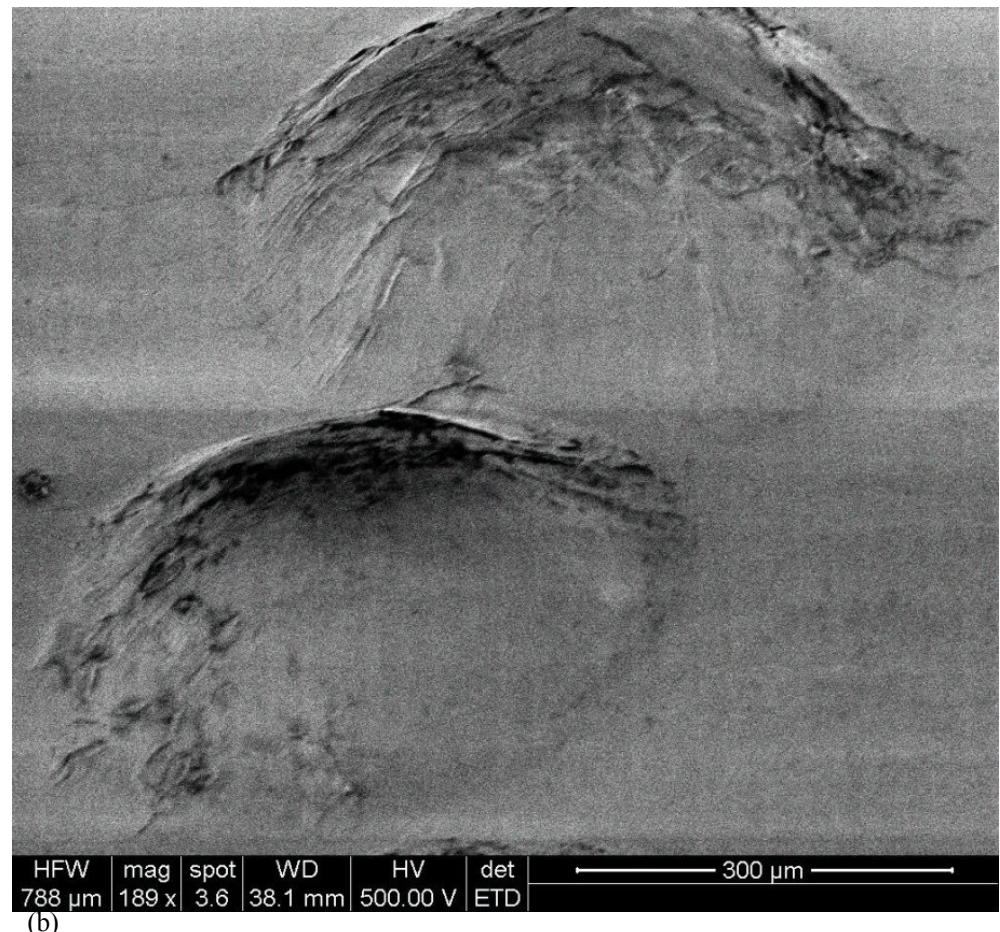

Figure 4.20: Patient E liner: (a) indentations and wear tracks, (b) complex morphology of indentations. 
The first sets of surface textures and possible defects of Figure 4.21, focus on the characteristic machine marks found on UHMWPE liners. Figure 4.21a displays what appears to be folded PE. Though, upon careful observation, the machine marks are located on the fold. Figure $4.21 \mathrm{~b}$ displays the machine marks in two directions. Both Figures $4.21 \mathrm{c}$ and $\mathrm{d}$ illustrate abrasions on the interfaces between the top of the rim and the plane at which the socket forms. In all four of the micrographs it is difficult to determine whether the defects were created in service or during fabrication of the liners.
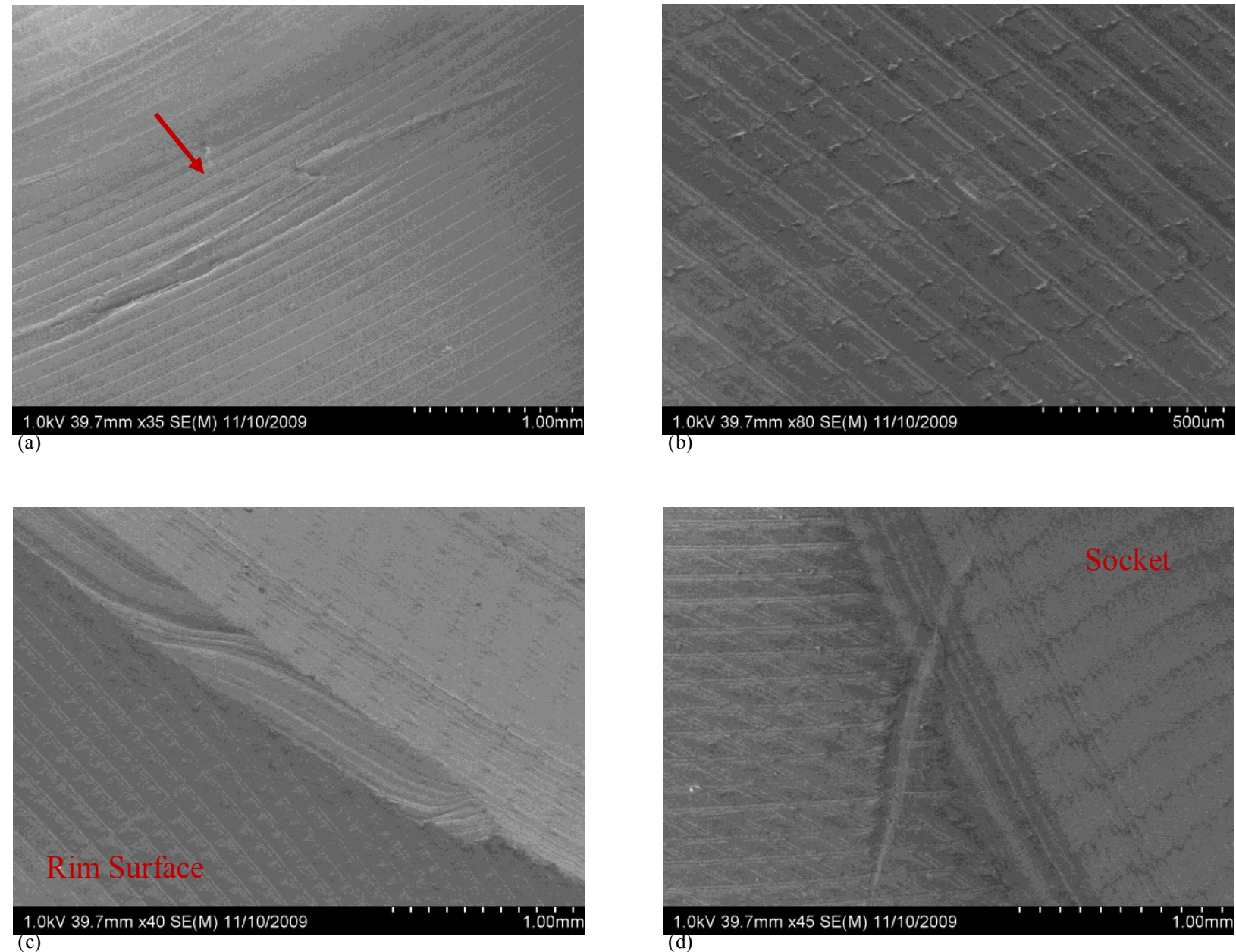

Figure 4.21: Patient W liner: (a) machine marks above PE fold, (b) two sets of evenly spaced machine marks, (c) and (d) abrasion on the interface of the rim surface and downward slope of the socket. 
Figure 4.22a provides an image of plastic flow off of the point where the rim surface meets the downward slope of the socket. This is an area that makes contact with the femoral head. In a different area of the rim surface, odd indentations were observed, Figure 4.22b.

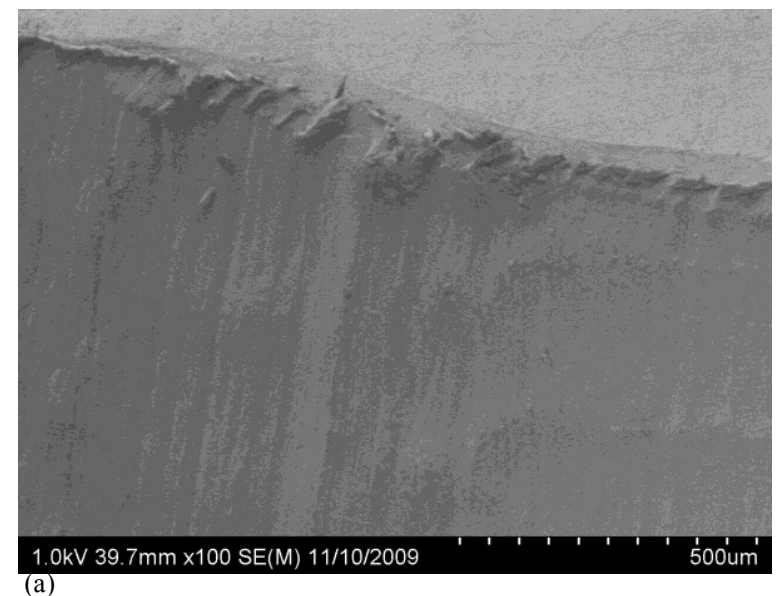

(a)

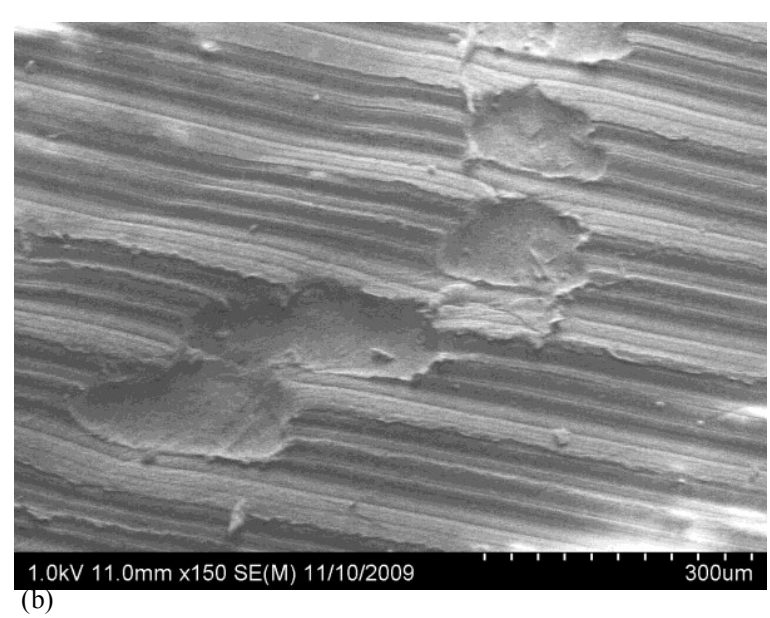

(b)

Figure 4.22: Patient W liner: (a) plastic flow, (b) surface indentations.

The SEM image of the Patient W liner contains a large area of deformation and plastic flow in Figure 4.23a and b. Figures 4.24 and 4.25 display multiple areas of severe deformation, plastic flow, and ripped areas.

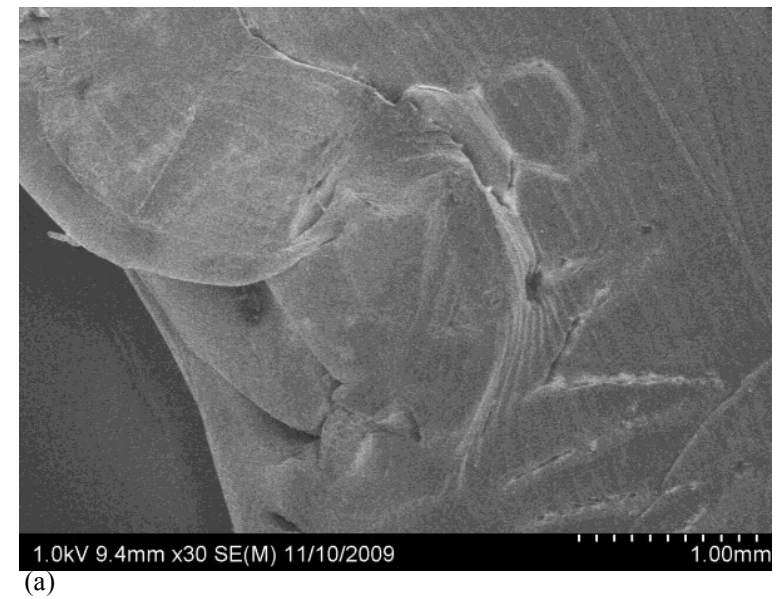

Figure 4.23: Patient W liner: (a) topical deformation, (b) multiple damage modes.

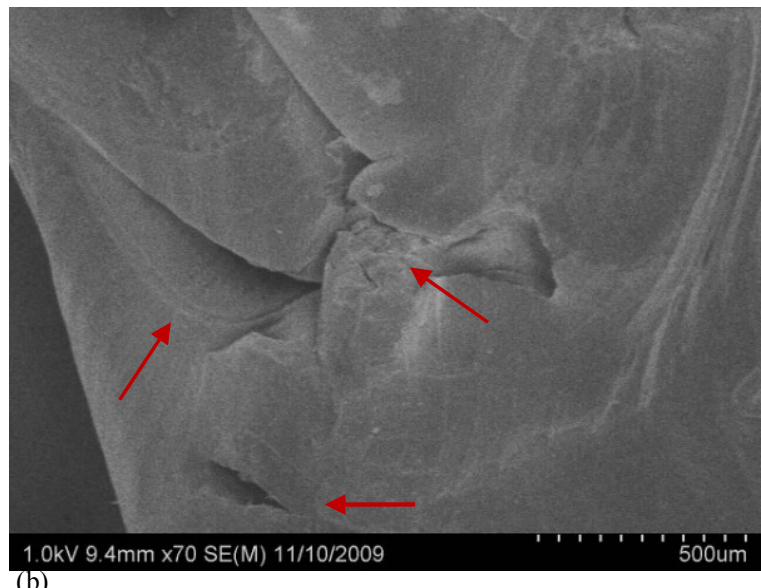

(b) 

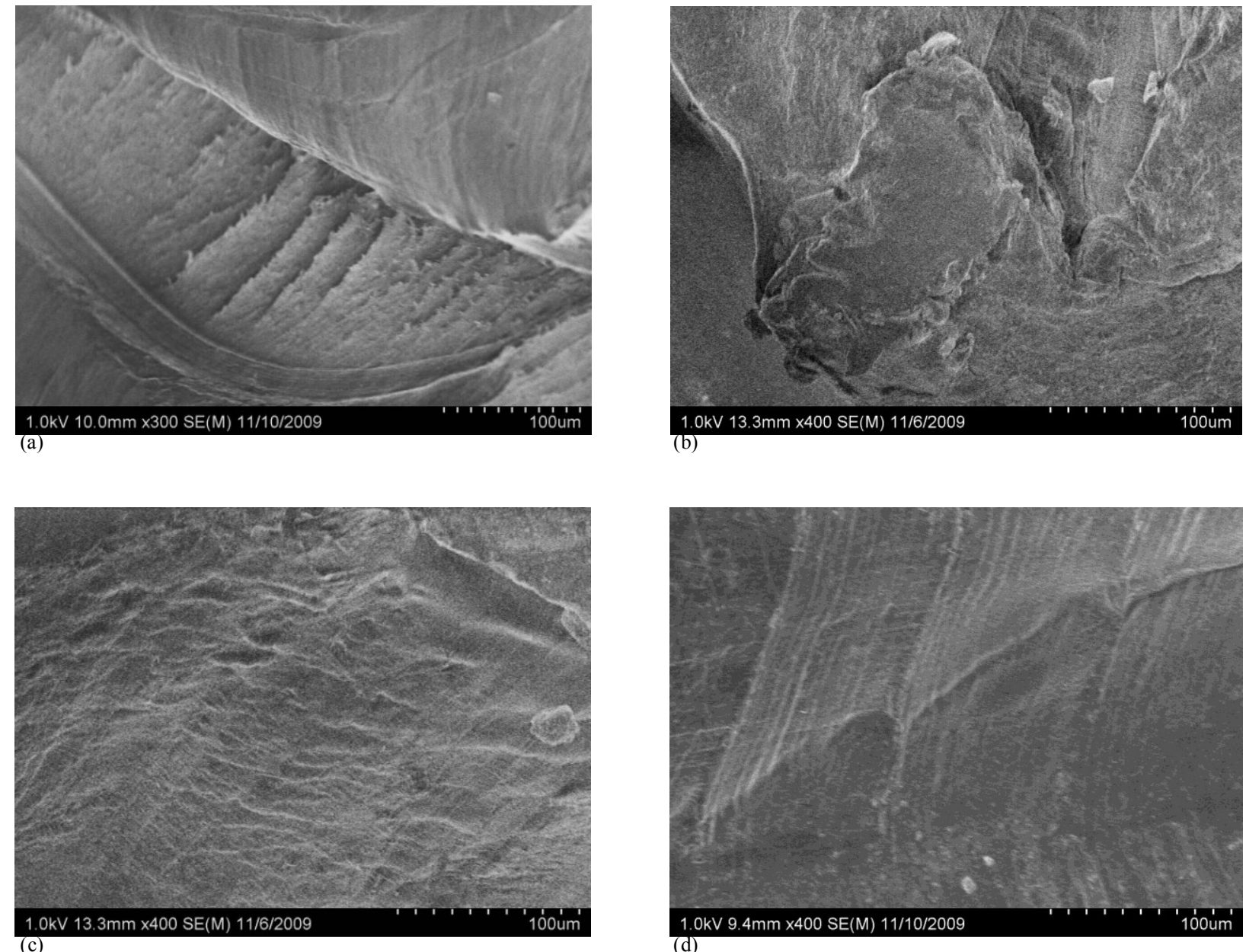

Figure 4.24: Patient W liner: (a) ripped layer of PE revealed a ductile fracture surface, (b) deformation containing PE surface debris and plastic flow, (c) close-up image of plastic flow lines, (d) more plastic flow lines with folded PE. 

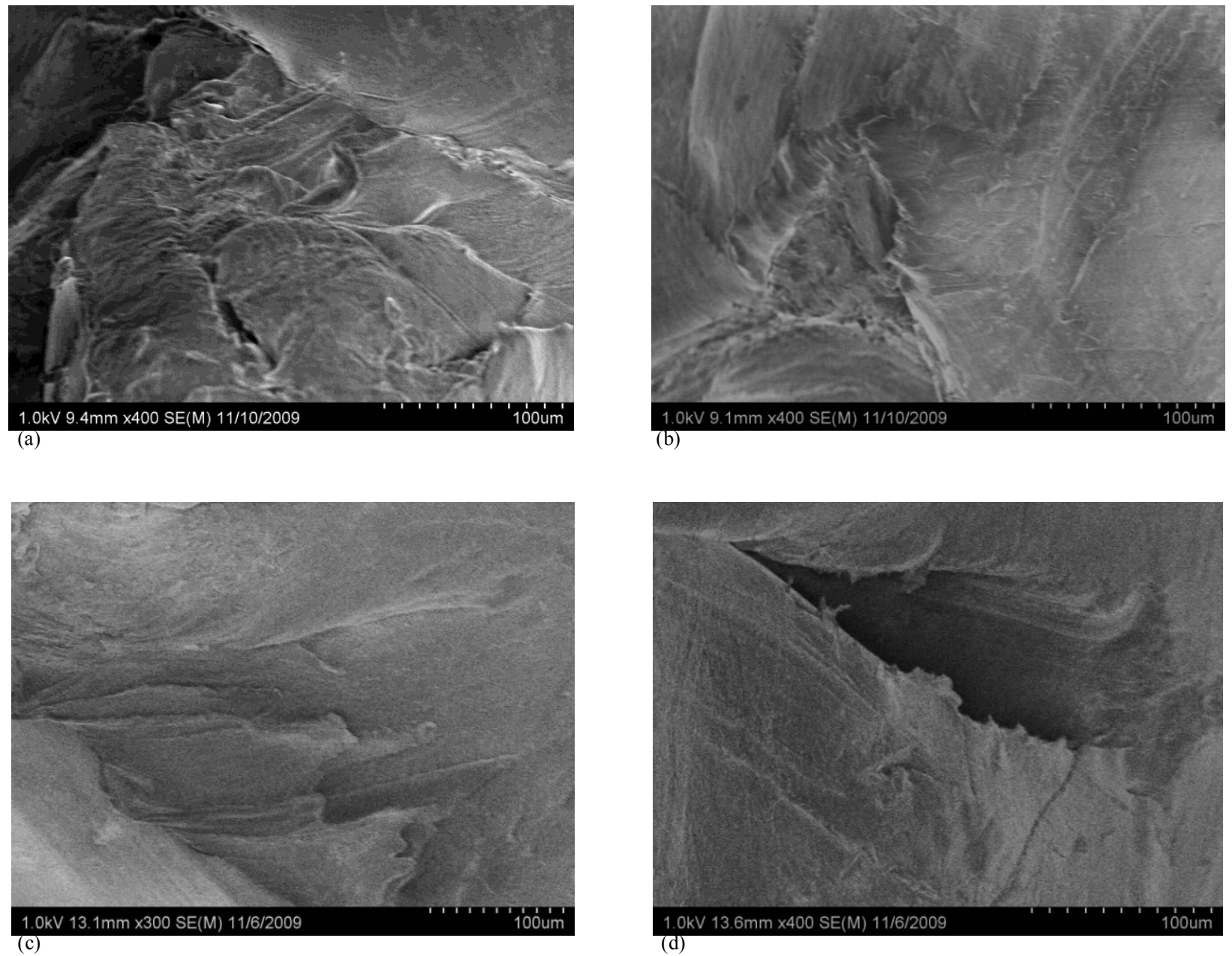

Figure 4.25: Patient W liner: (a) and (b) plastic flow in multiple directions with plastic flow lines, (c) and (d) PE that has been stretched and pulled apart. 
With the longest implant duration before the component retrieval, the Patient $\mathrm{H}$ liner was the only liner to display burnishing. While in service, the constant sliding motion of the femoral head with the PE liner can produce friction if there is a shortage of lubrication. In Figure 4.26a and $b$, the paths taken by the femoral head is easily visible. Large areas of PE appeared to begin delamination due to burnishing and possible adhesive wear.
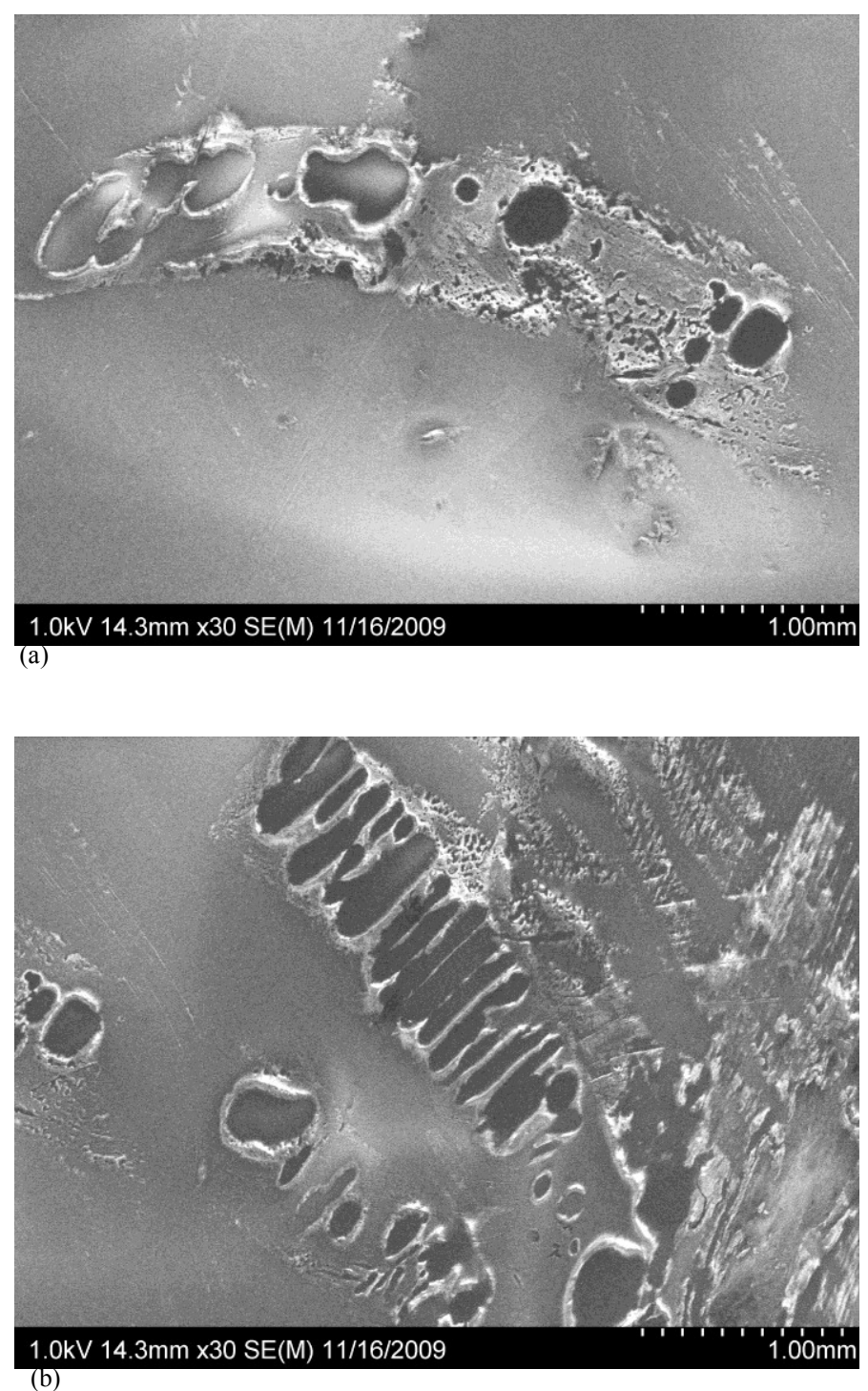

Figure 4.26: Patient H liner: (a) and (b) burnishing. 
In another unique case, the Patient $\mathrm{H}$ liner also contained a large area of abrasive wear. Aside from the previously mentioned burnished areas, the remaining liner socket was fairly unimpaired as seen in Figure 4.27 It appeared as though PE material may have been ripped off, base on the ductile fracture surface, Figure 4.28. Semicrystalline polymers, such as PE, are known to exhibit considerable post-yield plastic deformation, thus resulting in a ductile classification [38]. Yet, in the areas indicated by arrows, remnants of the original PE surface still remained.

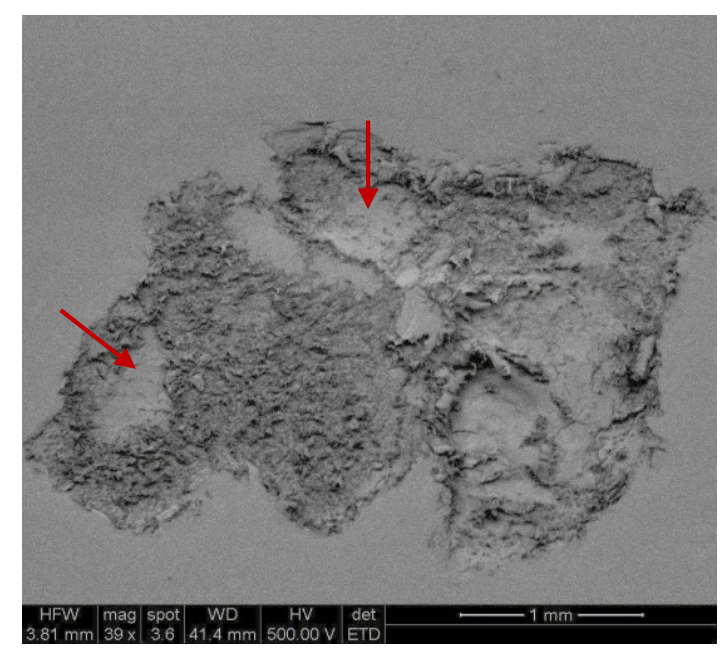

Figure 4.27: Patient $\mathrm{H}$ liner, abrasive wear of the socket.
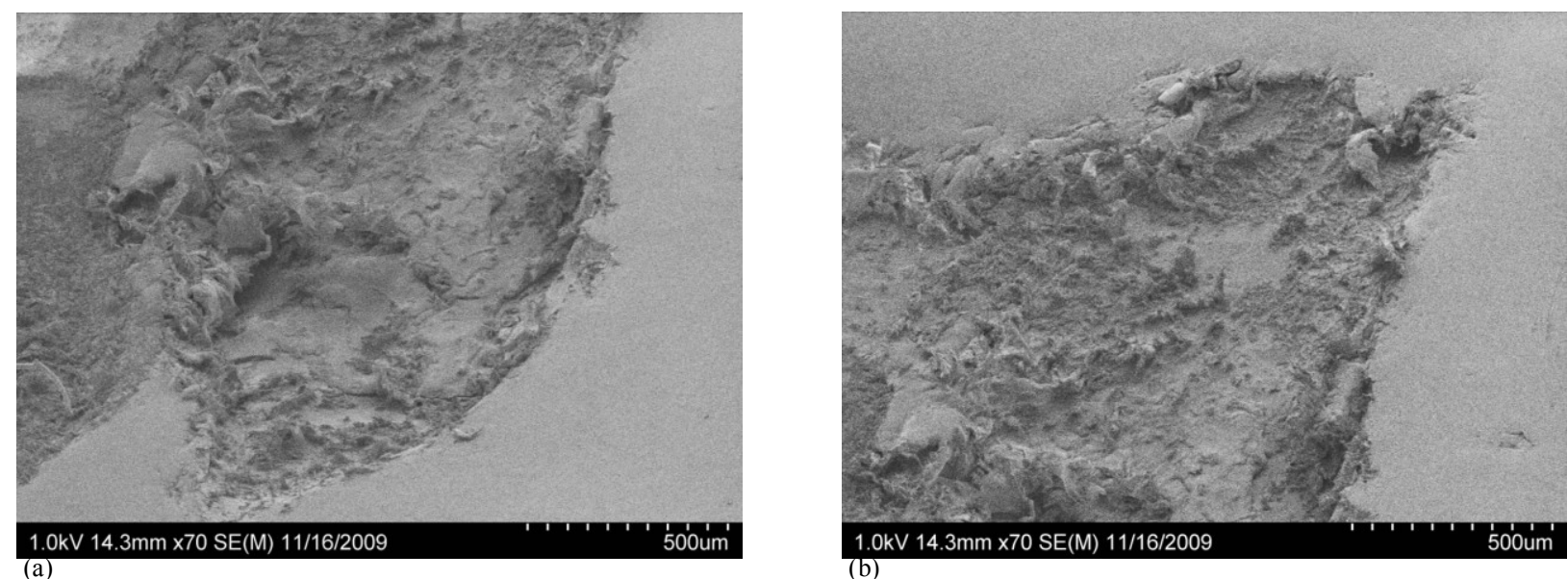

Figure 4.28: Patient $\mathrm{H}$ liner: (a) and (b) ductile fracture surfaces. 


\subsubsection{Femoral Heads}

Contact between a softer surface and a harder surface over a period of time should logically result in the wear of the softer material. Though this may be true, all four femoral heads proved otherwise. The Patient E femoral head had the most unimpaired surface save for scratches such as those in Figure 4.29a. Although, in a small area of the femoral head, large amounts of surface deposits and large wear tracks, Figure 4.29b-d were observed.

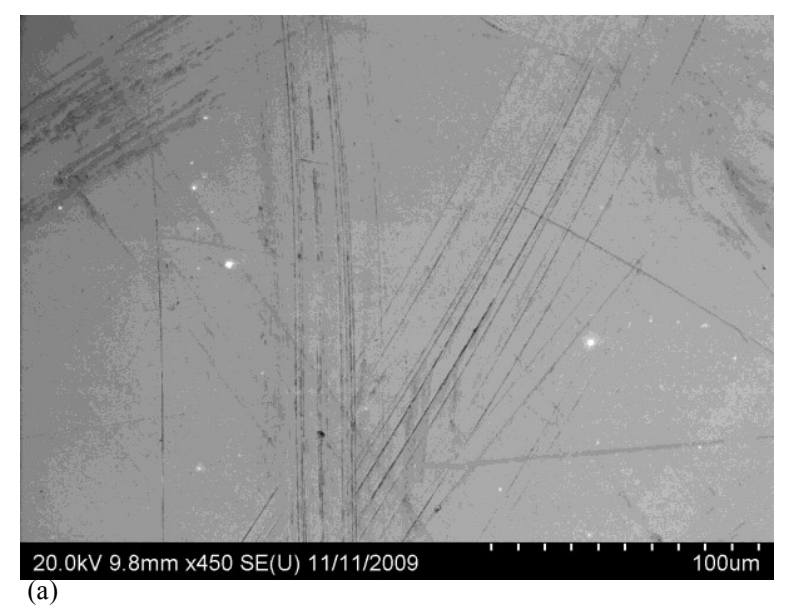

(a)

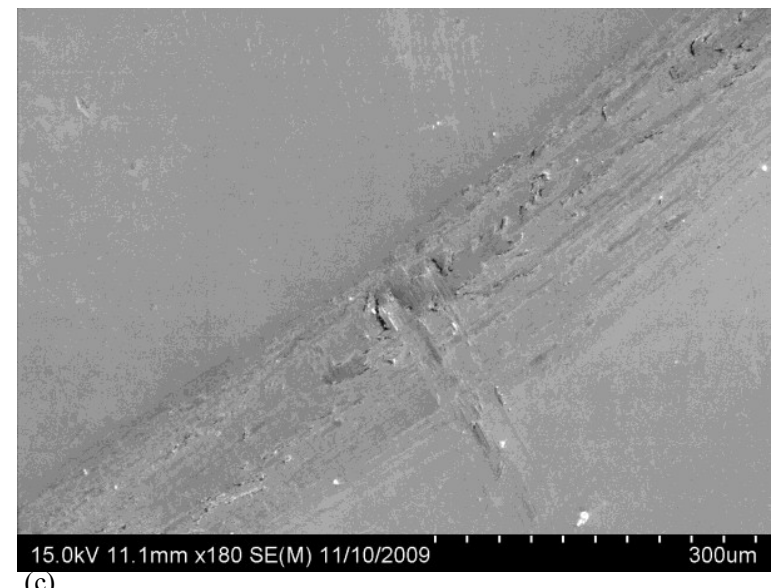

(c)
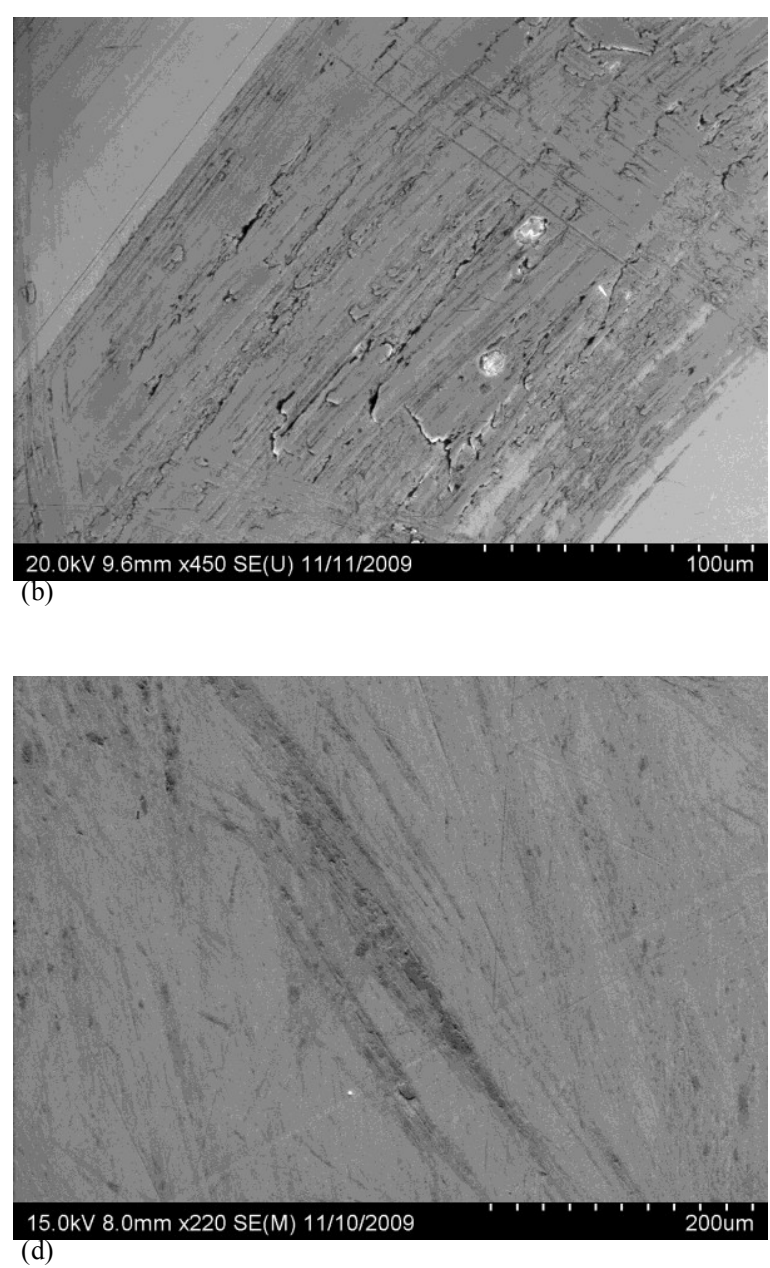

Figure 4.29: Patient E femoral head: (a) wear tracks and surface debris, (b) large streak of product deposit, (c) deposit and unimpaired surface, (d) wear tracks and product deposit. 
Further surface characterization of the Patient E femoral head was performed utilizing energy dispersive $\mathrm{x}$-ray spectroscopy (EDS). The energy spectrum of the surface deposit in Figure 4.30 revealed the typical alloying elements of the F75 alloy, and carbon, titanium, and aluminum. Another spectrum confirmed that the unknown product consisted of titanium and carbon, as well, Figure 4.31.

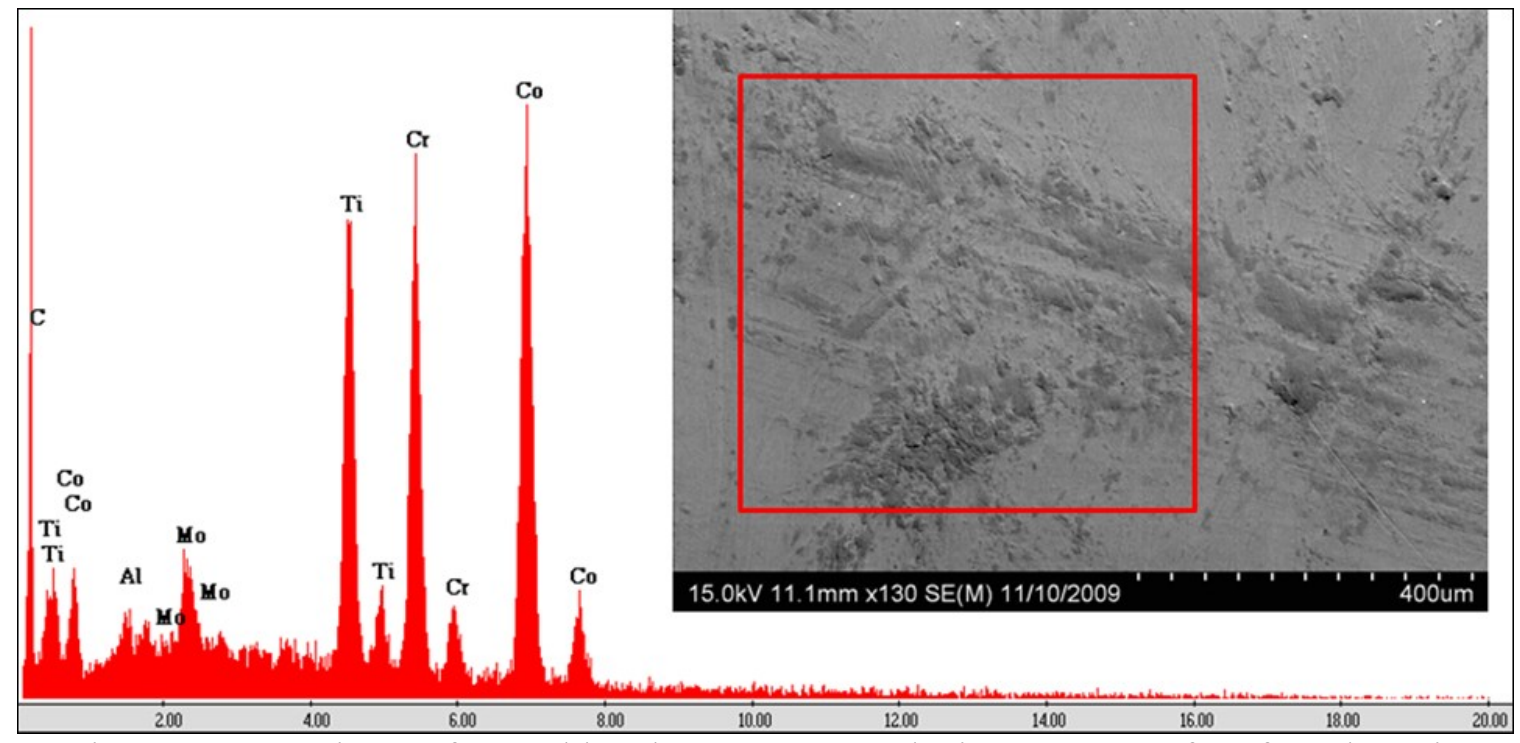

Figure 4.30: Patient E femoral head, EDS area analysis spectrum of surface deposit.

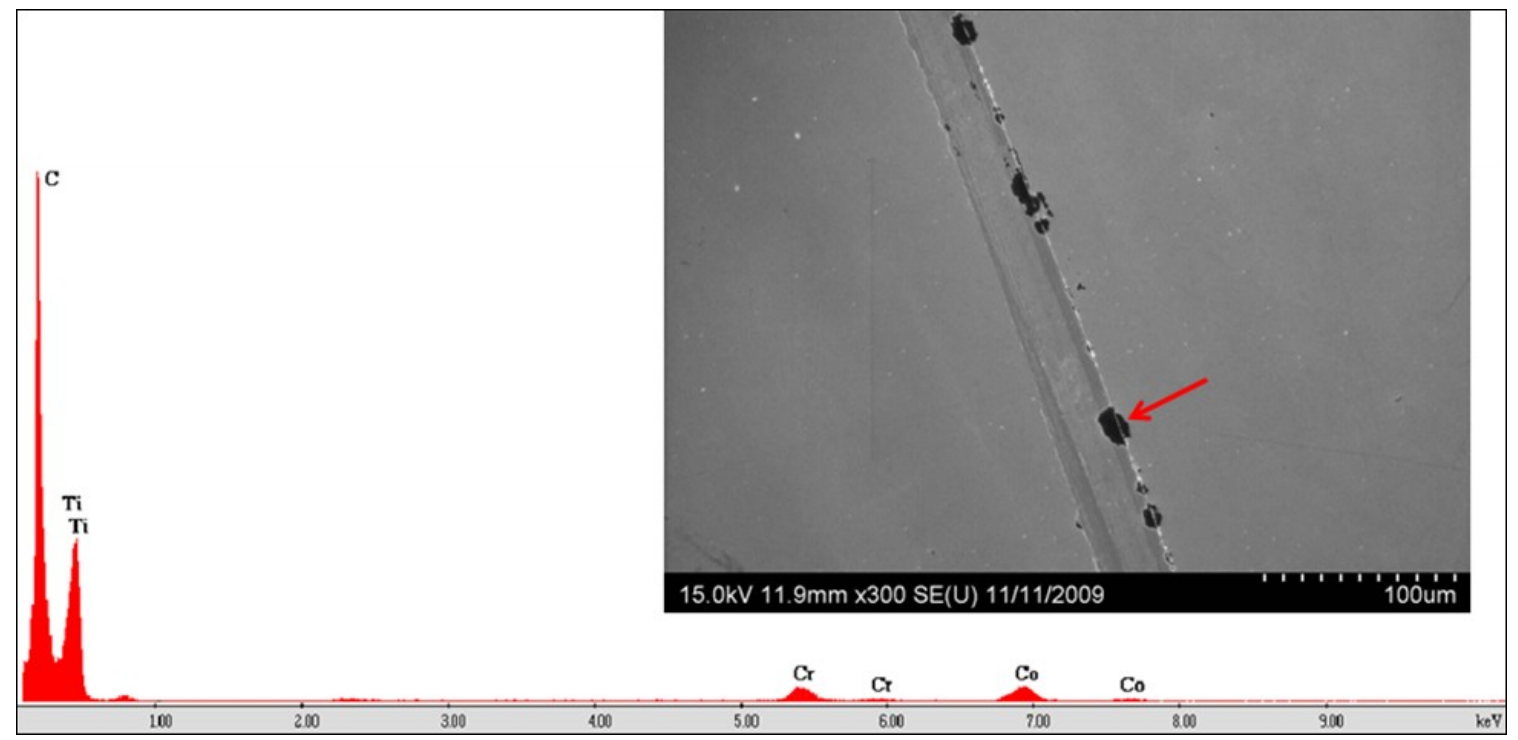

Figure 4.31: Patient E femoral head, EDS spot analysis spectrum of unknown product. 
The Patient W femoral head displayed the characteristic damage modes associated with a harder (metallic) component in contact with a softer (PE) component. During the visual examination, the Patient $\mathrm{W}$ femoral head in Figure 3.2 revealed a smooth, polished, semiunimpaired surface. During SEM, only wear tracks and pits were found, Figure 4.32a-d. While in service, hard third-body particles caught between the femoral head and PE liner can produce these types of characteristic wear tracks.

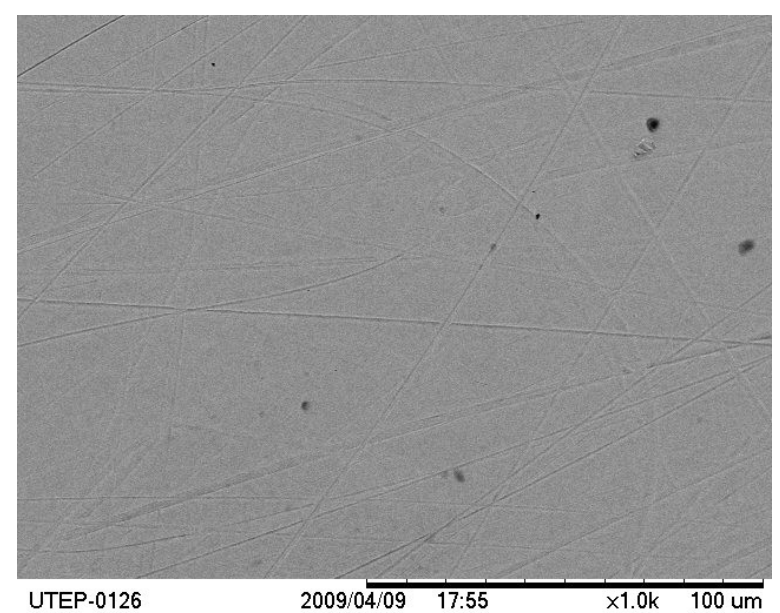

(a)

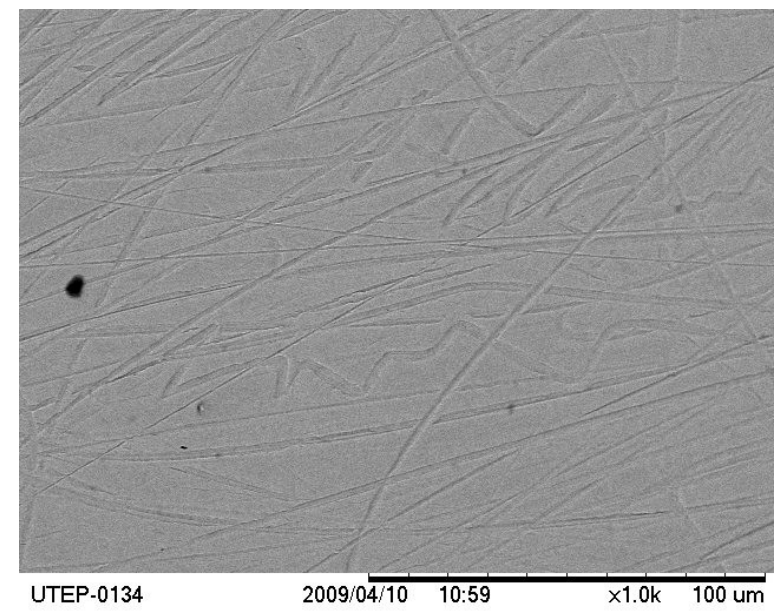

(c)

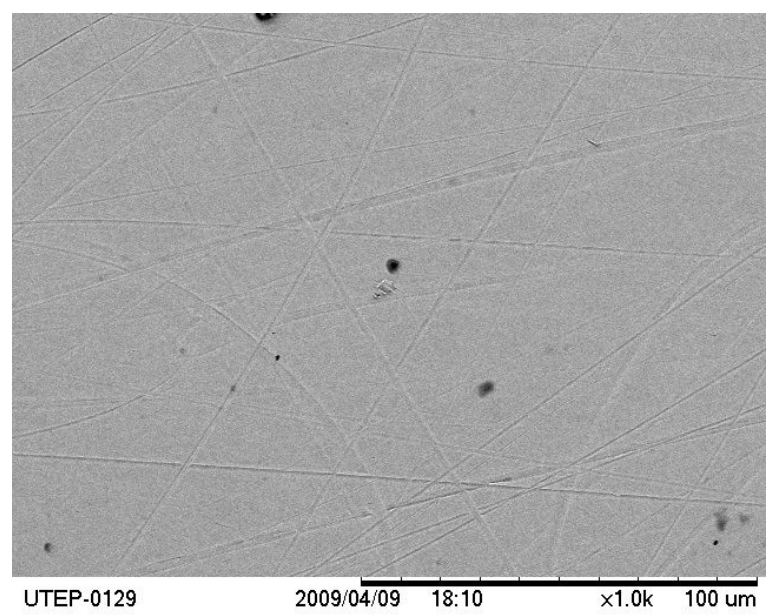

(b)

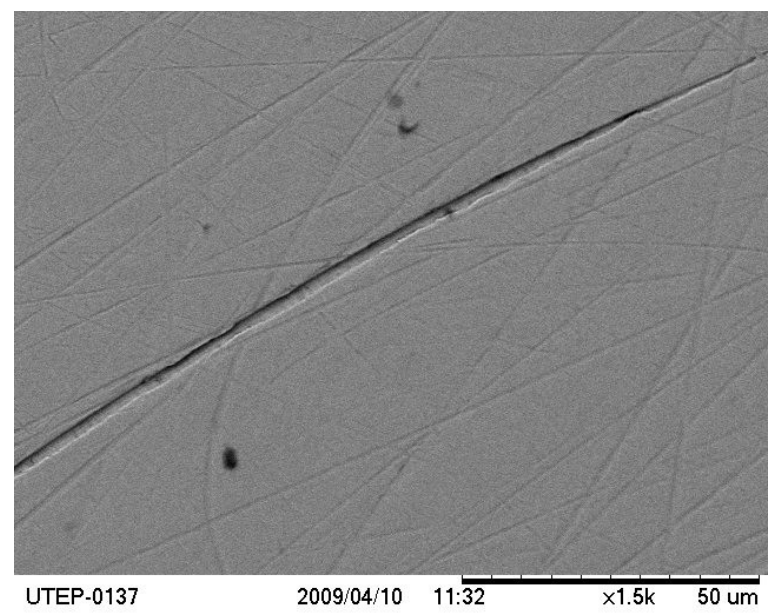

(d)

Figure 4.32: Patient W femoral head: (a) and (b) wear tracks and pits, (c) abnormal wear tracks, (d) large wear track. 
Of all four femoral heads, the Patient $U$ femoral head displayed the most severe deformation. As seen during the visual examination, Figure 3.4 displayed an incredibly dull component with questionable mechanical damage. In comparison with the wear tracks found on the Patient $\mathrm{W}$ femoral head, the Patient $\mathrm{U}$ femoral head consisted of densely filled scratches and abrasions with variable wear track sizes, Figure 4.33a. Crevices were also found dispersed throughout the surface, Figure $4.33 \mathrm{~b}$.

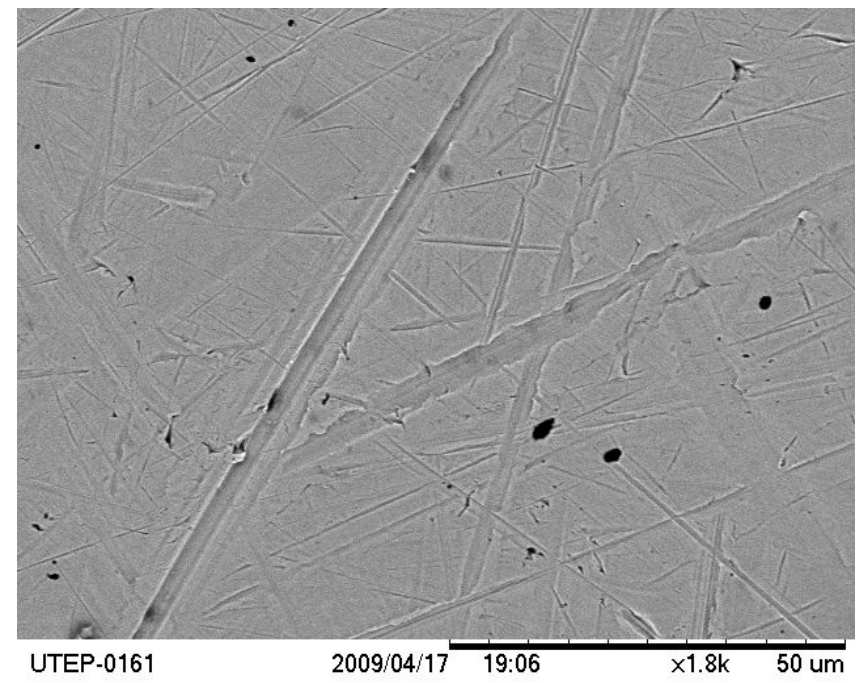

(a)

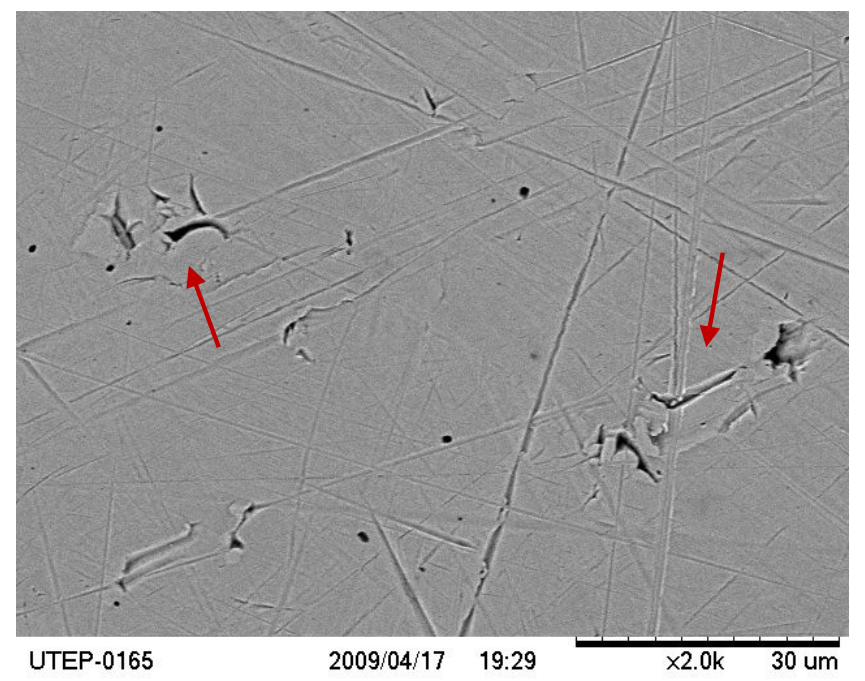

(b)

Figure 4.33: Patient U femoral head: (a) variable wear track sizes, (b) crevices. 
The remaining SEM images for the Patient $\mathrm{U}$ femoral head all display severe deformation that should not normally occur. The images in Figure 4.34a-d all displayed large amounts of plastic flow that resulted in crevices and scarring. As indicated by the arrows, pits were regularly found throughout the surface characterization. The crevices created in Figure 4.34b-d all have diameters of approximately $60 \mu \mathrm{m}$.
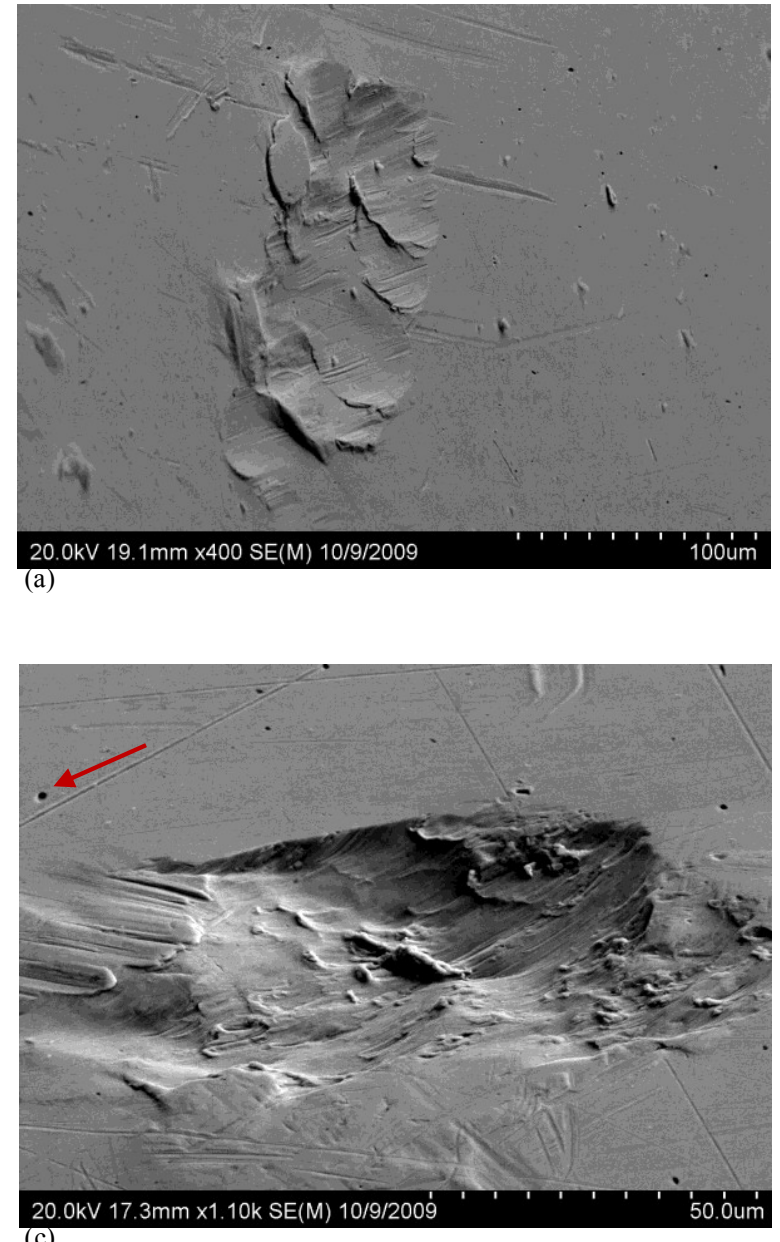

(c)
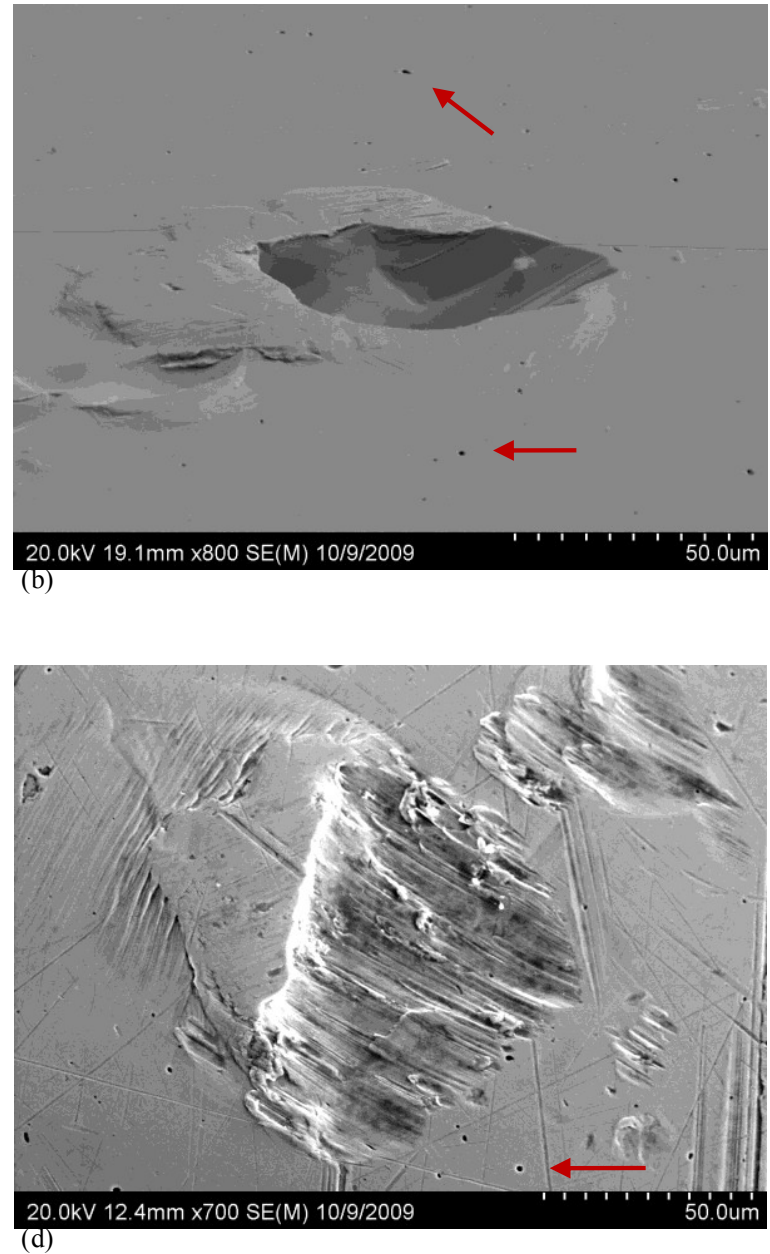

Figure 4.34: Patient U femoral head: (a)-(d) plastic flow and neighboring pits. 
In another region of densely packed scratches, plastic deformation and plastic flow we observed. The Patient U femoral head seem to have been pushed from many directions. A large crack was found along the deformed region. As indicated by the arrows in Figure 4.35a, the length of the crack is easily over $200 \mu \mathrm{m}$ in length. In Figure $4.35 \mathrm{~b}$, an unknown black product was also observed.

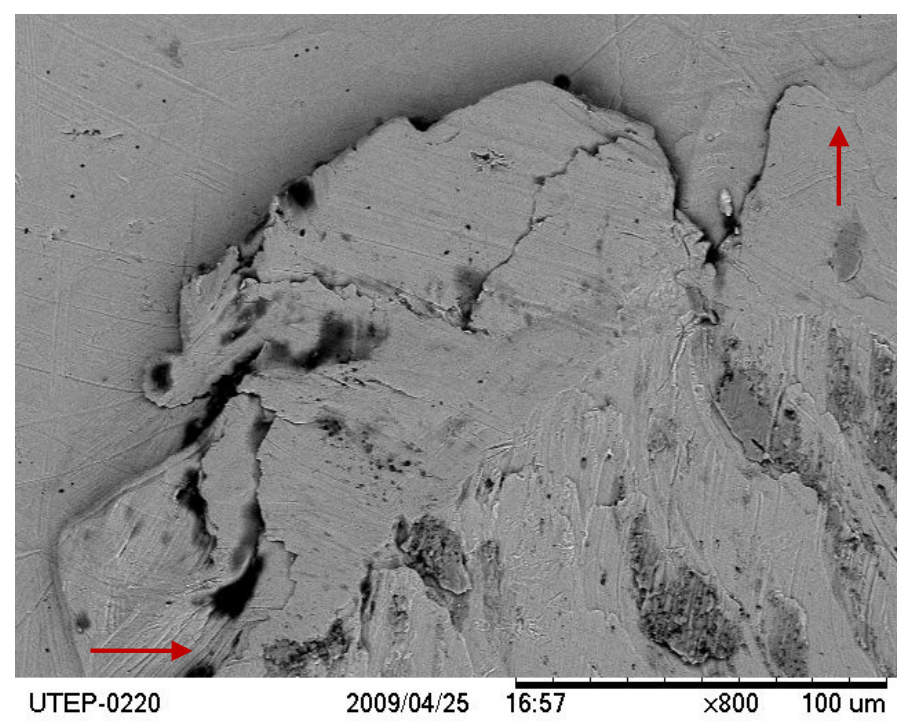

(a)

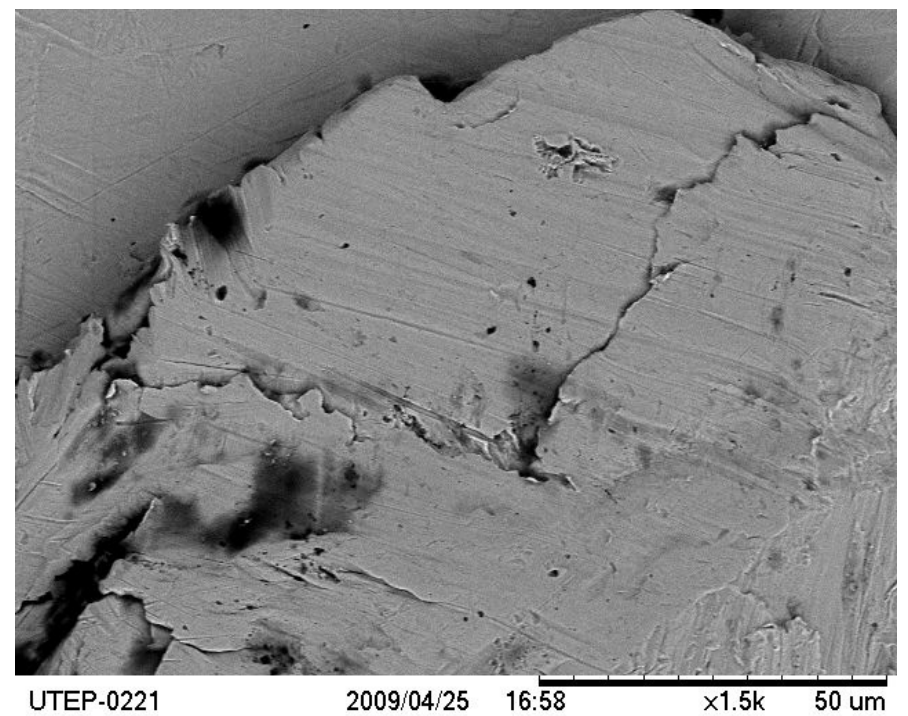

(b)

Figure 4.35: Patient $U$ femoral head: (a) severe deformation and plastic flow, (b) crack and unknown black product. 
Additional deformation features remain unique to the Patient $U$ femoral head. In Figure 4.36 to 4.39 , the images display damage modes in the forms of crevices, bulges, scarring, and areas containing an unknown surface deposit. The damage associated with this component had to have been the result of metal-on-metal contact because there is no way that the PE liner could produce these results. In Figure 4.40, EDS of the product revealed a composition of oxygen, aluminum, magnesium, and silicon. The possible magnesium aluminosilicates may be the surface contaminant.
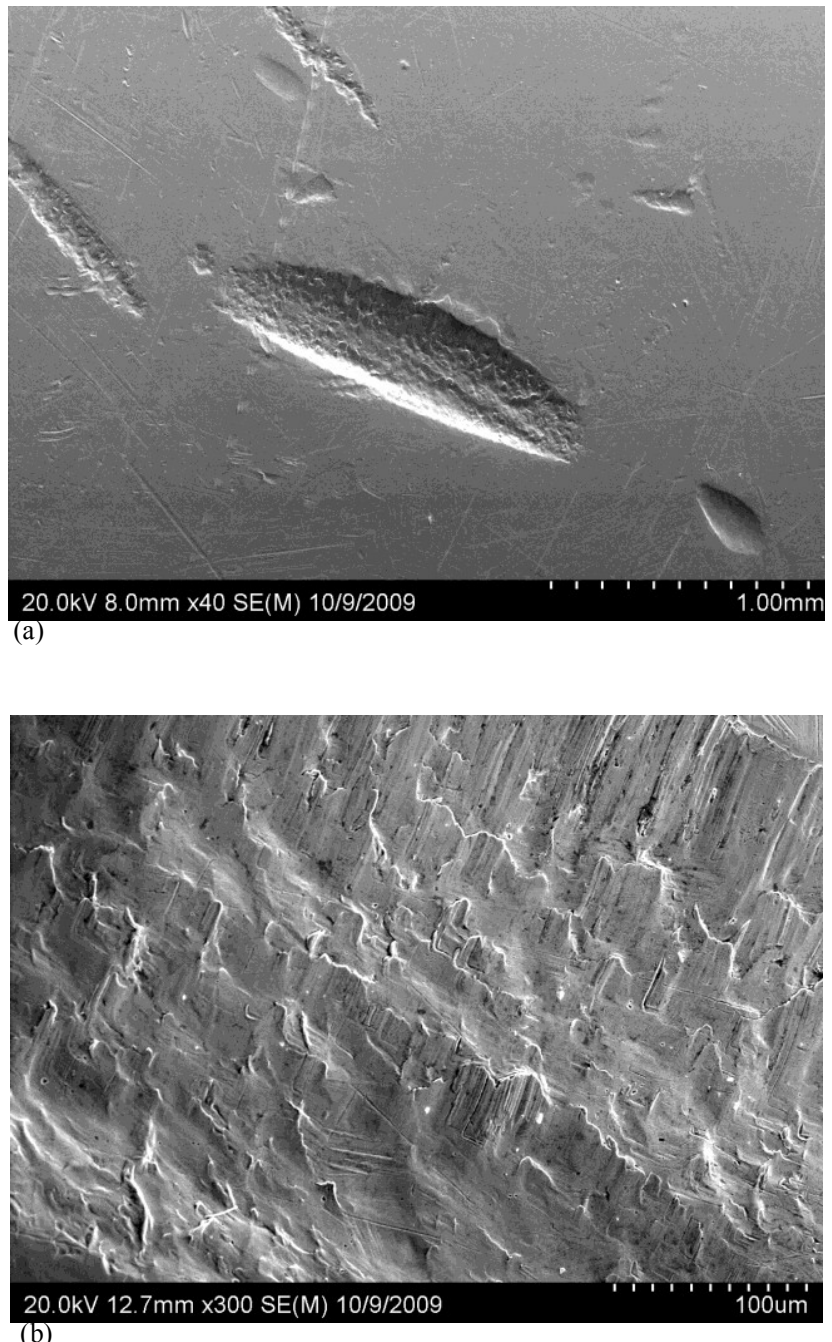

Figure 4.36: Patient U femoral head: (a) significant amount of large crevices (visible to the naked eye), (b) crevice scars. 


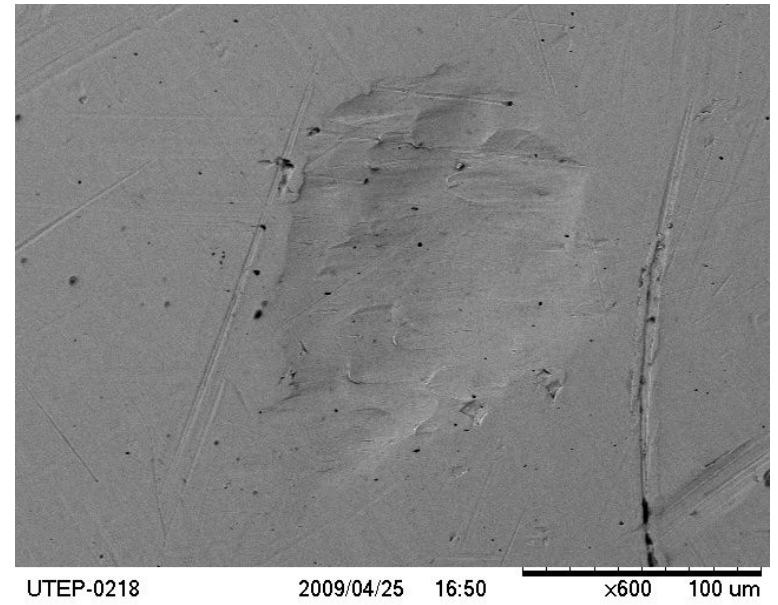

(a)

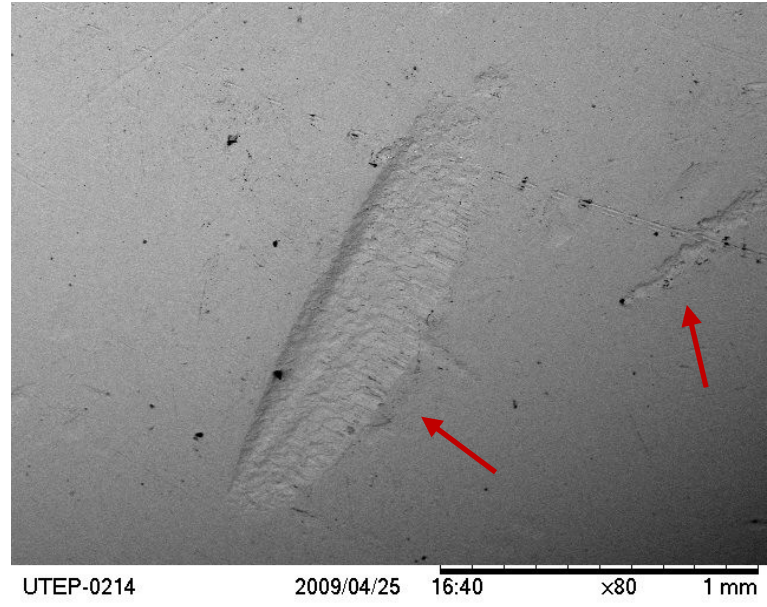

(b)

Figure 4.37: Patient U femoral head: (a) bulge with neighboring pits, (b) large bulge, smaller crevice, and wear tracks.

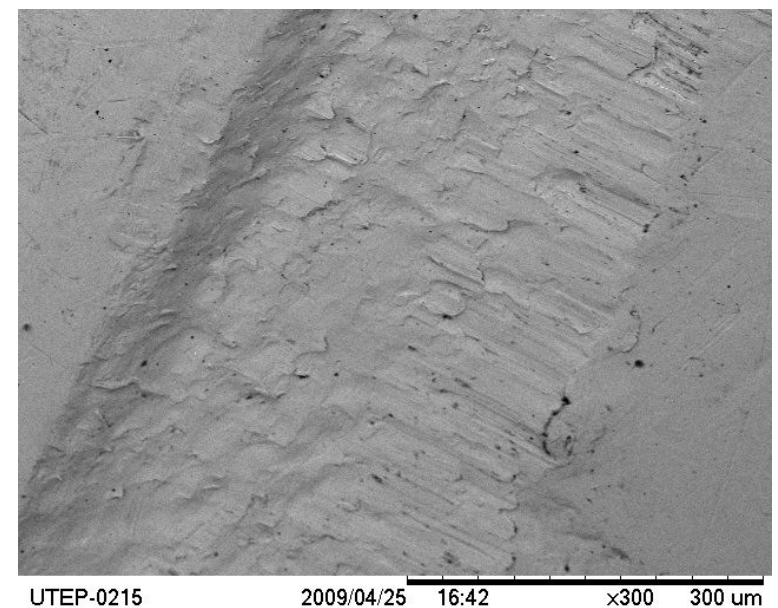

(a)

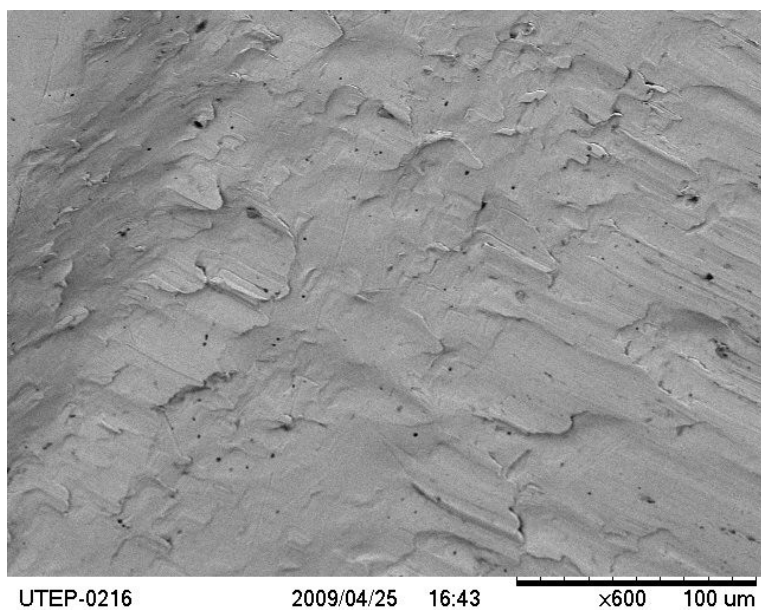

(b)

Figure 4.38: Patient U femoral head: (a) bulge with wear scars, (b) bulge at higher magnification. 


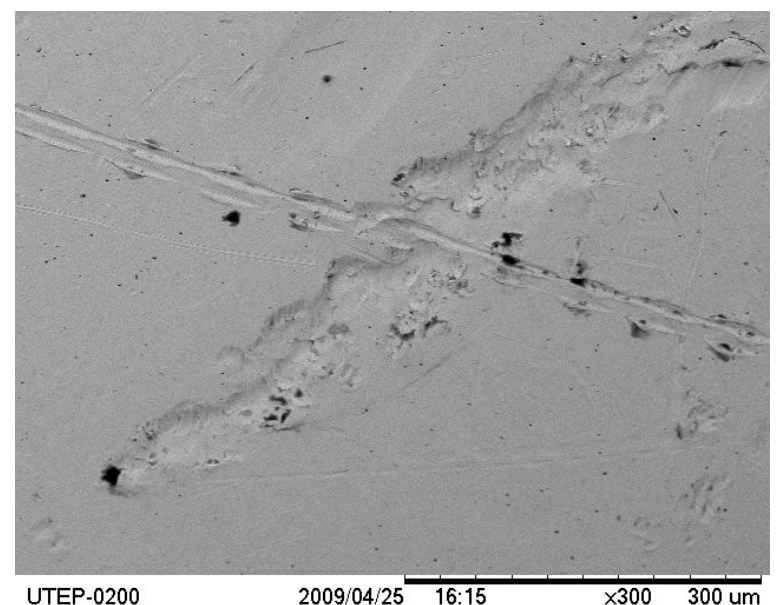

(a)

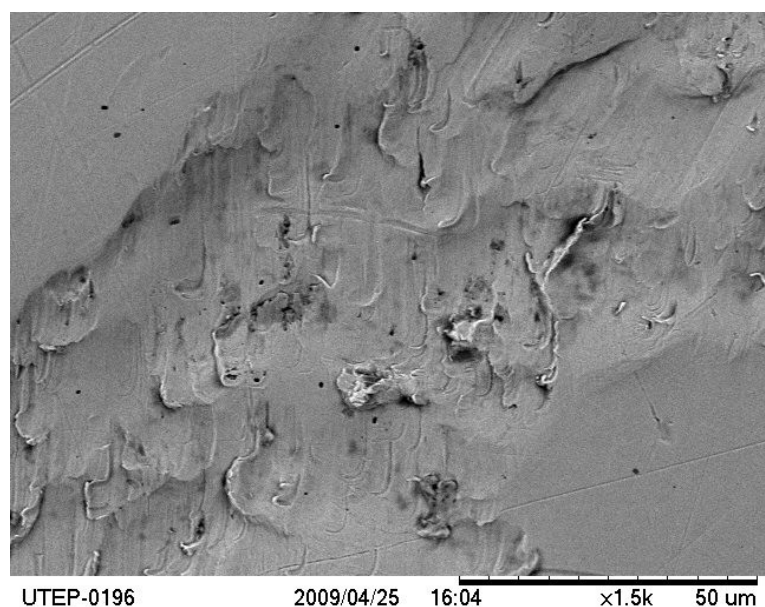

(b)

Figure 4.39: Patient U femoral head: (a) crevice with unknown product, (b) wear scars.

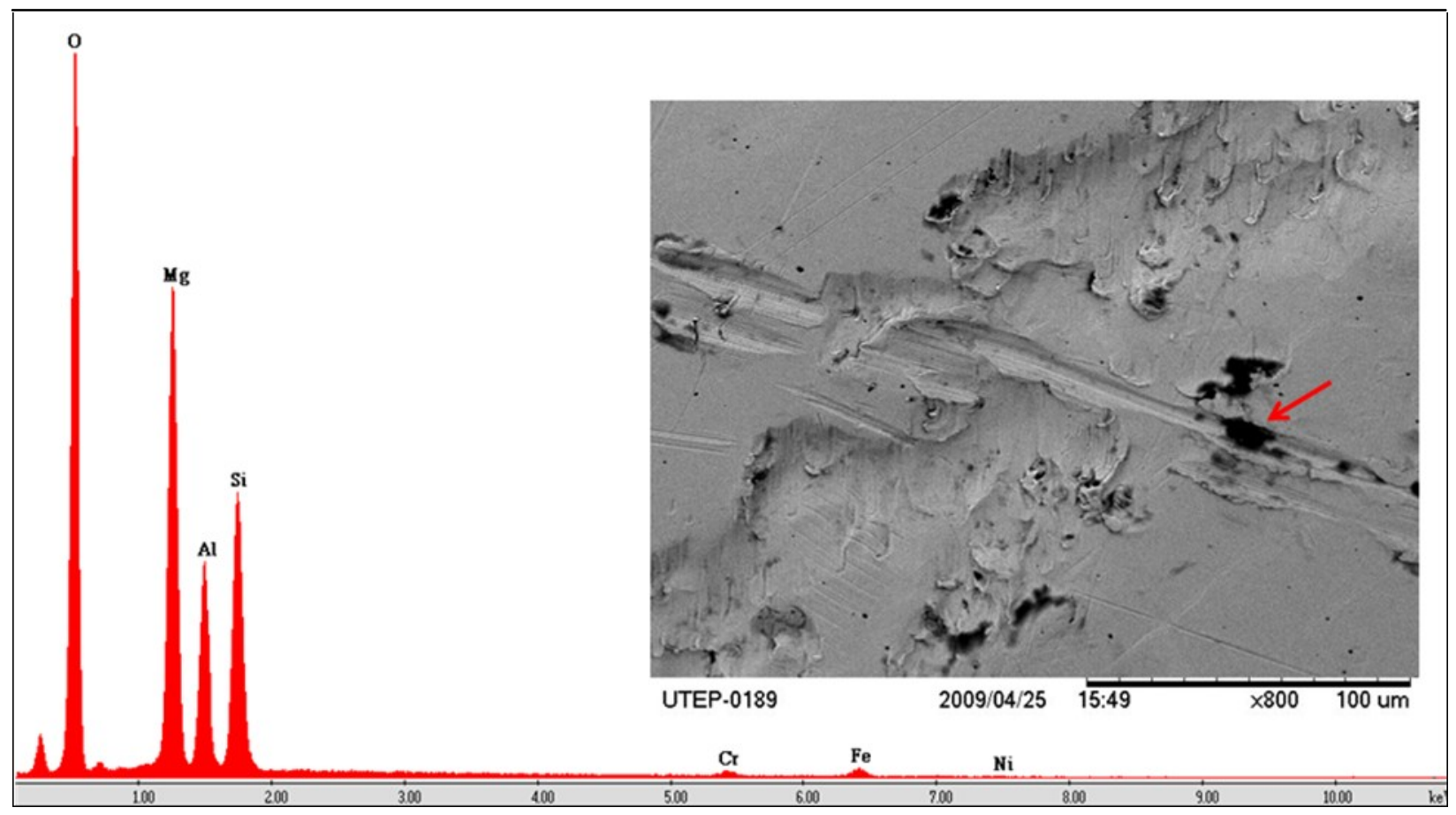

Figure 4.40: Patient U femoral head, EDS area analysis spectrum of unknown product. 


\subsubsection{Foreign Particle}

Upon SEM of the foreign particle from the Patient E liner, the particle had a round shape and a flat surface that made contact with the femoral head, Figure 4.41a and b. The EDS in Figure 4.42 revealed the particle to hold a composition of titanium, aluminum, and vanadium (i.e., Ti-6Al-4V).
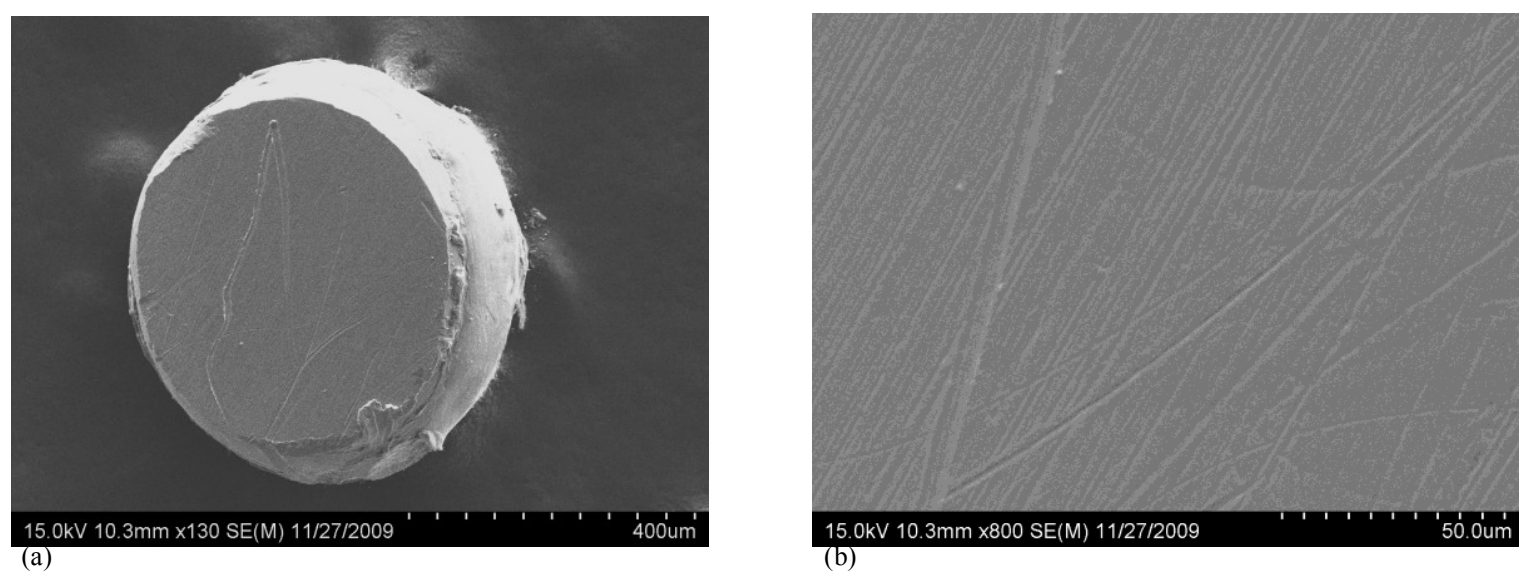

Figure 4.41: Patient E foreign particle: (a) round particle with flattened surface, (b) wear tracks.

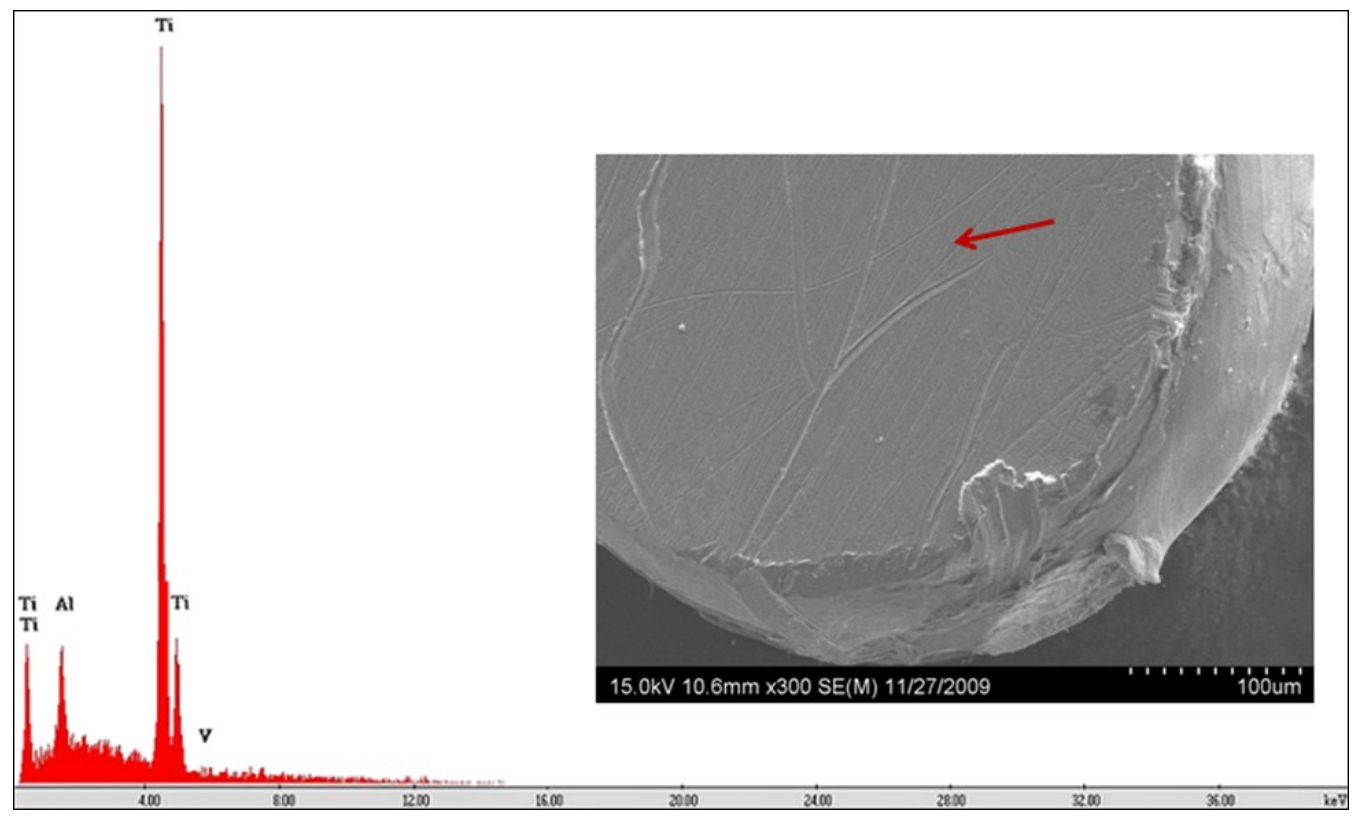

Figure 4.42: Patient E foreign particle, EDS spot analysis spectrum of foreign particle. 


\subsection{Discussion}

The Patient E liner had many scratches on the surface and rim. Found in the socket of the PE liner were two metallic "rods" that at first glance, during the visual examination, were considered to have been strategically placed by DePuy Orthopaedics, Inc. Further, upon dye penetrant inspection (DPI), many indentations with similar diameters were situated around a rod that was closer to the flat surface of the liner. Characterization by SEM found that the "rods" were most likely the cause of the indications. The indentations had particle tracks that led to or away from each area. At higher magnifications, it seemed as though the "rods" faced lateral loads which was supported by the plastic flow lines of the PE in at least two loads. These thirdbody particles came between the PE and metallic counterfaces. In terms of wear between contact of a harder surface and a softer surface, the softer material will wear faster. Maximum efficiency of the THA requires smooth movement between the femoral head and acetabular components. When particles come between the components, this creates friction and wear that disrupt motion and can cause discomfort to the patient. The oddity is that the component remained in service for 12 years, so these particles were most probably recent causes for deformation of the two components. EDS on a removed "rod" confirmed that the foreign particle is Ti-6Al-4V. Since titanium has a much higher hardness than both the PE and cobalt-alloy, this would definitely attribute to the wear of both components. The associated femoral head, Patient E, is a cast F75 co-based alloy with the main elements being cobalt, chromium, and molybdenum, with the correct microstructure of dispersed carbides. The majority of the head surface was unimpaired,

as seen in Figure 3.1, save for a small area of distinct scratches and surface deposits. It is possible that the titanium and aluminum elements found in the surface deposits coincide with 
that of the Ti-6Al-4V foreign particle. Since the particle revealed wear marks it did make contact with the femoral head.

Most damage associated with Patient W liner was on the rim surface. On the proximal region of the liner, a fairly large area was plastically deformed. SEM revealed plastic flow and wear tracks. There were a few scratches in which it was difficult to conclude if they were created in vivo or before component fabrication. Machine marks on the previously mentioned scratches and deformed regions were found. These marks indicate the possibility that defects can be formed during fabrication. The Patient $\mathrm{W}$ femoral head mainly displayed wear tracks and wear with third-body particles. In order for the femoral head to be deformed, the wear particle must have had an equally or greater hardness than the cobalt-based alloy.

The Patient $\mathrm{H}$ liner had the largest amount of socket damage. A visibly large area of adhesive wear was located in the proximal region of the femoral head. Under SEM, the area displayed ductile fracture zones. It appeared as though PE material was ripped off the surface. Another similar, though smaller, area of abrasive wear was situated to the left of the large spot in the superior region. Found during DPI, Patient E liner had a large amount of external damage. One specific area of the rim was severely deformed and cracked. The rim had multiple diagonal hash marks and scratched that had a "smeared" effect. Since the PE liners are secured in place with the acetabular shell, bending and flexing loads over the 10+ years of service may have been the cause for such damage. In another area of the rim, a large crack running parallel to rim surface was also discovered. The associated Patient $\mathrm{H}$ femoral head is also a cast F75 cobaltalloy component with a similar microstructure to that of Patient E. The surface of the femoral head had few scratches but was generally unimpaired, save for burnishing of the neck due to contact and micromotions with the femoral stem. 
Though the Patient $U$ case was based upon aseptic mechanical loosening of the femoral stem, it is odd that the stainless steel femoral head should display such a great amount of physical damage. Specifically with this component is it hard to distinguish with damage caused in vivo. The surface of the femoral head contained an immense amount of scratches that caused the once polished surface to appear dull, as can be seen in the visual examination image of Figure 3.4. Upon visual examination the surface consisted of scratches and indentations. The indentations were randomly spread over the surface and had varying diameters and depths of penetration. It is especially with this sample that characterization is difficult. Although the case came with a full background, it remained difficult to characterize damage modes with mechanical damage that may have been induced during implantation or revision. An interesting aspect discovered during SEM, was that many areas of the femoral head contained large amounts of plastic flow, cracks, smears, and surface deposits. Considering that the harder femoral head was in contact with the softer PE, the PE should be the component to have the greater amount of wear and deformation. Large areas of scarring and cracks also contained a black product. With the use of EDS, the spectrum acquired displayed the product to have remnants of $\mathrm{Mg}, \mathrm{Al}, \mathrm{Si}$, and O. Previous research in the areas of failed stainless steel hip components has found that the scars are indicative of corrosive attack. XRF of the acetabular shell revealed a $99.53 \%$ pure titanium component with a small alloying addition of Fe. Again, no true answer can be provided based on the fact that transportation and containment of the component is unknown. It is an interesting fact is that these scars and products were discovered on the proximal region of the femoral head, exactly where the component makes full contact with the PE liner. Even during revision surgery, the femoral head is typically retrieved with instrumentation in the distal region where the head 
makes contact with the neck of the femoral stem. As far as retrieval goes, this specific area of the component should not have been mechanically affected. 


\section{Chapter 5: Conclusions}

\section{$5.1 \quad$ Summary}

This research involved the failure analysis and materials characterization of UHMWPE liners, metallic femoral heads, and an acetabular shell. Three sets of components and patients history were provided by Dr. Richard Westbrook of the El Paso Orthopaedic Surgery Group. The fourth set was provided by a surgeon from Mexico City, Mexico.

The overall chance of a hip replacement lasting 20 years is approximately $80 \%$ [1]. The variables that affect implant duration include the patients' background, activity, and lifestyle. The sex, age, and weight of a THA recipient can greatly affect the outcome. For people who are more active, typically younger THA patients, the implant lifetimes can be seriously decreased. When a THA is performed, it is best that the patient continues to lead a much more relaxed lifestyle to help reduce the wear upon such components. Depending on the size of the person, there are many options from sizes, textures, and biomaterials can be of use. In vivo variables that cause component damage are wear mechanisms and third-body particles such as metal, bone, or polymethyl methacrylate (PMMA) bone cement particles.

The UHMWPE components in this research demonstrated many of the damage modes associated with wear, such as: abrasion, adhesion, wear tracks, and fatigue. Plastic deformation of such biomaterials is generally expected upon retrieval. Unique to one case were indentations with complex morphologies and slight amounts of plastic flow. The femoral heads, consisting of stainless steel and cobalt-based materials also demonstrated abrasive damage such as scratches and plastic deformation. 
The forms of wear observed were difficult to assess in terms of distinguishing damage sustained in service and damage induced in installation/revision and part surgical removal. An example of after service damage can be found in the retrieval of such components. The revision total hip arthroplasty (THA) involves the use of many instruments for component retrieval. The newer method of separation of the femoral head from the femoral stem is the use of a ballistic chisel powered by controlled bursts of pressurized nitrogen [59]. Once the femoral head is loosened by the chisel, the surgeon can easily remove it by hand. Though the chisel is used on the distal region of the femoral heads, mechanical damage can be found. Aside from removal, it is necessary to safely contain retrieved components and ensure their safety during transportation. Therefore, without complete patient information and history, the forms of damage observed throughout this research are difficult to quantify.

It was also concluded that the wear damage observed was not construed to be severe and debilitating. As a result, removal and/or replacement of the components may have been for other reasons. One must remember that the purpose of revision hip arthroplasties may take root with problems other than with the components themselves. Previous cases have shown that the patient may have developed an infection due to foreign body reaction, broken bones, or periprosthetic osteolysis, etc. [44]. In such cases the surgeons may replace components for safety precautions. Further inspection of these components and additionally failed hip implants with detailed backgrounds would be required obtain more concrete conclusions. 


\subsection{Recommendations}

As wear remains one of the largest failure mechanism associated with decreased lifetimes of UHMWPE liners, techniques that measure wear rate should be employed. After sterilization and packaging, the vendors should request that profilometry of the liners be performed. Profilometry can provide detailed surface information such as: (1) arithmetic mean derivation of the roughness profile, (2) root-mean-squared (RMS) deviation of the roughness profile, (3) $\max$ peak height, (4) max valley depth, (5) total height, and (6) max height. The illustration in Figure 5.1 presents an example of the surface plot that profilometry software can produce. After the component retrieval from the revision surgery the components would undergo final profilometry testing to gather the new surface roughness data. With the initial and final surface roughness values, the amount of material lost to wear can be acquired.

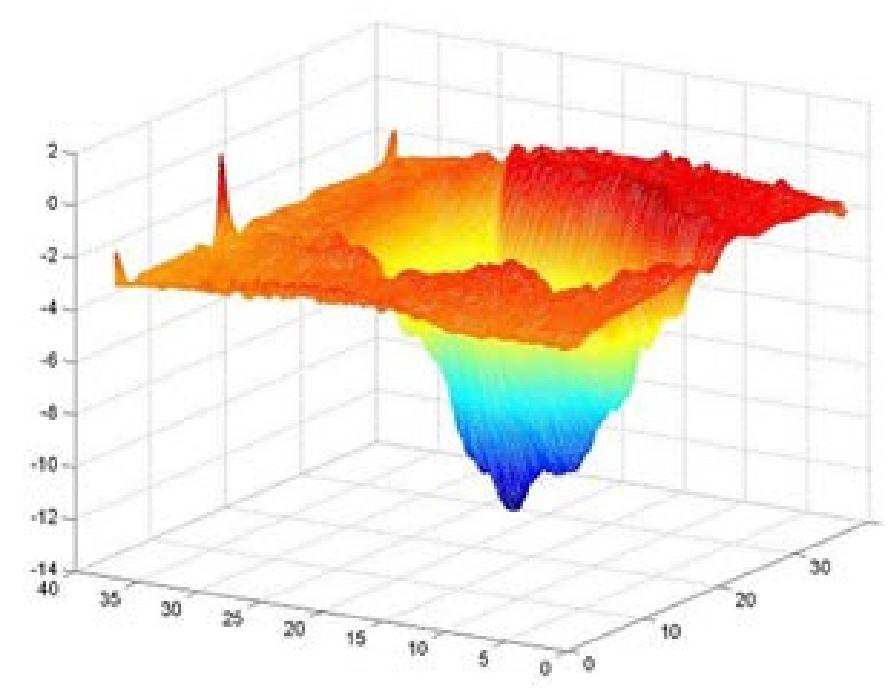

Figure 5.1: Surface profilometry plot. [60] 
To get quantitative wear values, equations such as that of volumetric wear rate (VWR) can be applied to the UHMWPE components at the retrieval [34]. The equation is:

$$
\mathrm{VWR}=\mathrm{A} \times \mathrm{LWR}=(\pi / 4) \times \mathrm{D}^{2} \times(\Delta \mathrm{P} / \Delta \mathrm{t})
$$

where,

$$
\begin{aligned}
& \mathrm{A}=\text { circular area of the femoral head } \\
& \mathrm{LWR}=\text { linear wear rate }=(\Delta \mathrm{P} / \Delta \mathrm{t}) \\
& \mathrm{D}=\text { femoral head diameter } \\
& \Delta \mathrm{P}=\text { change in apparent femoral head penetration } \\
& \Delta \mathrm{t}=\text { change in time }
\end{aligned}
$$

Damage scoring of polyethylene components can also provide a method for quantification of damage sustained on retrieved components. In related methods, semiquantitative wear damage scoring methods have been developed for UHMWPE inserts in total knee replacements (TKR). By applying a similar method that assigns scores of severity of pitting, scratching, burnishing, delamination, third-body debris, abrasion, and cold flow, a total damage score, for UHMWPE liners in THAs can be achieved [61]. 


\section{References}

[1] American Academy of Orthopaedic Surgeons. (2009, September 3). Hip Implants. Retrieved from Your Orthopaedic Connection website:

http://orthoinfo.aaos.org/topic.cfm?topic=A00355

[2] Clarke, Ian, Hywel Jones, and Darren Swinson. (2009, September 3). Biomaterials - An Overview. Retrieved from AZoM - The A to Z of Materials website:

http://www.azom.com/Details.asp?ArticleID=108

[3] American Academy of Orthopaedic Surgeons. (2009, September 7). Total Hip Replacement. Retrieved from Your Orthopaedic Connection website: http://orthoinfo.aaos.org/topic.cfm?topic=A00377

[4] National Institute of Arthritis and Musculoskeletal and Skin Diseases. (2009, October 26). Hip Replacement. Retrieved from http://www.niams.nih.gov/Health_Info/Hip_Replacement/default.asp

[5] Schiel, William C. Jr., and Dennis Lee. (2009, October 26). Total Hip Replacement Surgery Description, Complications and Recovery. Retrieved from MedicineNet website: http://www.medicinenet.com/total_hip_replacement/article.htm

[6] Zhan, Chunlin, et al. "Incidence and Short Term Outcomes of Primary and Revision Hip Replacement in the United States." Journal of Bone and Joint Surgery. 89A.3 (2007): 526-533. doi: 10.2106/JBJS.F.00952

[7] Schiel, William C. Jr., and Melissa Conrad Stoppler. (2009, October 14). Arthritis Causes, Symptoms, Diagnosis and Treatment Information. Retrieved from MedicineNet website: http://www.medicinenet.com/arthritis/article.htm

[8] Bhat, Sujata V. Biomaterials (2 ${ }^{\text {nd }}$ ed.). Harrow, UK: Alpha Science International Ltd., 2005.

[9] Sarkar, Michael R. "Acute Total Hip Replacement for Displaced Acetabular Fractures in Older Patients." European Journal of Trauma. 30.5 (2004): 296-304. doi: 10.1007/s00068-004-1351-7

[10] Eustice, Carol, and Richard Eustice. (2009, October 29). Advances in Hip Replacement Surgery: Cemented vs. Cementless Implants. Retrieved from About.com:Arthritis website: http://arthritis.about.com/cs/jtreplace/a/cement.htm

[11] Black, J., et al. "In vivo wear of Ti6Al4V femoral heads: A retrieval study." Journal of Biomedical Materials Research Part A. 32.3 (1996): 447-457. doi: 10.1002/(SICI)10974636(199611)32:3<447::AID-JBM19>3.0.CO;2-D 
[12] Smith, Evert. (2009, April 22). Innovations in Total Hip Replacement. Retrieved from http://evertsmith.com/img/content/480-hip-components.jpg

[13] Solid freeform fabrication. (n.d.). In Wikipedia. Retrieved October 28, 2009, from http://en.wikipedia.org/wiki/Solid_freeform_fabrication

[14] Gaytan, Sara, et al. "Advanced metal powder based manufacturing of complex components by electron beam melting." Materials Technology. 24.3 (2009): 180-191. doi: 10.1179/106678509X12475882446133

[15] Lindhe, Ulf, and Ola Harrysson. (2009, October 24). Rapid Manufacturing with Electron Beam Melting (EBM) - A Manufacturing Revolution?. Retrieved from Arcam AB website: http://www.arcam.com/Downloads/PDF/SME_aug_18/Arcam_SME\%20presentation_De arborn_0818.pdf

[16] Solid freeform fabrication. (n.d.). In Wikipedia. Retrieved September 10, 2009, from http://en.wikipedia.org/wiki/Bone_cement

[17] Arola, D., K.A. Stoffel, and D.T. Yang. "Fatigue of the Cement/Bone Interface: The Surface Texture of Bone and Loosening." Journal of Biomedical Materials Research B: Applied Biomaterials. 76B.2 (2006): 287-297. doi: 10_1002/jbm.b.30364

[18] Granholm, John W. "Computer Design of Custom Femoral Prostheses." IEEE Computer Graphics and Applications. 7.2 (1987): 26-35 1987. doi: 10.1109/MCG.1987.277103

[19] Stryker. (2009 September 25). Fit and Fixation. Retrieved from About Stryker website: http://www.aboutstryker.com/images/hip/femoral-stems.jpg

[20] University of Missouri School of Medicine. (2009, November 12). Hip and Knee Surgery. Retrieved from http://som.missouri.edu/ortho/hipandknee/generalquestions.html\#weight

[21] Nakoshi, Yutaka, et al. "A long-term follow-up study of the cementless THA with anatomic stem/HGPII cup with 22-mm head.” International Orthopaedics. 33.2 (2009): 381-385. doi: $10.1007 / \mathrm{s} 00264-007-0505-8$

[22] Stevenson, M.E., M.E. Barkey, and R.C. Bradt. "Fatigue Failures of Austenitic Stainless Steel Orthopedic Fixation Devices." Journal of Failure Analysis and Prevention. 2.3 (2002): 57-64. doi: 10.1007/BF02719191

[23] Fante's Kitchen Wares Shop. (2009 November 9). Stainless Steel. Retrieved from http://www.fantes.com/stainless-steel.html

[24] Becker, William T., and Roch J. Shipley (Eds.). ASM Handbook: Heat Treating (Vol. 4). Materials Park, Ohio: ASM International, 2002. 
[25] Xulin, Sun, et al. "Fretting corrosion resistance and fretting corrosion product cytocompatibility of ferritic stainless steel." Journal of Biomedical Materials Research Part A. 34.1 (1996): 9-14. doi: 10.1002/(SICI)1097-4636(199701)34:1<9::AIDJBM2>3.0.CO;2-V

[26] Allain, J., et al. "Failure of a Stainless-Steel Femoral Head of a Revision Total Hip Arthroplasty Performed after a Fracture of a Ceramic Femoral Head." The Journal of Bone and Joint Surgery. 80-A.9 (1998): 1255-1360.

[27] Saldivar-Garcia, A.J., and H. F. Lopez. "Microstructural effects on the wear resistance of wrought and as-cast Co-Cr-Mo-C implant alloys." Journal of Biomedical Materials Research Part A. 74A.2 (2005): 269-274. doi: 10.1002/jbm.a.30392

[28] Ratner, Buddy D., et al. Biomaterials Science (2 ${ }^{\text {nd }}$ ed.). New York: Elsevier Inc., 2004.

[29] Chiba, Akihiko, Naoyuki Nomura, and Yoshiki Ono. "Microstructure and mechanical properties of biomedical $\mathrm{Co}-29 \mathrm{Cr}-8 \mathrm{Mo}$ alloy wire fabricated by a modified meltspinning process." Acta Materialia. 55.6 (2007): 2119-2128. doi:10.1016/j.actamat.2006.10.060

[30] Lyman, Taylor (Ed.). Metals Handbook: Atlas of Microstructures of Industrial Alloys ( $2^{\text {nd }}$ ed., Vol. 4). Metals Park, Ohio: American Society for Metals, 1972.

[31] Hallab, James Nadim. "Differences in the fretting corrosion of metal-metal and ceramicmetal modular junctions of total hip replacements." Journal of Orthopaedic Research. 22.2 (2004): 250-259. doi: 10.1016/S0736-0266(03)00186-4

[32] Cawley, J., J.E.P. Metcalf, and A.H. Jones. "A tribological study of cobalt chromium molybdenum alloys used in metal-on-metal resurfacing hip arthroplasty." Wear. 255.7-12 (2003): 999-1006. doi: doi:10.1016/S0043-1648(03)00046-2

[33] Black, Jonathan. Biological Performance of Materials: Fundamentals of Biocompatibility ( $4^{\text {th }}$ ed.). New York: CRC Press Taylor and Francis, 2006.

[34] Kurtz, Steven M. The UHMWPE Handbook: Ultra High Molecular Weight Polyethylene in Total Joint Replacement. New York: Elsevier Inc., 2004.

[35] Lewis, Gladius. "Polyethylene Wear in Total Hip and Knee Arthroplasties." Journal of Biomedical Materials Research Part B: Applied Biomaterials. 38.1 (1997): 55-75.

[36] McKellop, Harry., et al. "Development of an Extremely Wear-Resistant Ultra High Molecular Weight Polyethylene for Total Hip Replacements." Journal of Orthopaedic Research. 17.2 (1999): 157-167. doi: 10.1002/jor.1100170203

[37] Wear. (n.d.). In Wikipedia. Retrieved September 24, 2009, from http://en.mWikipedia.org/wiki/Wear?wasRedirected=true 
[38] Becker, William T., and Roch J. Shipley (Eds.). ASM Handbook: Failure Analysis and Prevention (Vol. 11). Materials Park, Ohio: ASM International, 2002.

[39] DePuy International Ltd. (2005). The DePuy ASR XL Head System [PowerPoint Slides] Retrieved from http://www.articularsurfacereplacement.com/fileadmin/user_upload/professional_healthc are/downloads/asr_xl_heads_pr.pdf

[40] Rogers, Susan D., et al. "A Method for Production and Characterization of Metal Prosthesis Wear Particles." Journal of Orthopaedic Research. 11.6 (1993) 856-864. doi: 10.1002/jor.1100110612

[41] Dumbleton, John H. Tribology of Natural and Artificial Joints (Series 3). New York: Elsevier Scientific Publishing Company, 1981.

[42] Ohnsorge, Jorg Axel Karl. "Early Polyethylene Wear and Excessive Acetabular Granuloma in an Uncemented HA-Coated Total Hip Arthroplasty-Midterm Results of a Prospective Study." HSS Journal. 2.2 (2006): 114-120. doi: 10.1007/s11420-006-9001-8

[43] Granchi, Donatella, et al. "Sensitivity to Implant Materials in Patients Undergoing Total Hip Replacement." Journal of Biomedical Materials Research Part B. 77B.2 (2006): 257264. doi: $10.1002 / \mathrm{jbm} . b .30445$

[44] Takagi, Michiaki. "Bone-Implant Interface Biology: Foreign Body Reaction and Periprosthetic Osteolysis in Artificial Hip Joints." Journal of Clinical and Experimental Hematopathology. 41.2 (2001): 81-87.

[45] Friberg, Lars, Gunnar F. Nordberg, and Velimir B. Vouk. Handbook on the Toxicology of Metals. New York: Elsevier/North-Holland Biomedical Press, 1979.

[46] Ramsden, Jeremy. Biomedical Surfaces. Boston: Artech House, 2008.

[47] Bronzino, Joseph D. The Biomedical Engineering Handbook. New York: CRC Press LLC and Springer-Verlag GmbH \& Co. KG, 2000.

[48] Revie, R. Winston, and Herbert H. Uhlig. Corrosion and corrosion control: An Introduction to Corrosion Science and Engineering ( $4^{\text {th }}$ ed.). New York: John Wiley \& Sons, Inc., 2008.

[49] Ellingsen, Jan Eirik, and S. Petter Lyngstadaas. Bio-Implant Interface: Improving Biomaterials and Tissue Reactions. New York: CRC Press, 2003.

[50] Jacobs, Joshua J., Jeremy L. Gilbert, and Robert M. Urban. "Current Concepts Review: Corrosion of Metal Orthopaedic Implants." Journal of Bone and Joint Surgery. 80.2 (1998): 268-282. 
[51] Fisher, Walter. "Pitting Corrosion." Lecture/Class Notes, University of Texas at El Paso, unpublished, 2009.

[52] Gilbert, Jeremy L., Christine A. Buckley, and Joshua J. Jacobs. "In vivo corrosion of modular hip prosthesis components in mixed and similar metal combinations. The effect of crevice, stress, motion, and alloy coupling." Journal of Biomedical Materials Research Part A. 27.12 (1995): 1533-1544. doi: 10.1002/jbm.820271210

[53] Fisher, Walter. "Crevice Corrosion." Lecture/Class Notes, University of Texas at El Paso, unpublished, 2009.

[54] Gilbert, Jeremy L., Manav Mehta, and Bryan Pinder. "Fretting Crevice Corrosion of Stainless Steel Stem-CoCr Femoral Head Connections: Comparisons of Materials, Initial Moisture, and Offset Length." Journal of Biomedical Materials Research Part B: Applied Biomaterials. 88.1 (2009): 162-173. doi: 10.1002/jbm.b.31164

[55] Universal ATR Sampling Accessory. (2006). Spectrum 100 Universal ATR Sampling Accessory User's Guide [CD ROM]. Waltham, Massachusetts: PerkinElmer, Inc.

[56] Zimmer, Inc. (1998). LD/Fx Hip Prostheses: Versatile Solutions for Total and Partial Hip Replacement [Brochure] Retrieved from http://www.zimmer.com/web/enUS/pdf/product_brochures/versys_ldfx.pdf

[57] Clark, Jim. (2009, November 16). Interpreting an Infra-Red Spectrum. Retrieved from http://www.chemguide.co.uk/analysis/ir/interpret.html

[58] Jaffer, Aubrey. (2009, November 16). FreeSnell: Polyethylene. Retrieved from http://people.csail.mit.edu/jaffer/FreeSnell/polyethylene

[59] Answers.com. (2009, November 15). Hip Revision Surgery. Retrieved from http://www.answers.com/topic/hip-revision-surgery

[60] Information Technology Laboratory. (2009, November 15). The Engineering and Informatic Systems Division. Retrieved from http://itl.erdc.usace.army.mil/eisd.htm

[61] Camacho, Nayeli. (2008). Wear Characterization on Retrieved Ultra-High-Molecular Weight Polyethylene Tibial Components (Masters thesis). Available from Dissertations and Theses database. (UMI No. 1453837) 
Amanda Marie Bastidos was born in El Paso, Texas, on 7 June 1985, the daughter of Frances Rivera and Gilbert Rivera. As a graduate of Americas High School in El Paso, TX, she attended the University of Texas at El Paso (UTEP) where she received her Bachelor of Science in Metallurgical and Materials Engineering in December 2007. During her undergraduate years, she gained additional experience throughout internships with NASA Glenn Research Center in Cleveland, $\mathrm{OH}$, and Argonne National Laboratory in Argonne, IL. In the spring of 2008 she entered The Graduate School at UTEP where she continued her studies with the Department of Metallurgical and Materials Engineering. As a graduate student, Amanda was awarded the GEM Fellowship by the National Consortium for Graduate Degrees for Minorities in Engineering and Science, Inc. An accompaniment to the fellowship, she was sponsored by Fermi National Accelerator Laboratory, in Batavia, IL, as a GEM Fellow intern. In addition, she was also awarded the Bridge to the Doctorate Fellowship from the Louis Stokes Alliances for Minority Participation (LSAMP) Program with the National Science Foundation (NSF).

Permanent address: 1441 Chato Villa Dr.

El Paso, Texas, 79936

This thesis was typed by Amanda Marie Bastidos. 